Supporting Information

\title{
Cosolvent-Promoted O-Benzylation with Silver(I) Oxide: Synthesis of 1'-Benzylated Sucrose Derivatives, Mechanistic Studies, and Scope Investigation
}

\author{
Lei Wang,* Yasuyuki Hashidoko, and Makoto Hashimoto*
}

Division of Applied Bioscience, Graduate School of Agriculture, Hokkaido University, Kita 9, Nishi 9, Kita-ku, Sapporo 060-8589, Japan

* E-mail: lei870610@gmail.com (L. Wang)
* E-mail: hasimoto@abs.agr.hokudai.ac.jp (M. Hashimoto)

\section{Table of Contents}

${ }^{1} \mathrm{H}-$ and ${ }^{13} \mathrm{C}-\mathrm{NMR}$ Spectra

Two types of ${ }^{1} \mathrm{H}-\mathrm{NMR}$ for 1 '-hydrogens of compound $\mathbf{1}$

Kinetic investigation of benzylation of 1 by $\mathrm{Ag}_{2} \mathrm{O}$ in $\mathrm{CD}_{2} \mathrm{Cl}_{2}$ and deuterated cosolvent S55

Mass spectra of $\mathbf{6 n}$ after irradiation for $10 \mathrm{~min}$ in $\mathrm{CH}_{3} \mathrm{OH}$ or $\mathrm{CD}_{3} \mathrm{OD}$ S57

HPLC analysis data for compounds $\mathbf{8 k}$ and $\mathbf{8 1}$ S58 
${ }^{1} \mathrm{H}$ - and ${ }^{13} \mathrm{C}$-NMR Spectra

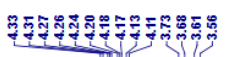

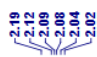
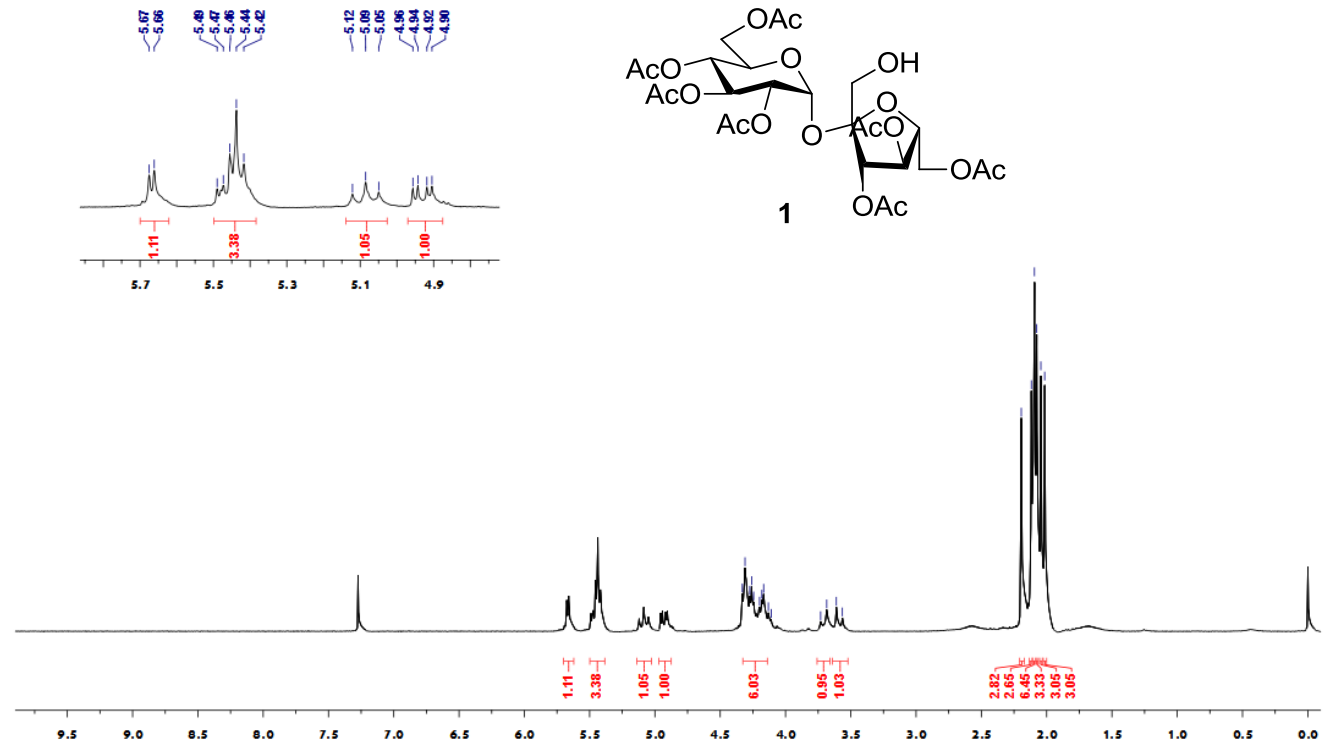

ำ

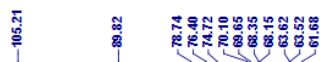

$\frac{2}{\bar{\nu}}$

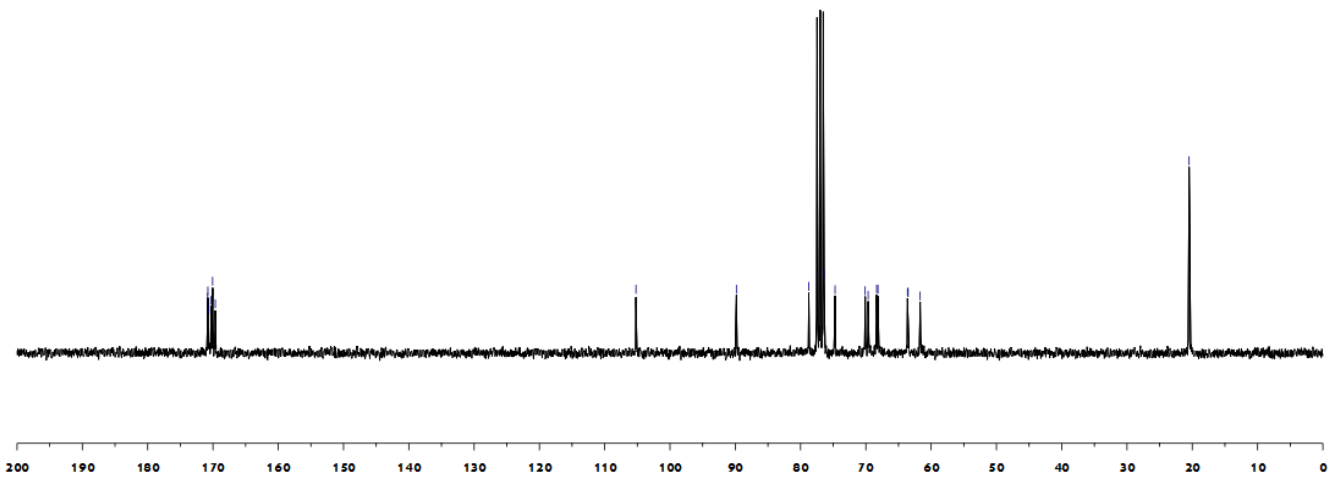




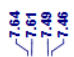

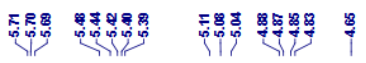

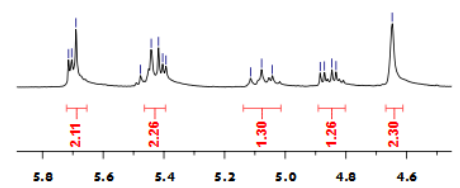

$\begin{array}{lllllll}5.8 & 5.6 & 5.4 & 5.2 & 5.0 & 4.8 & 4.6\end{array}$

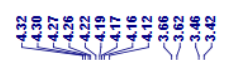

ำำำำำำ

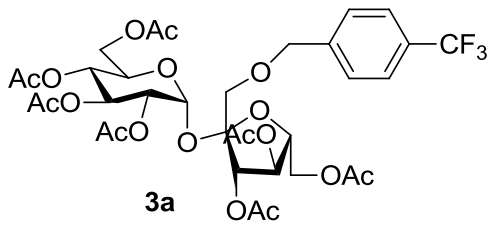

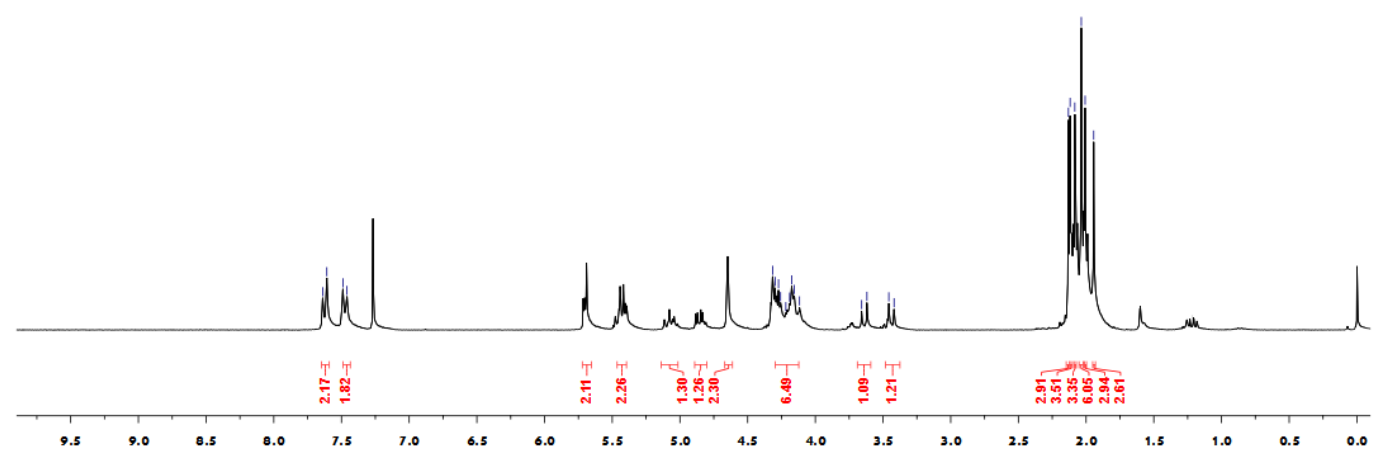

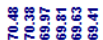

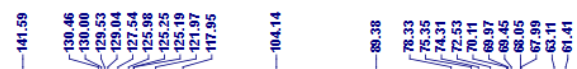

รูก

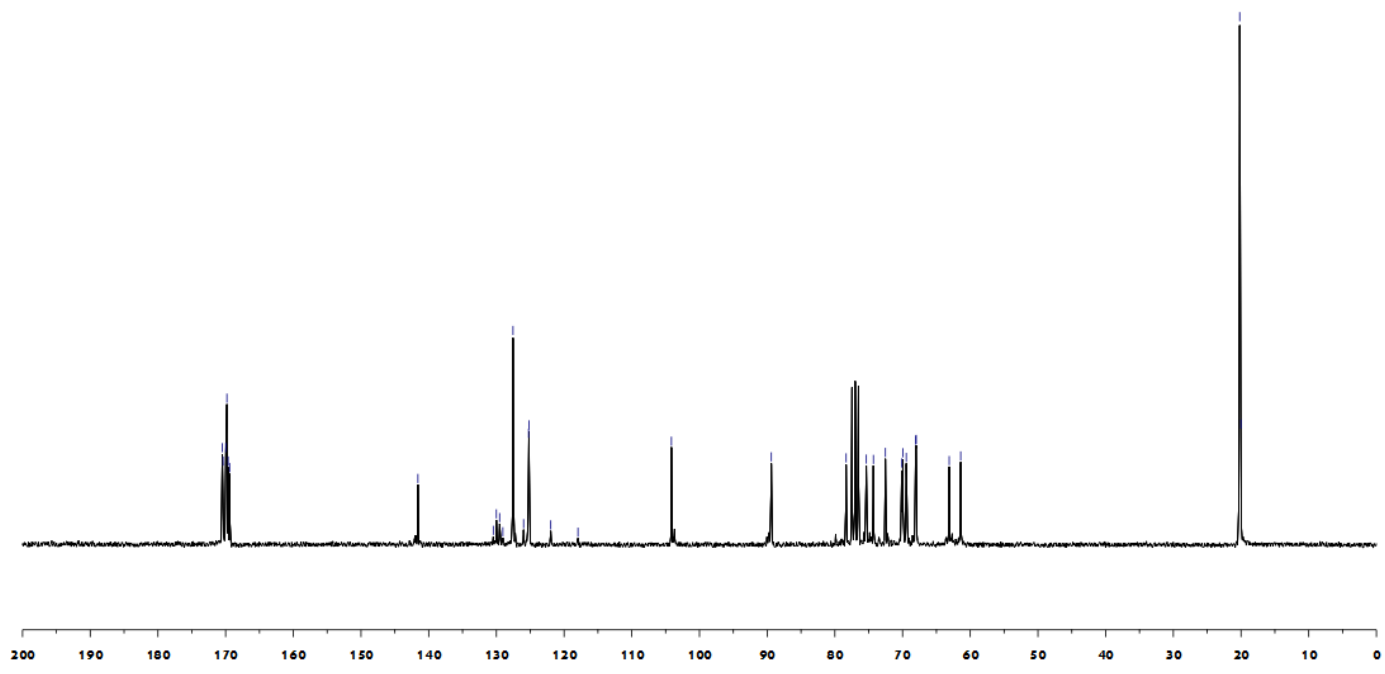




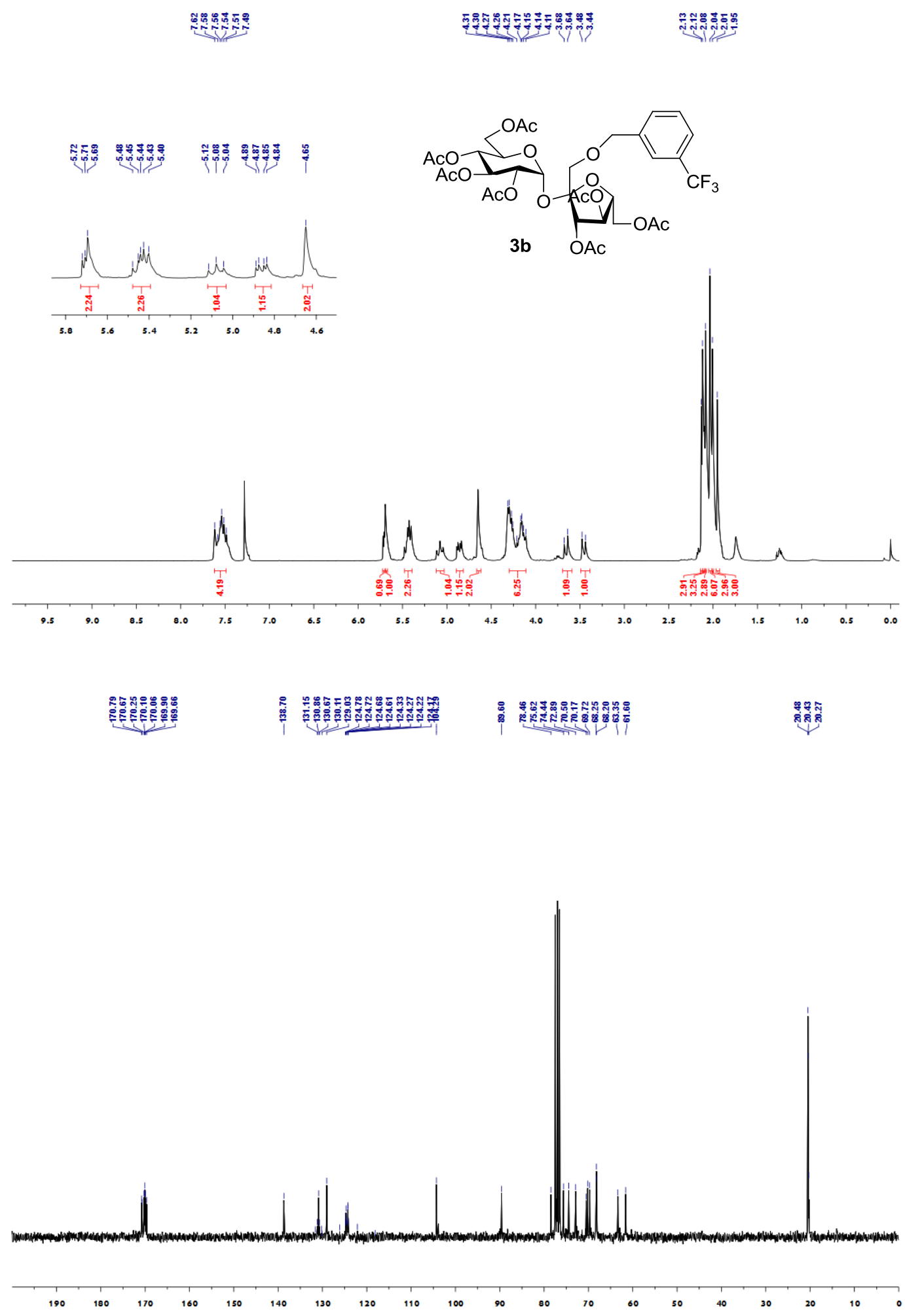




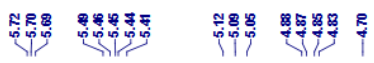
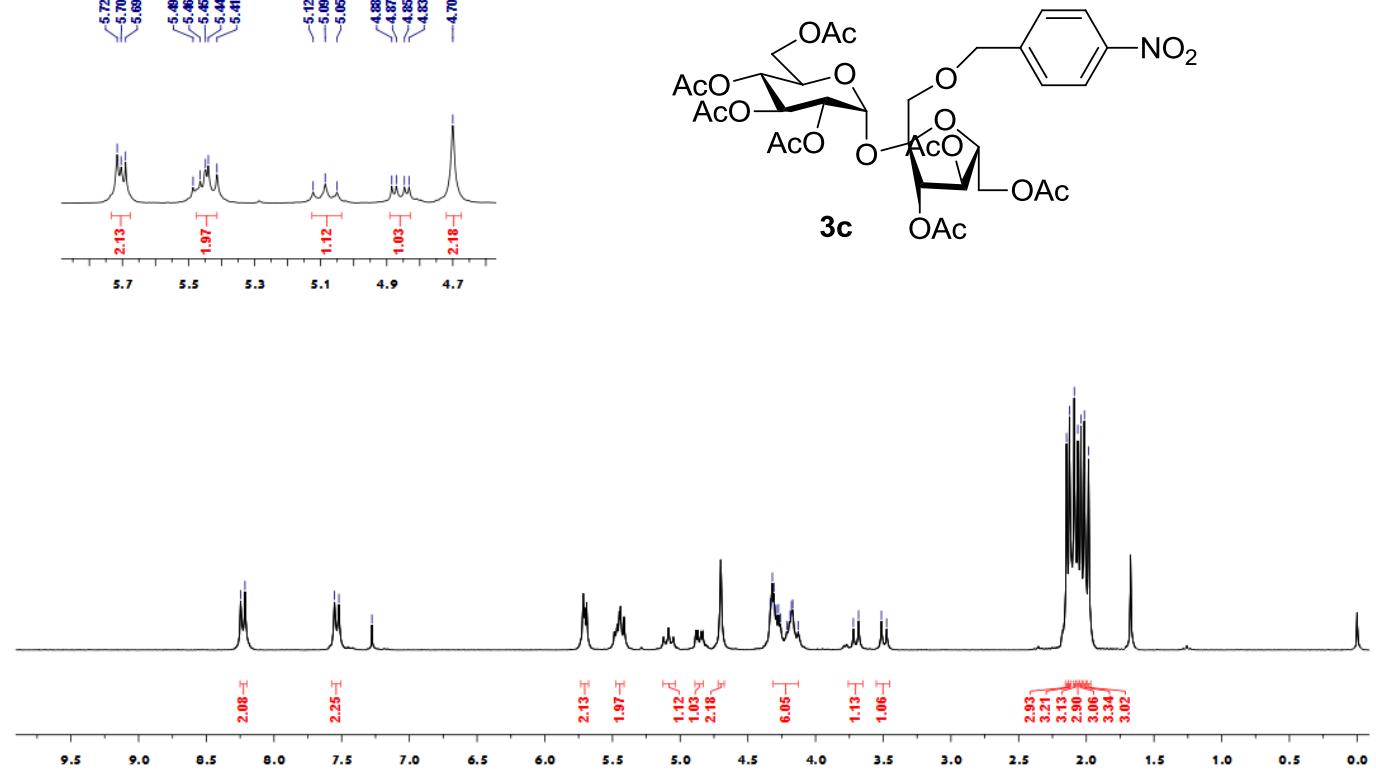

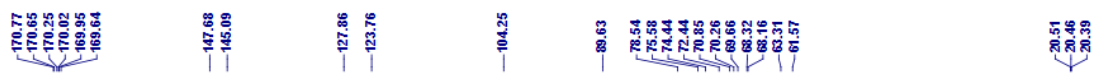

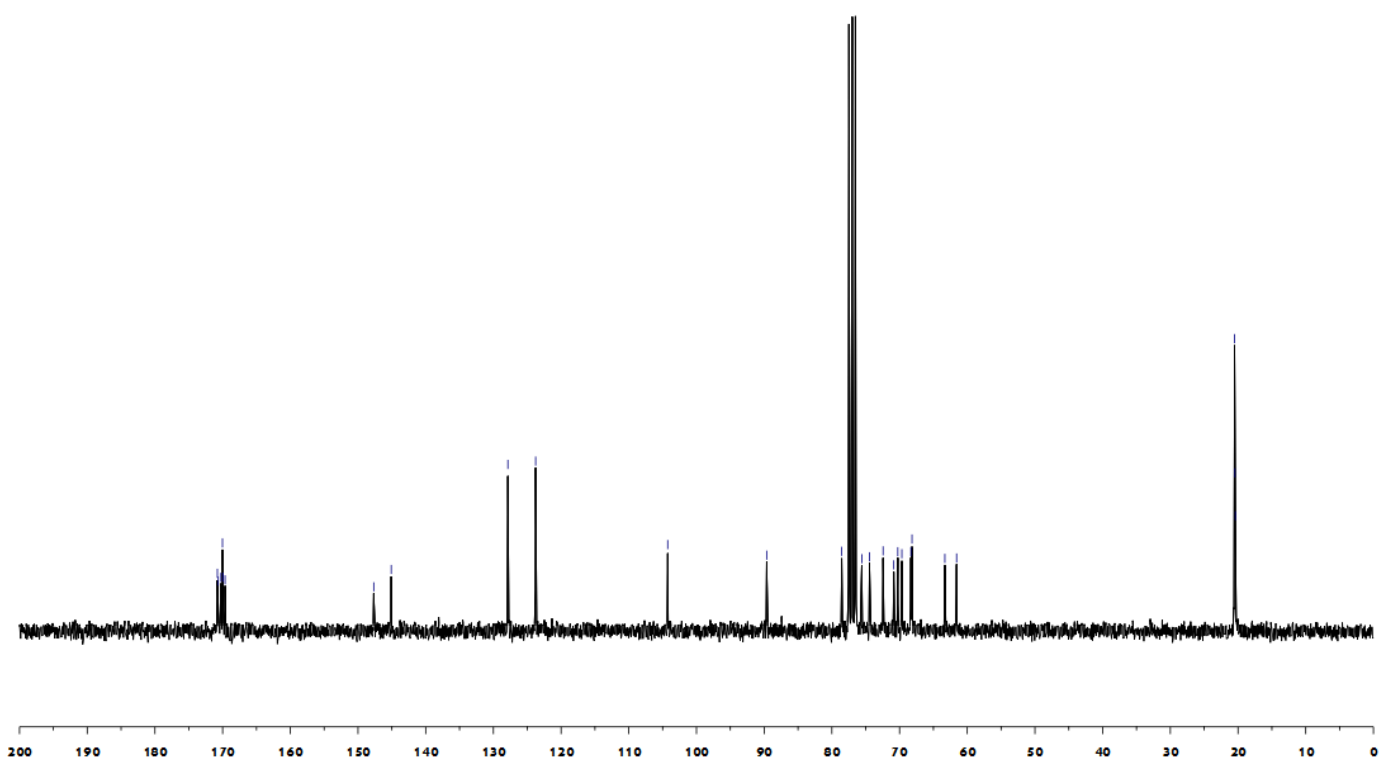


ำㅇำ
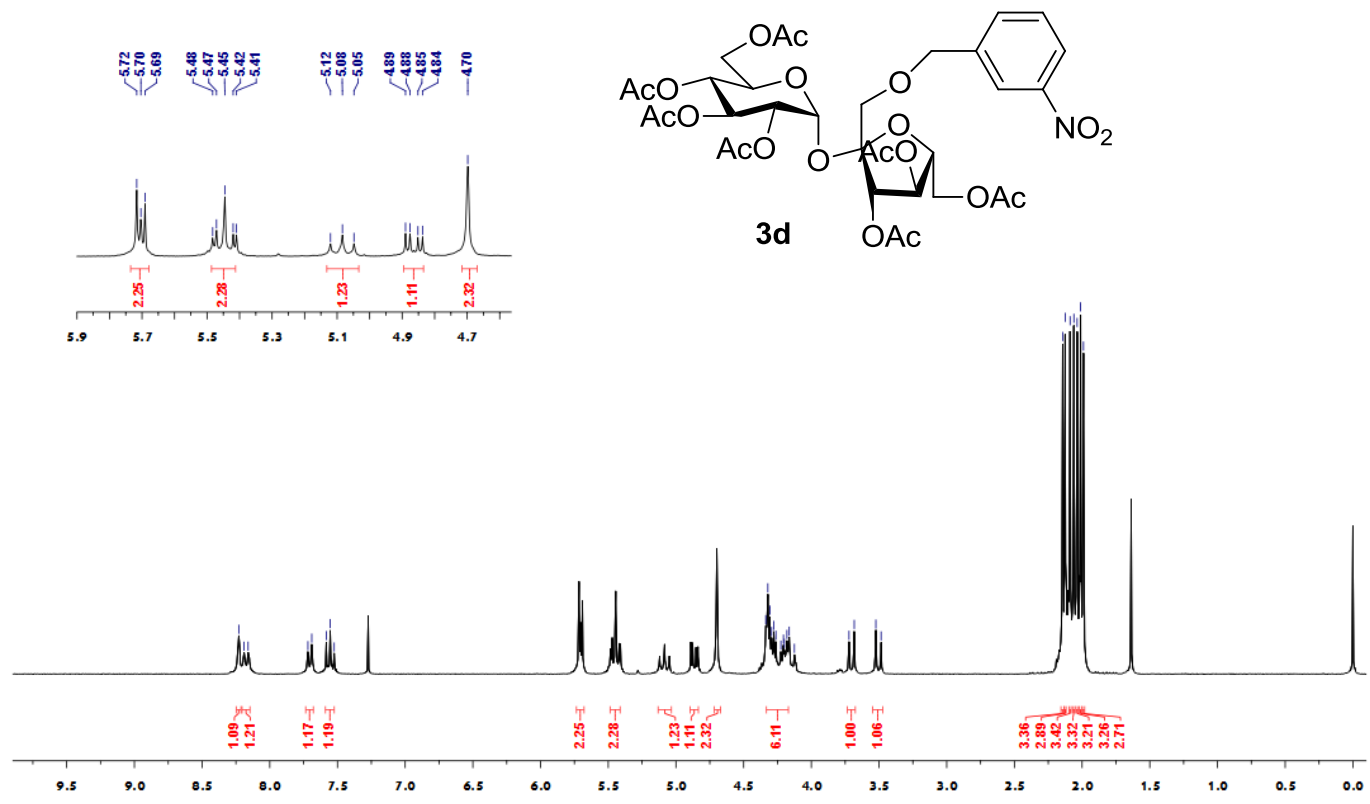

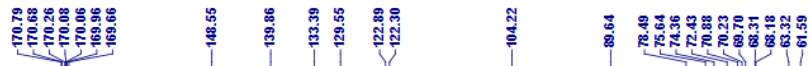

สูกิ
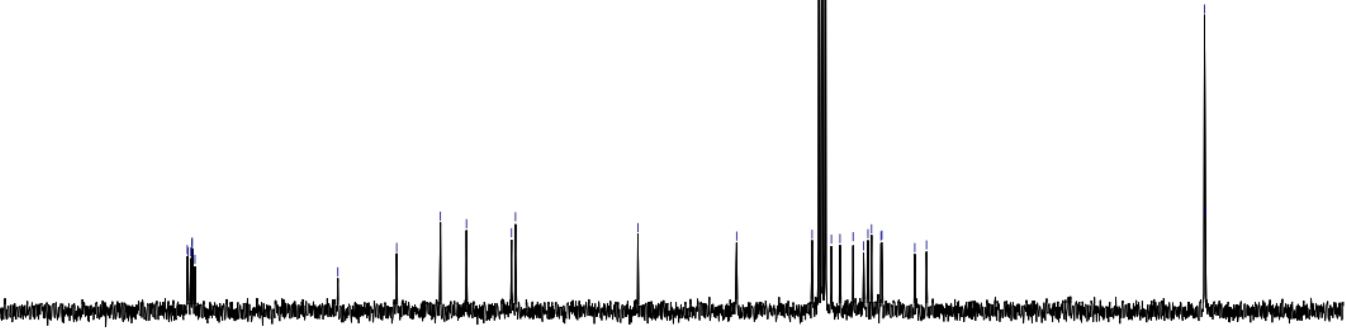

$200 \quad 190 \quad 100$ 


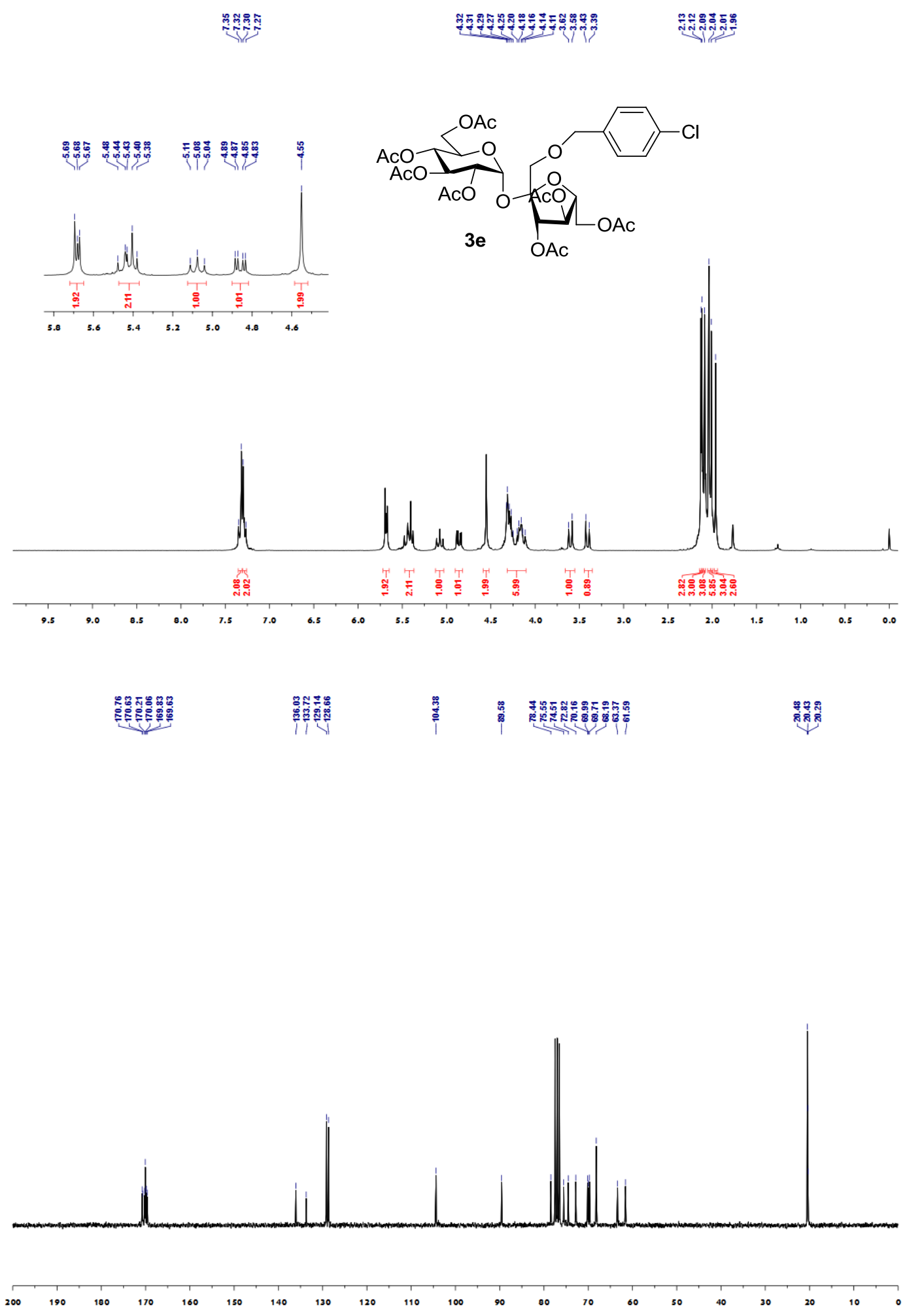



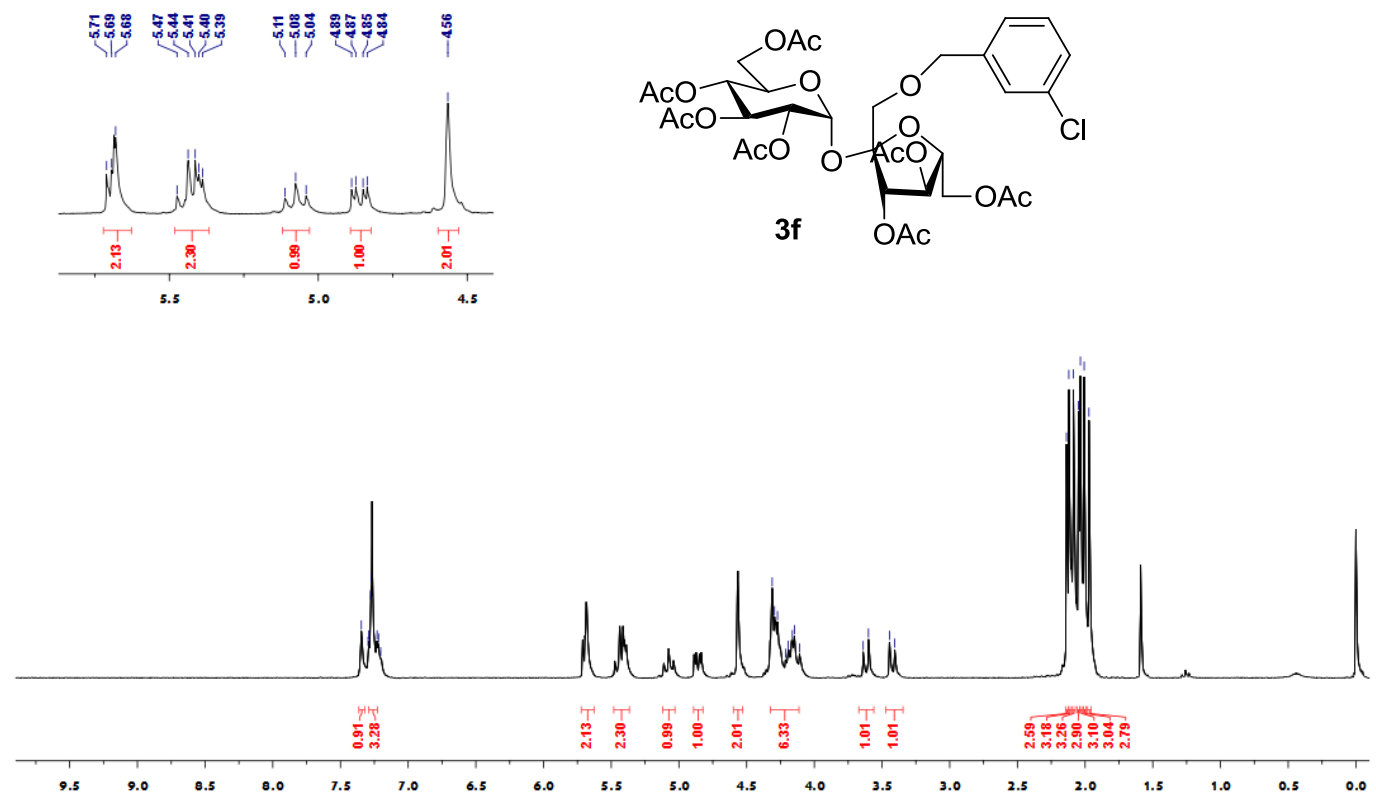

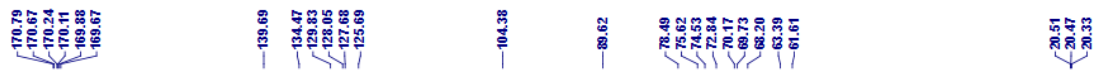

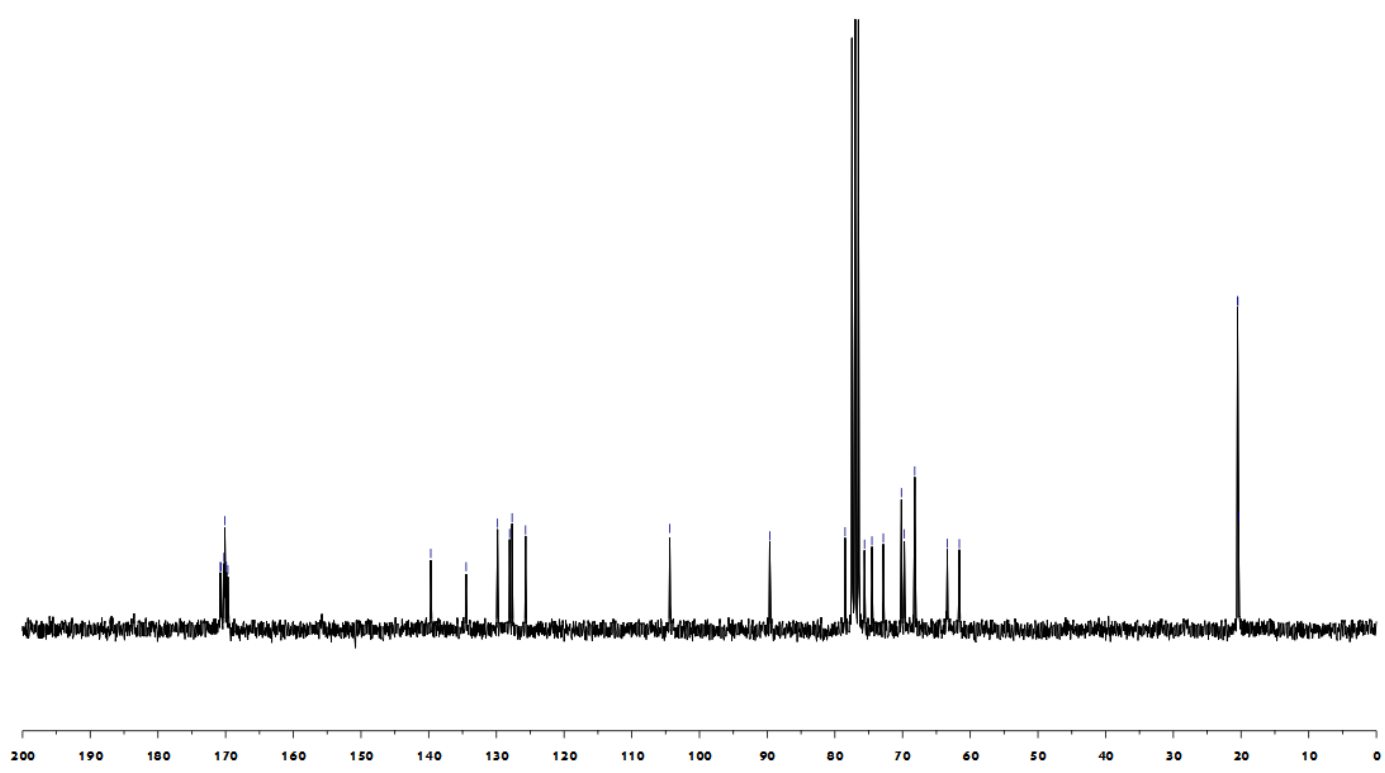




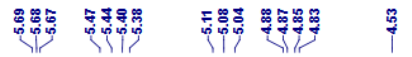
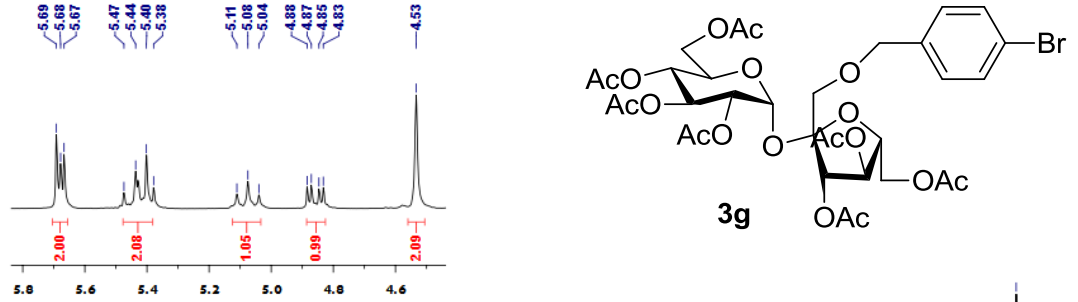

$\begin{array}{lllllll}5.8 & 5.6 & 5.4 & 5.2 & 5.0 & 4.8 & 4.6\end{array}$
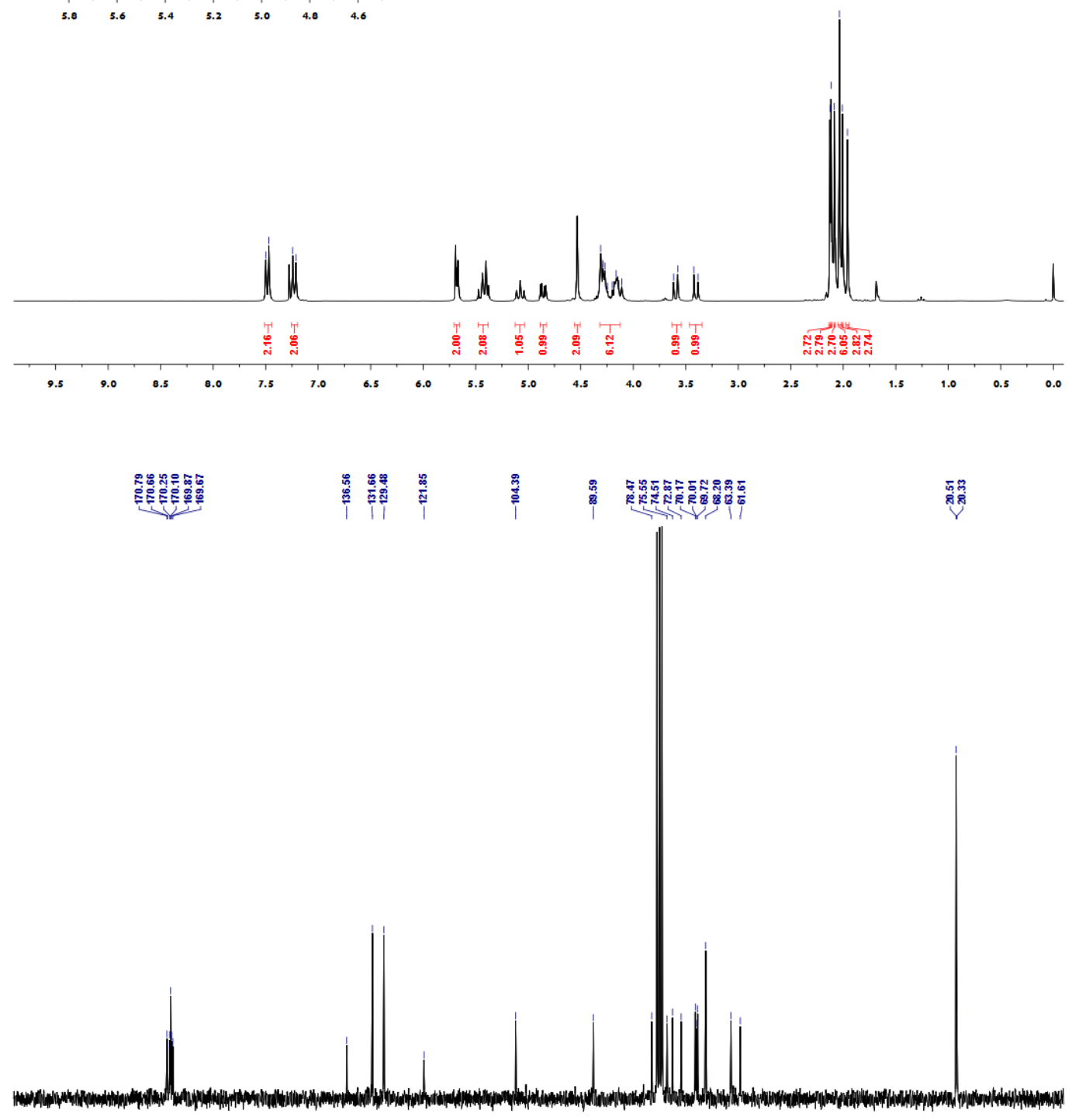

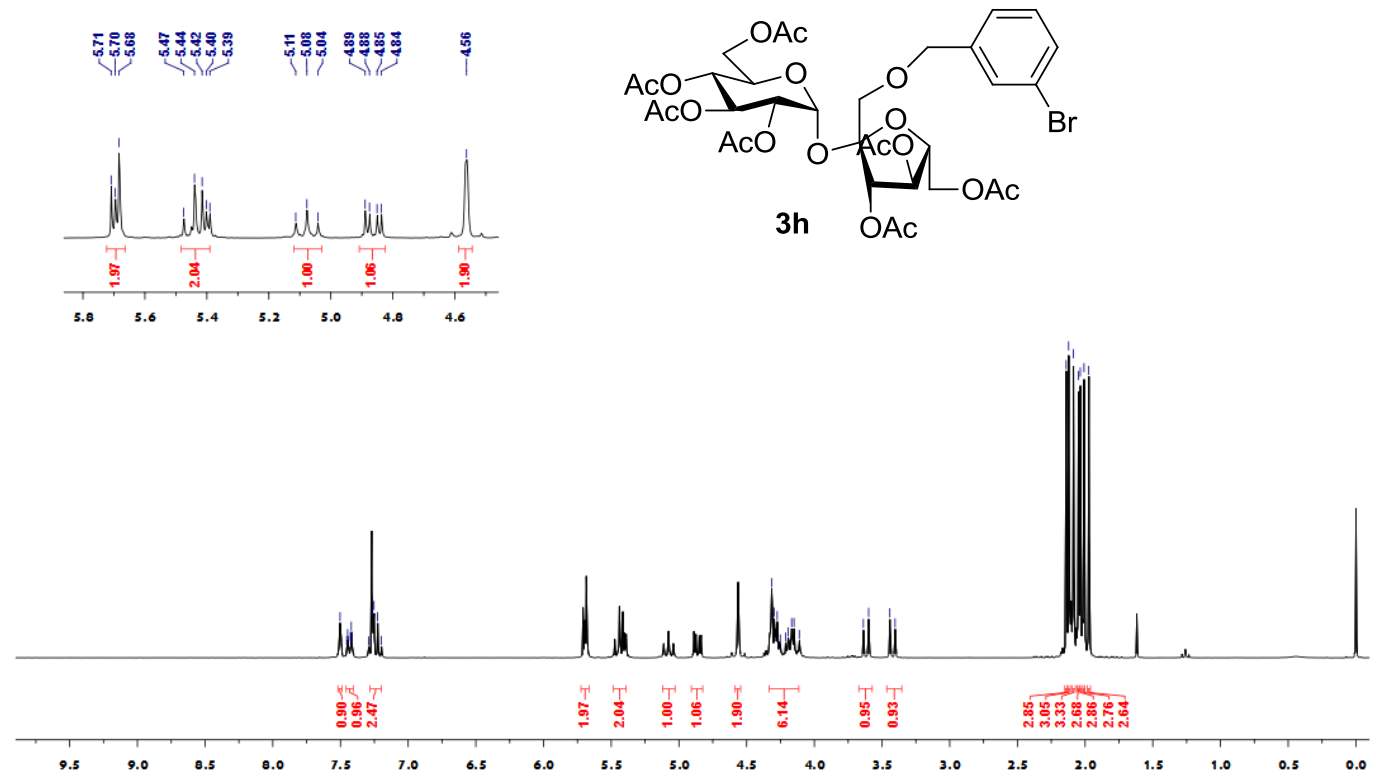

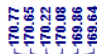

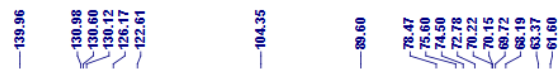

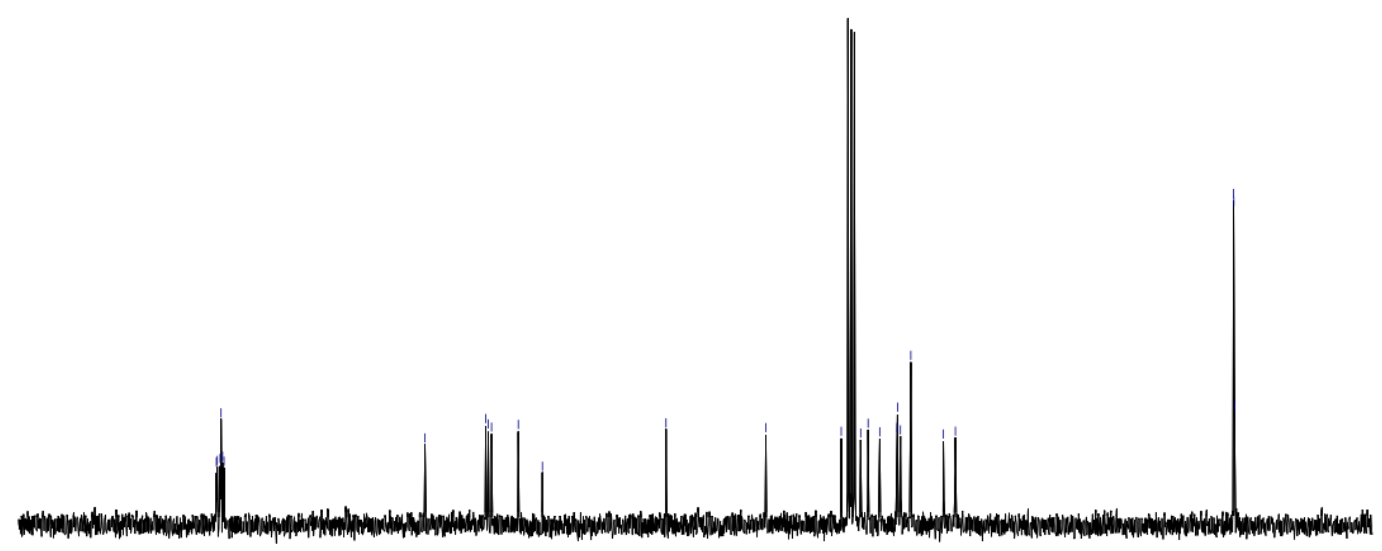




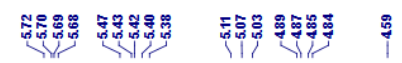
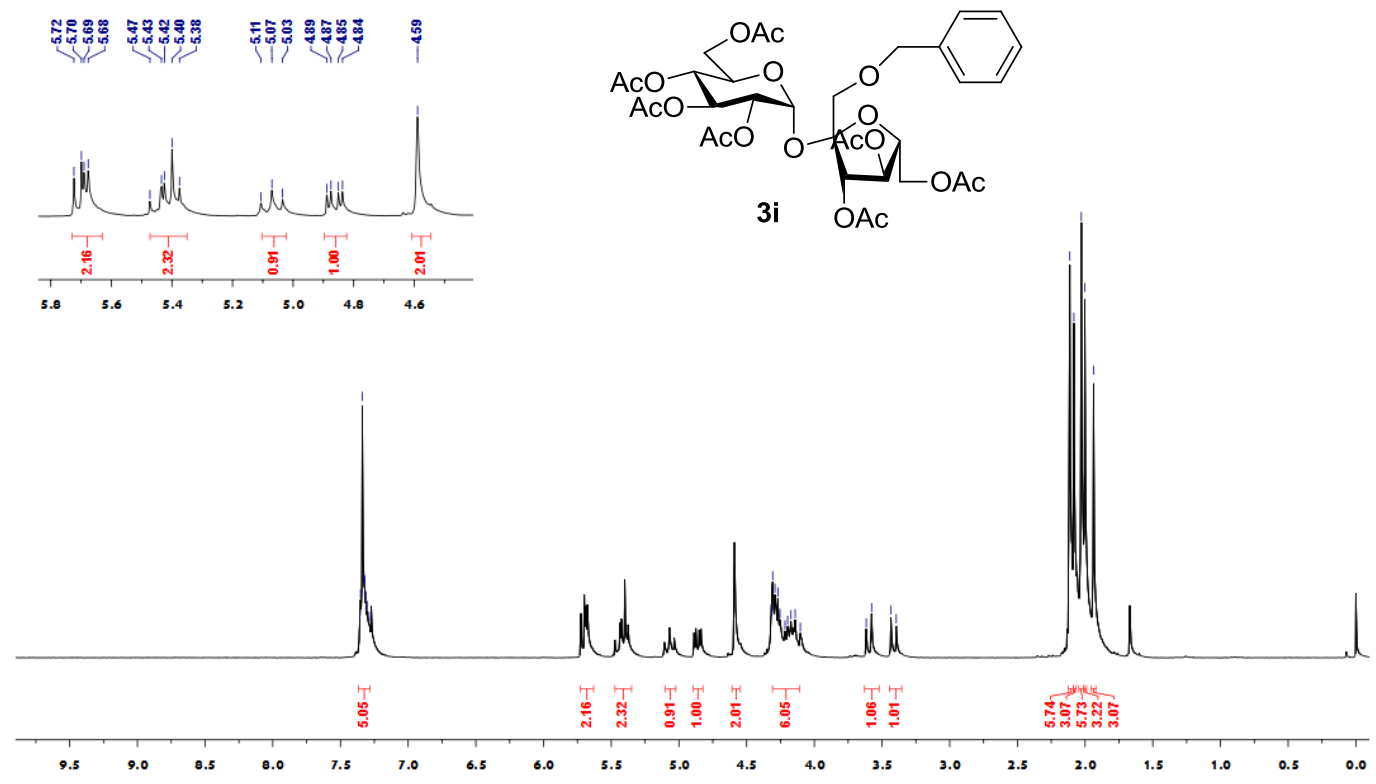

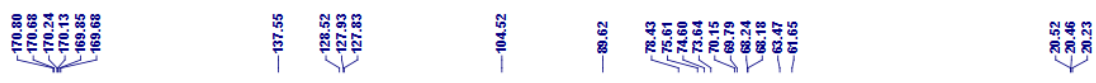

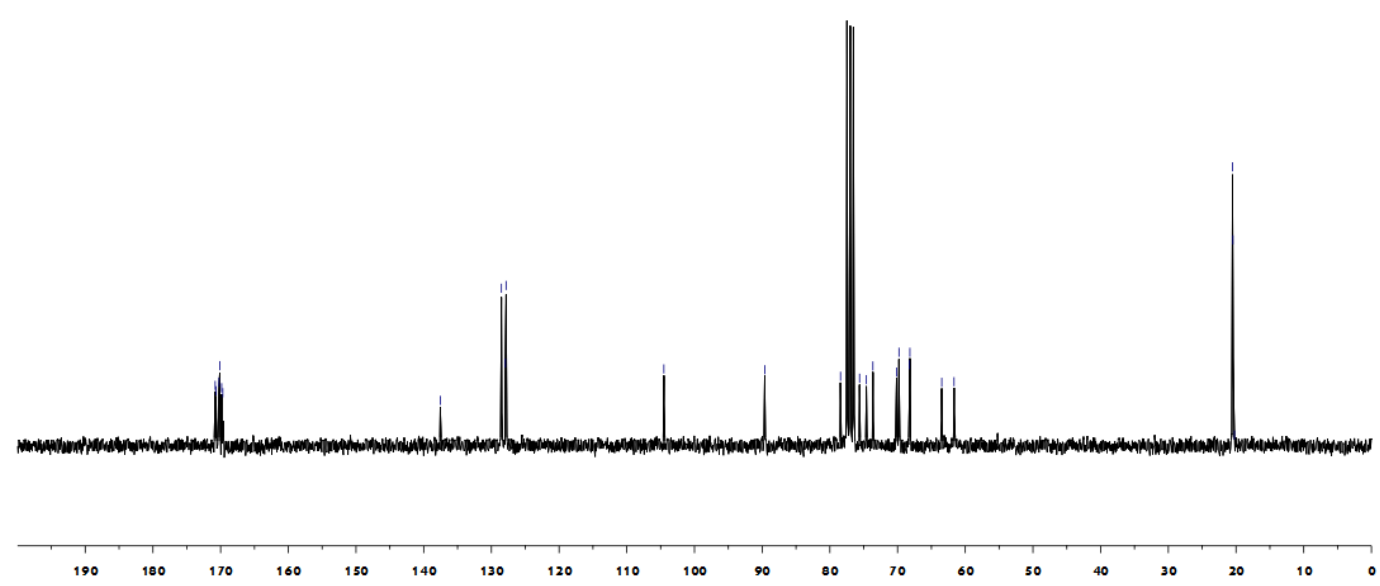




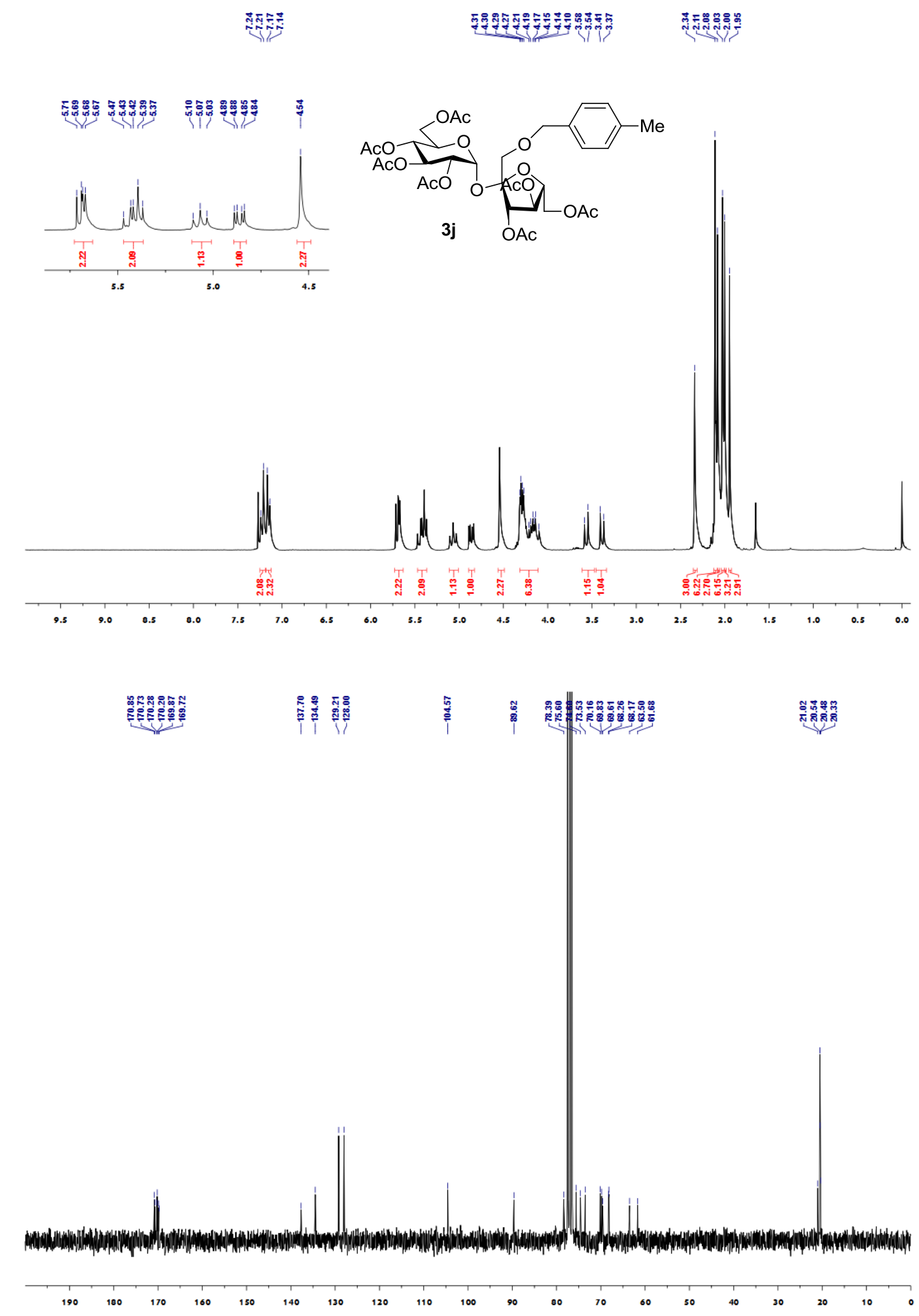



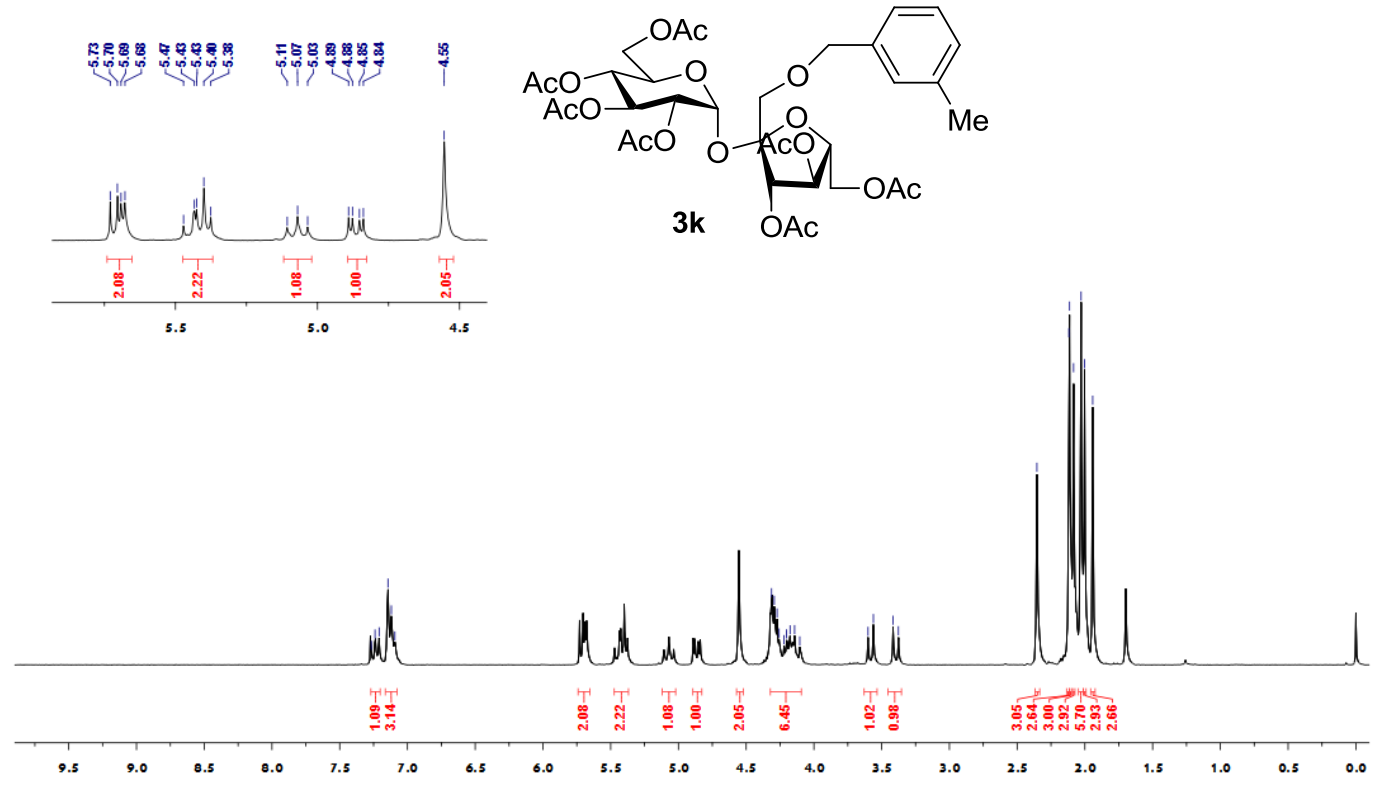

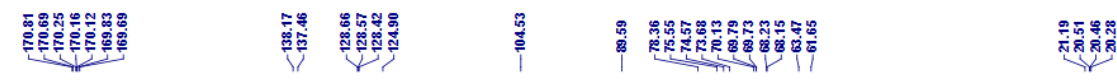

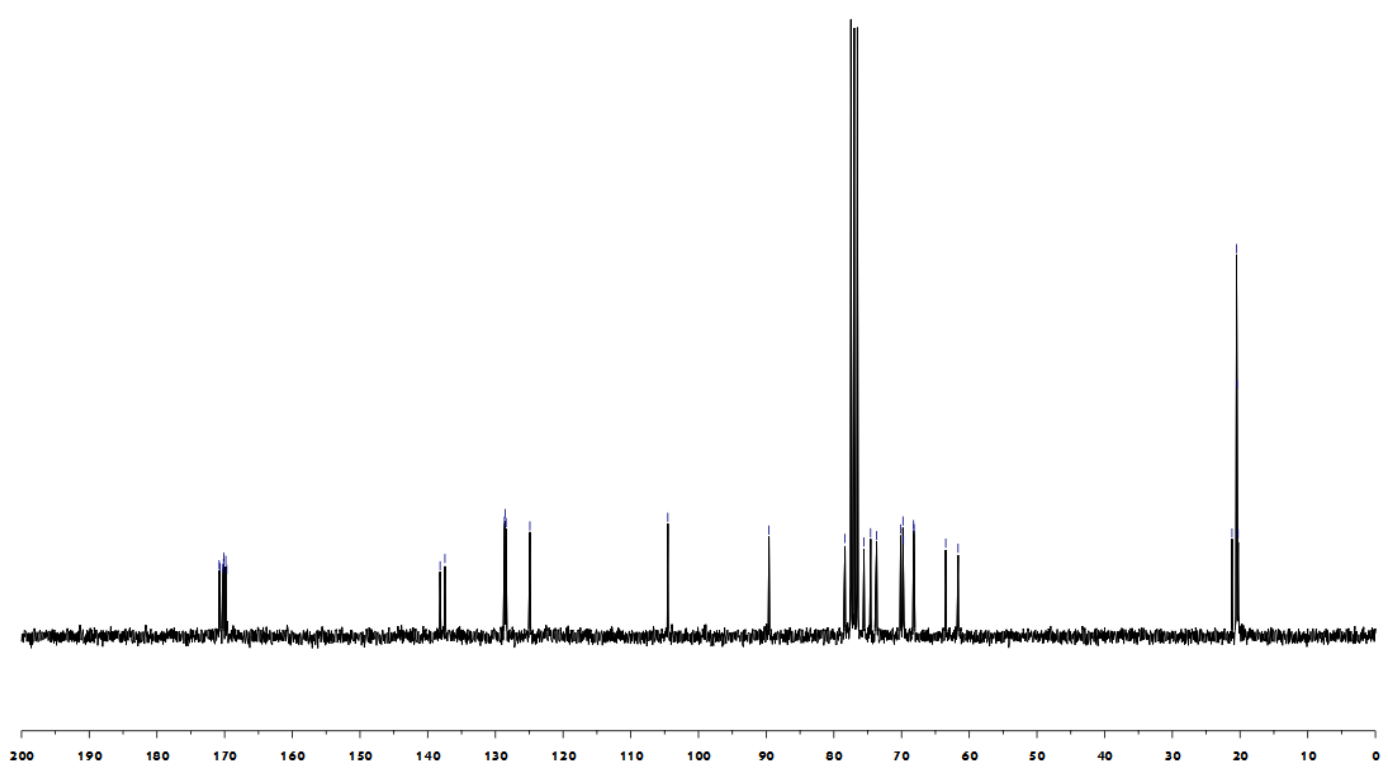



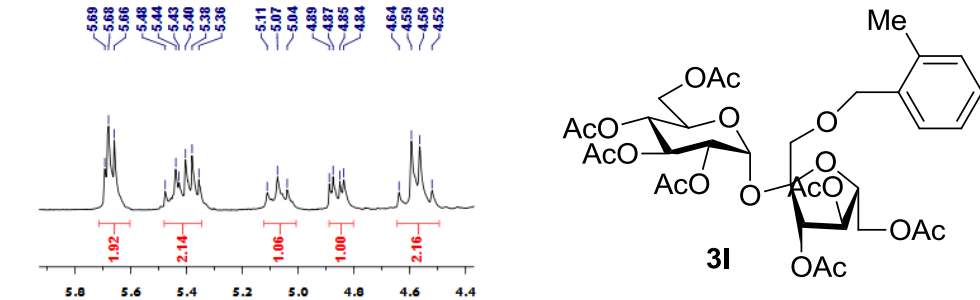

$\begin{array}{llllllll}5.8 & 5.6 & 5.4 & 5.2 & 5.0 & 4.8 & 4.6 & 4.4\end{array}$

3) $\mathrm{OAc}$
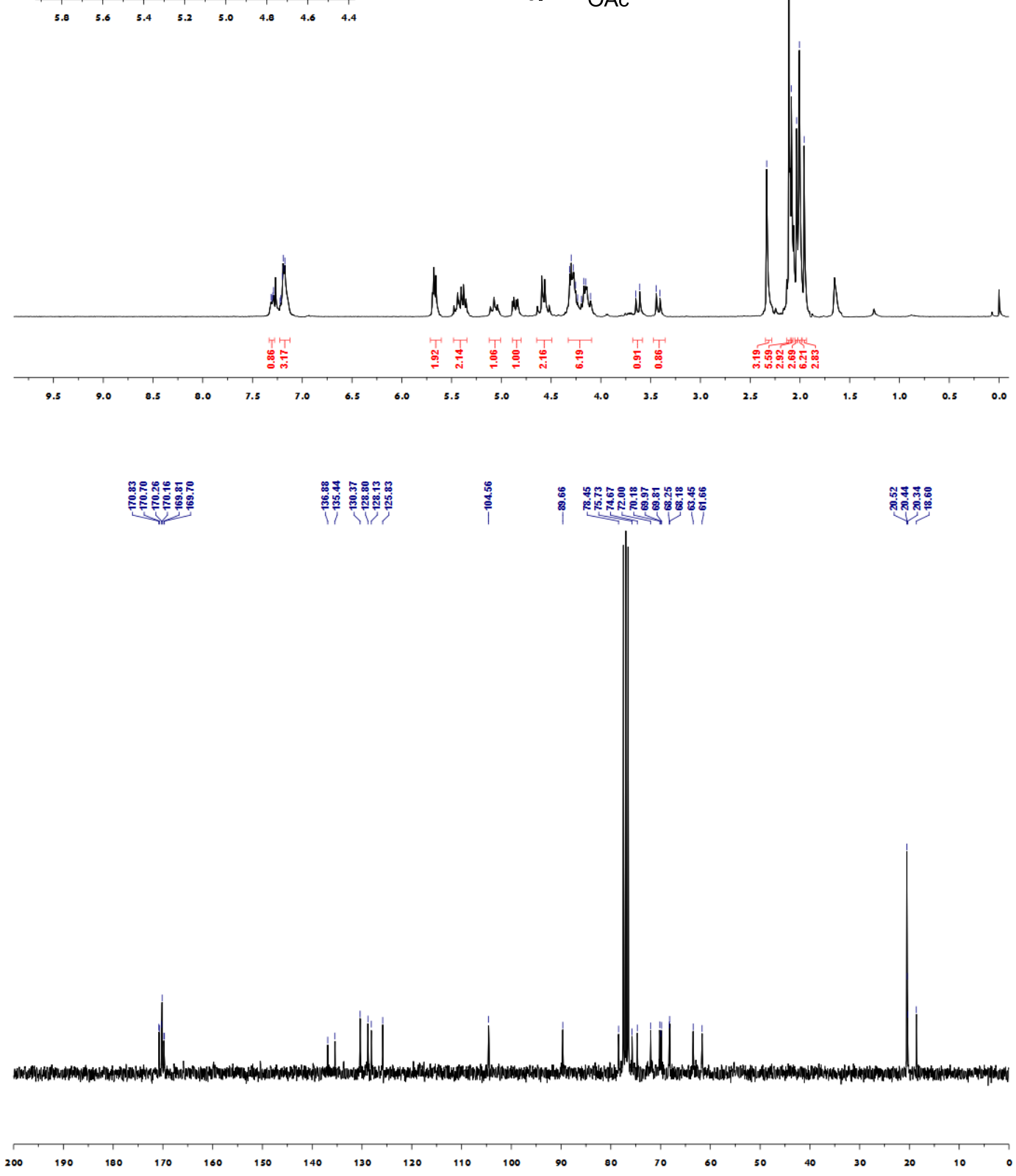


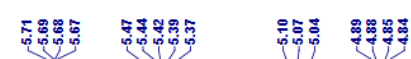
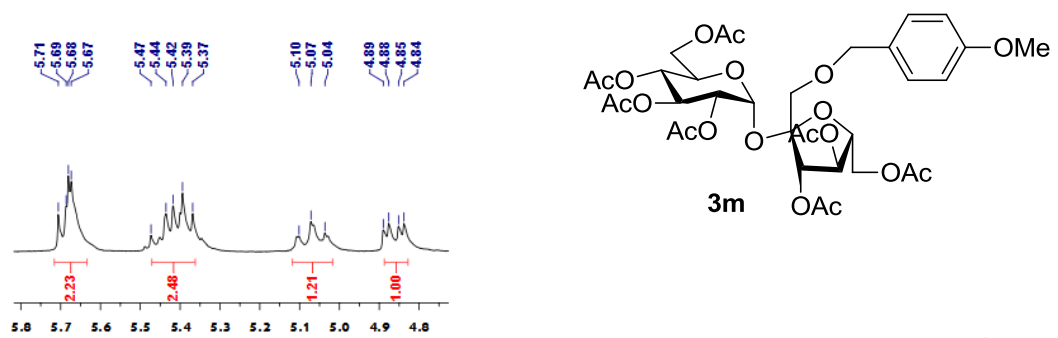

$3 m \quad O A c$

$\begin{array}{lllllllllll}5.8 & 5.7 & 5.6 & 5.5 & 5.4 & 5.3 & 5.2 & 5.1 & 5.0 & 4.9 & 4.8\end{array}$

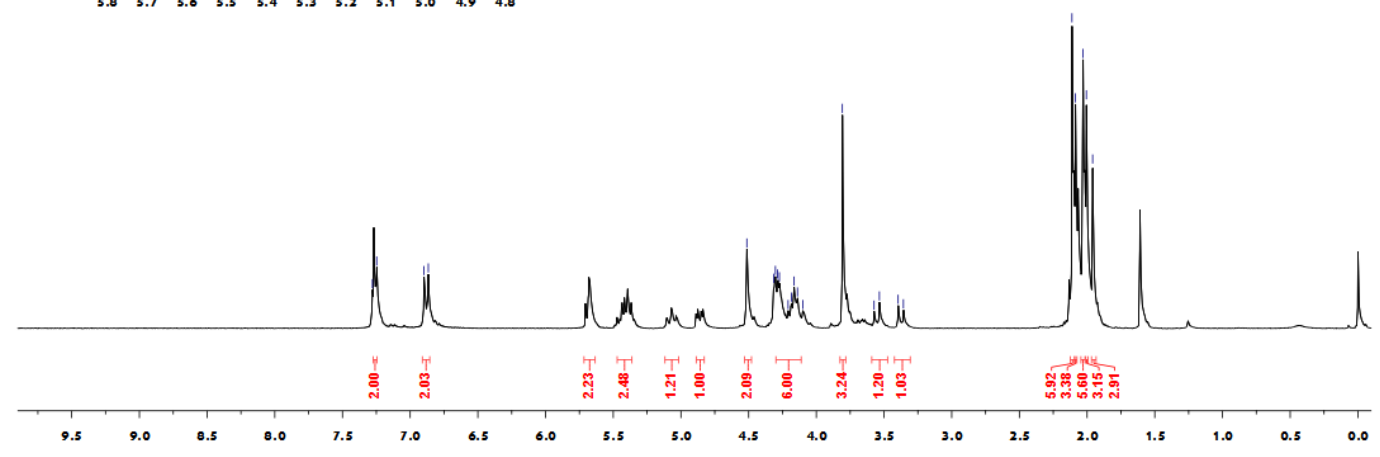

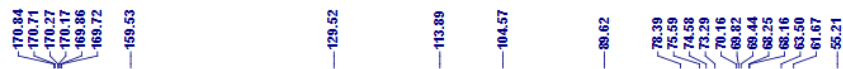

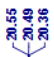

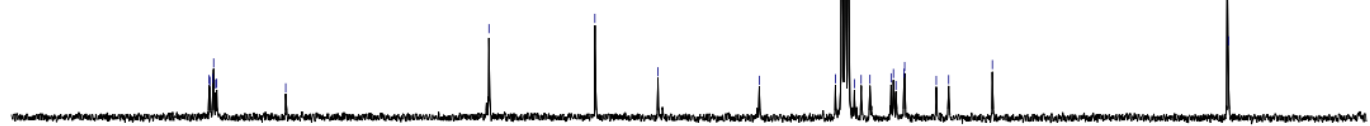



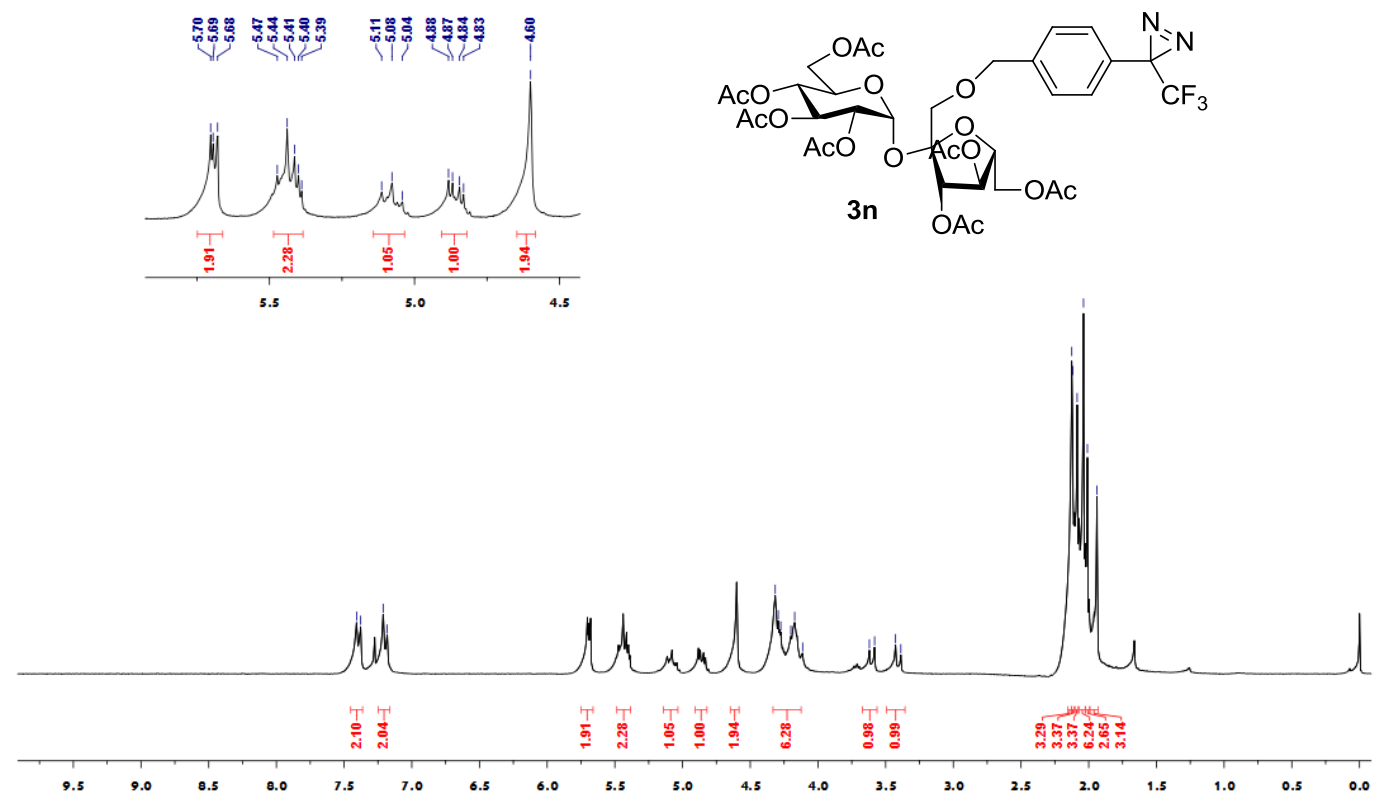

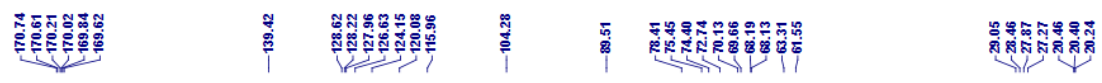

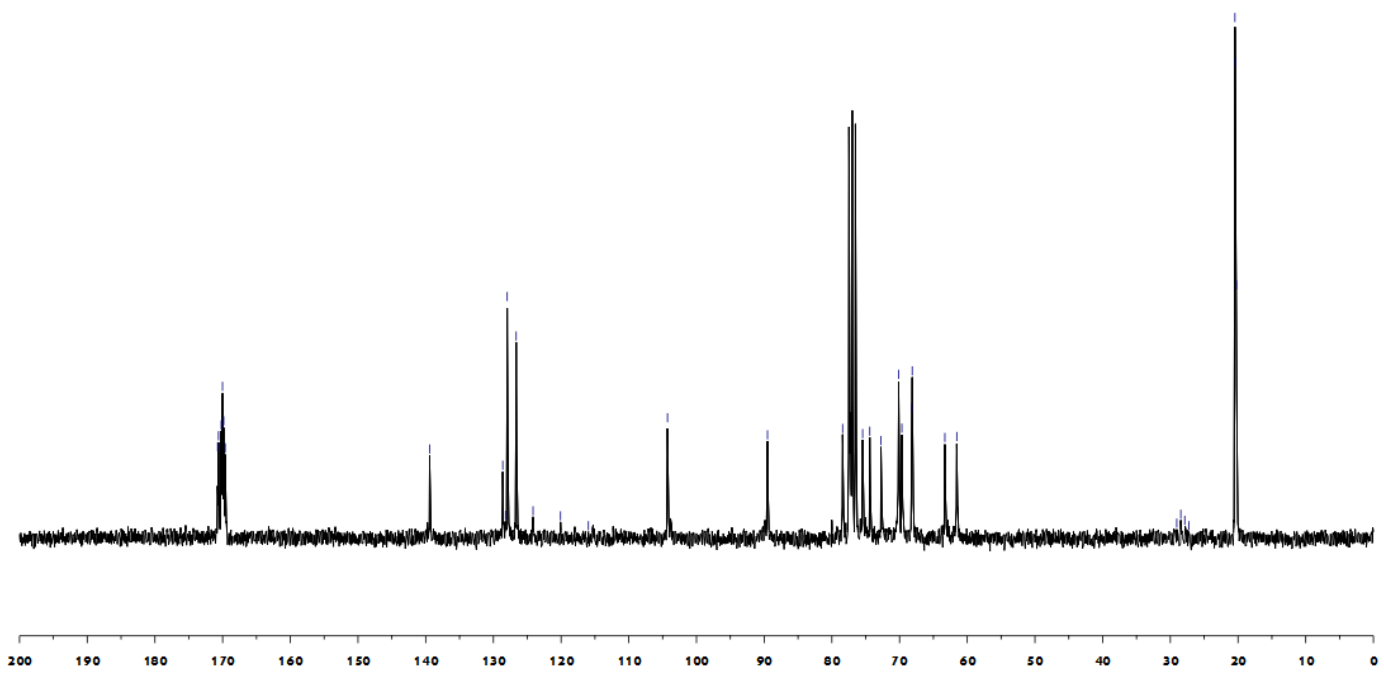



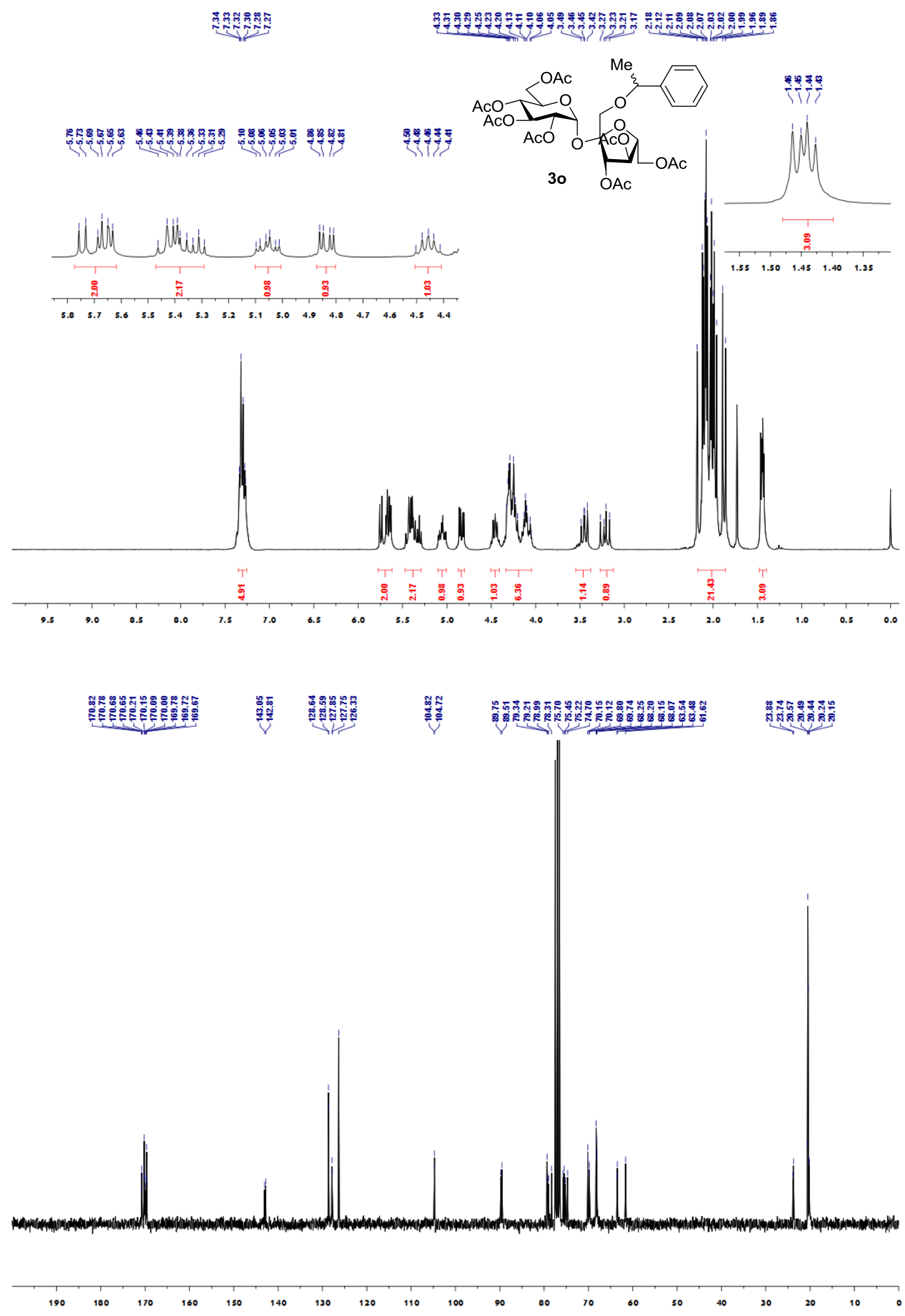


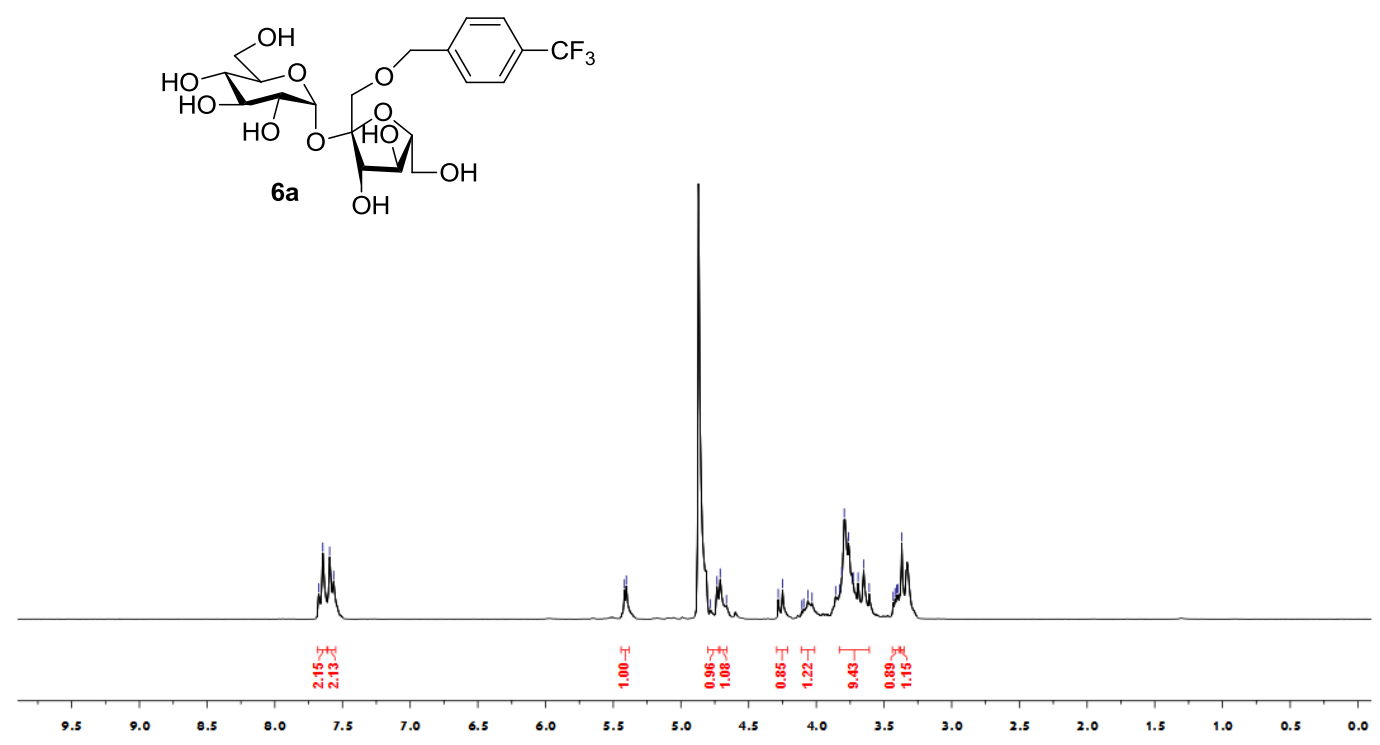

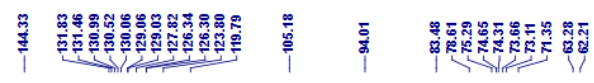

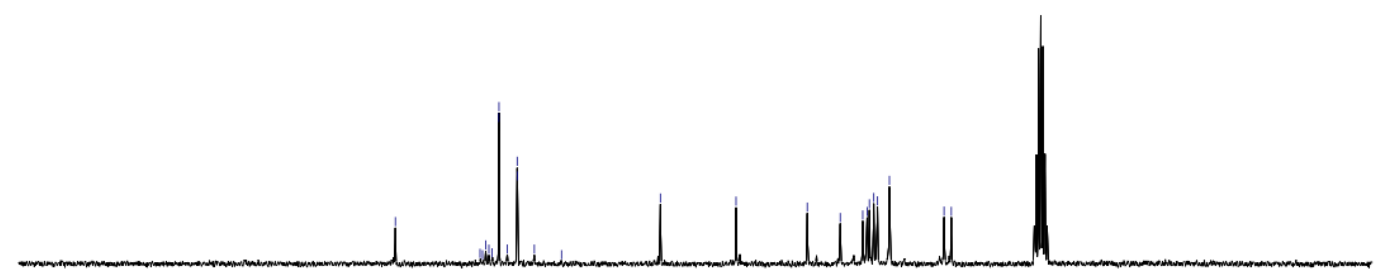

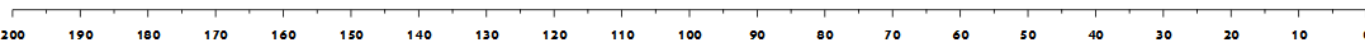




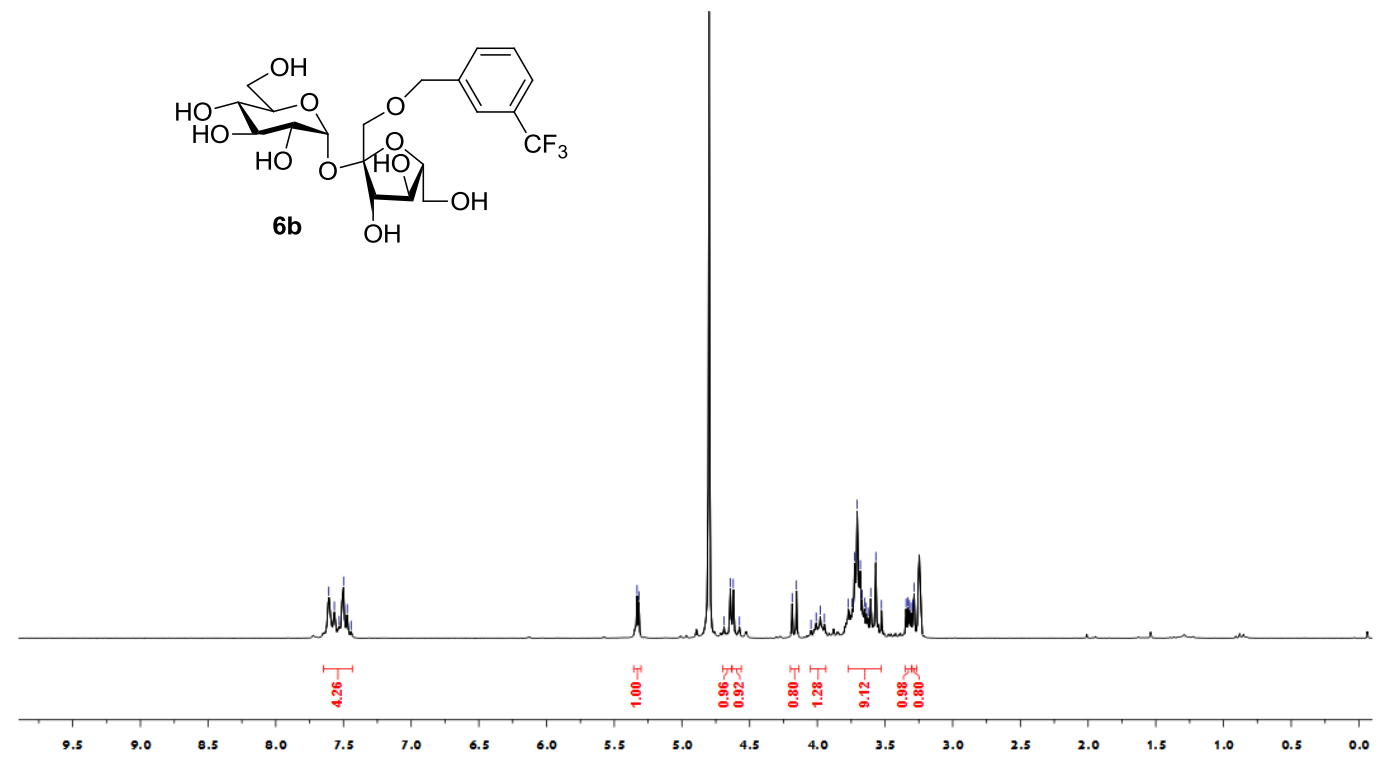

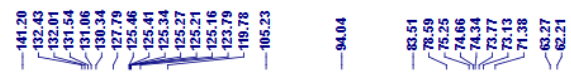

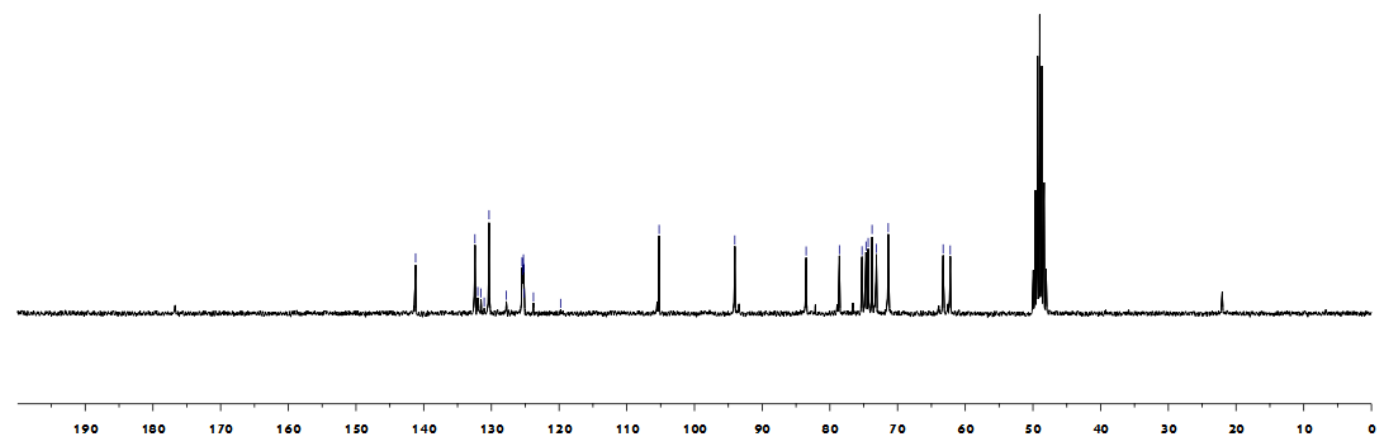




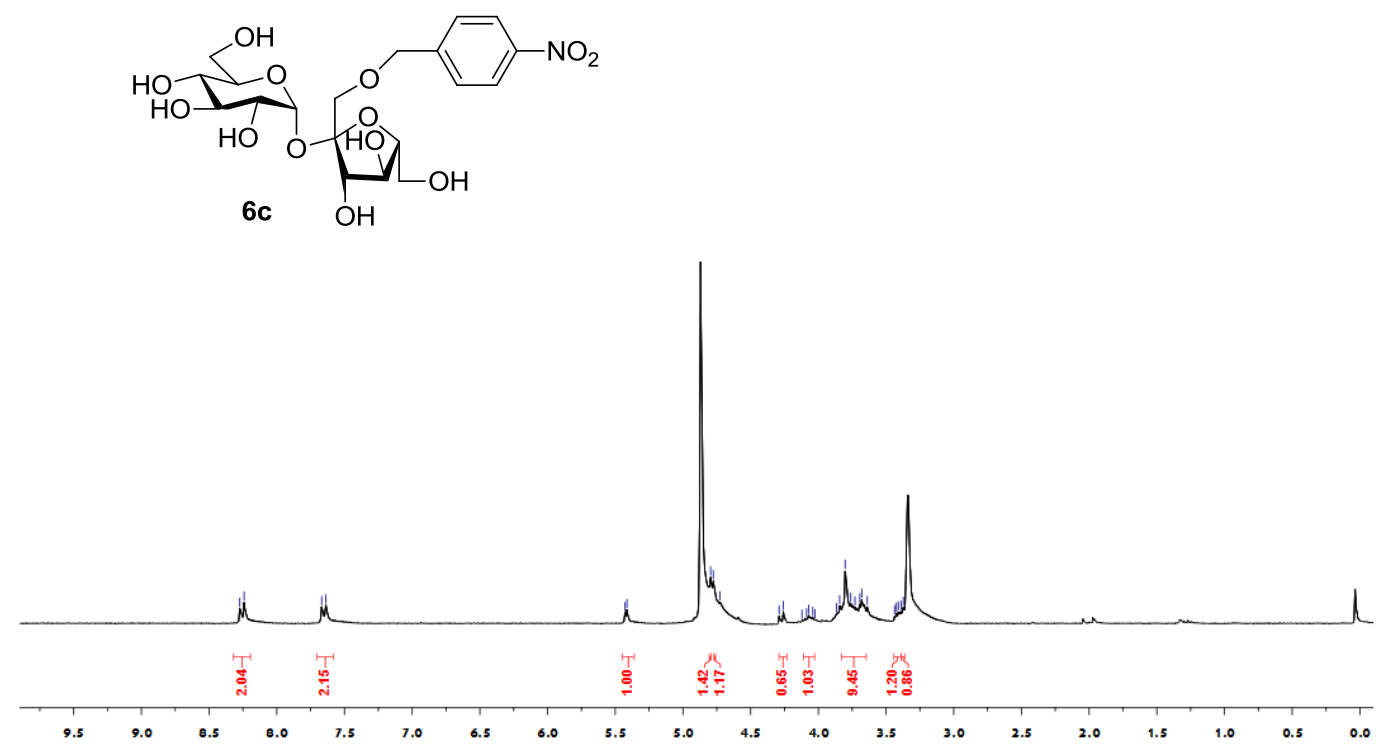

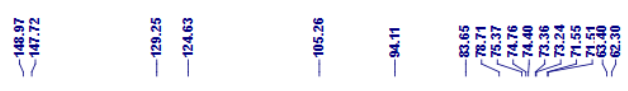
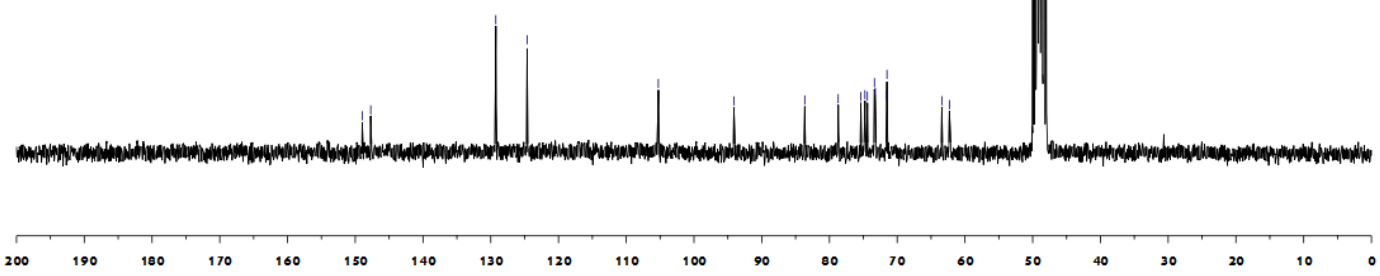


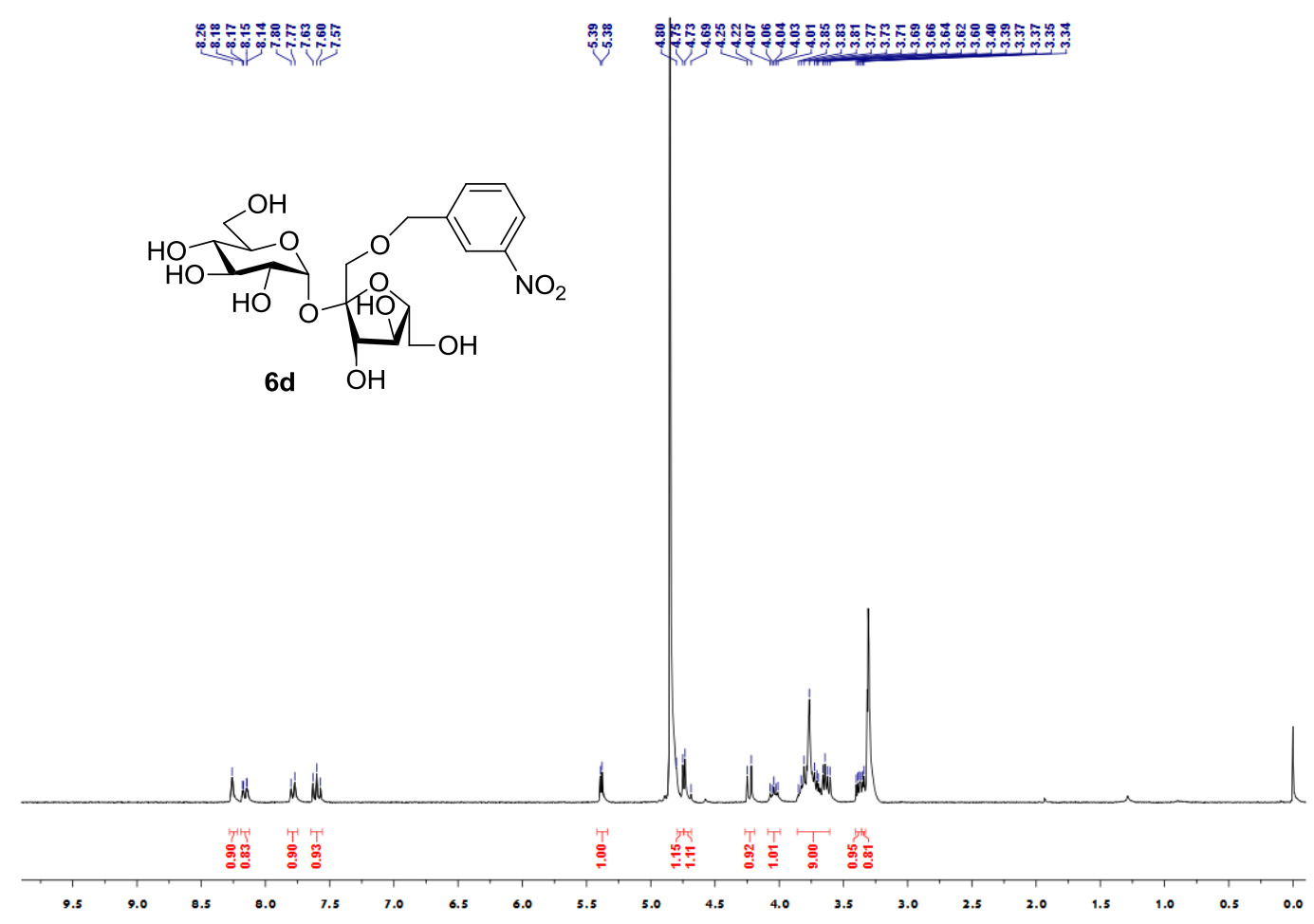

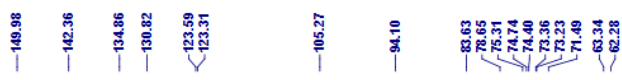
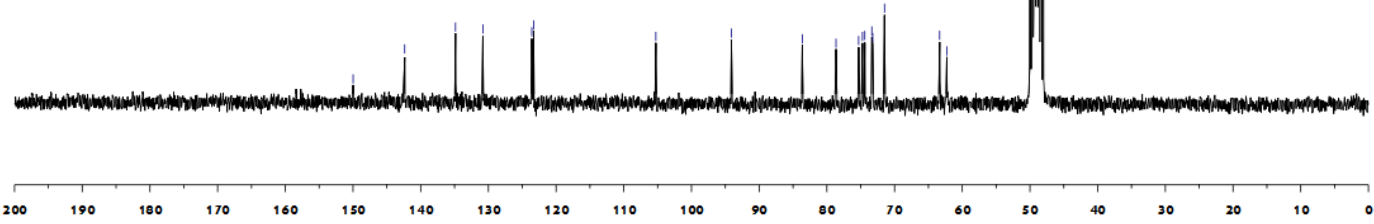


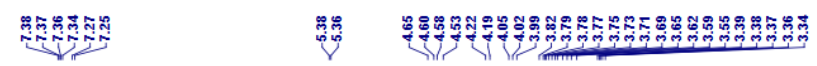
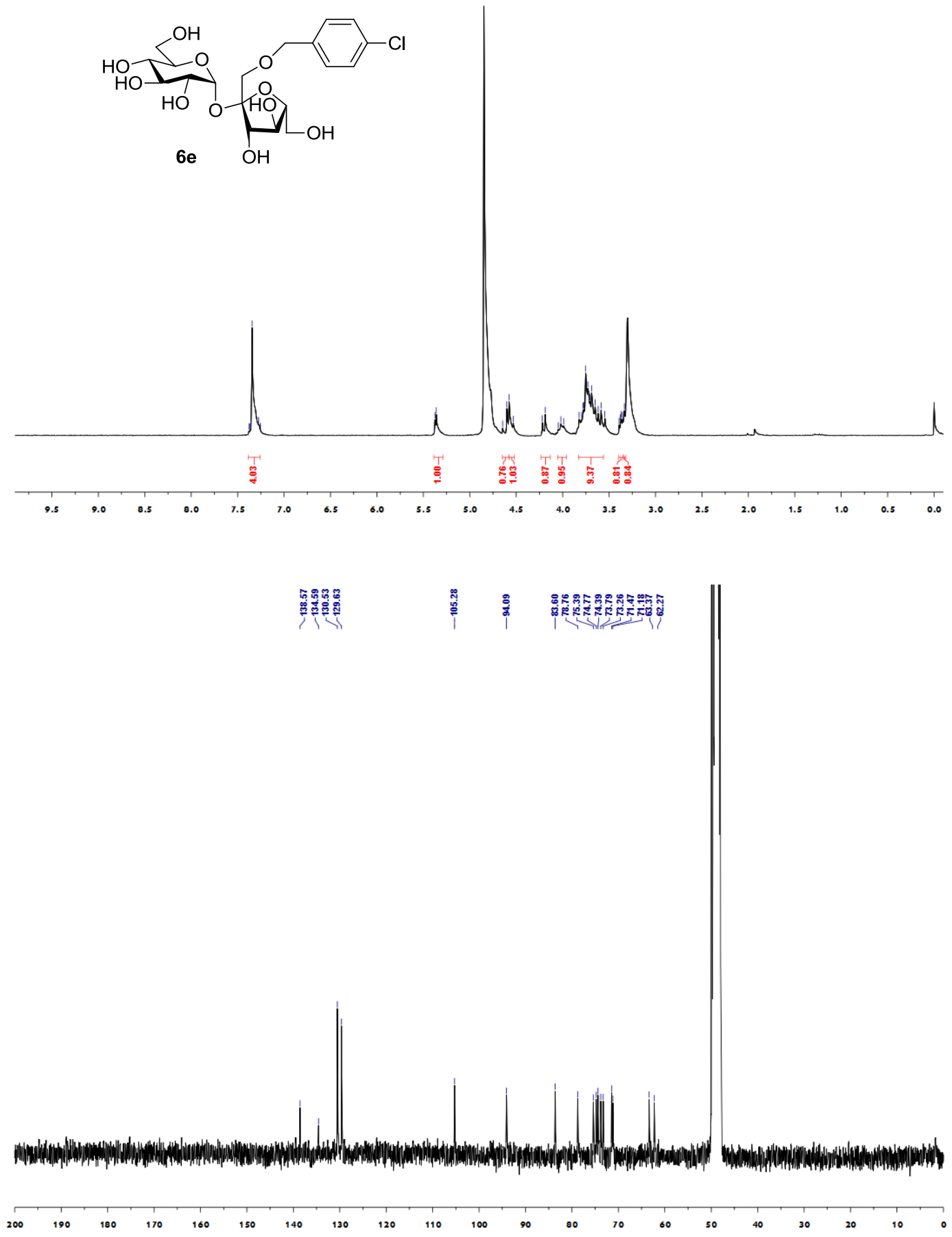

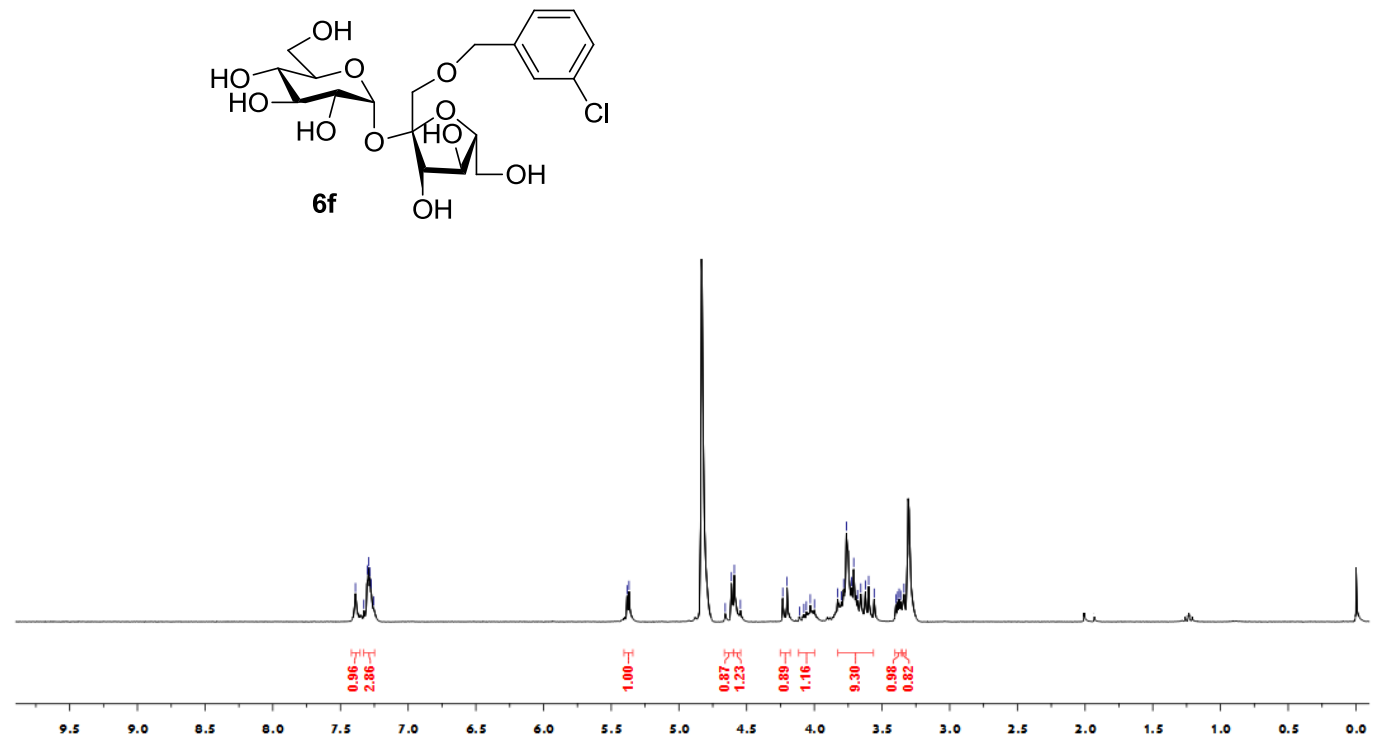

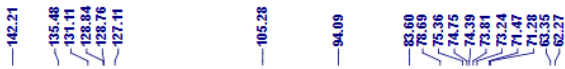

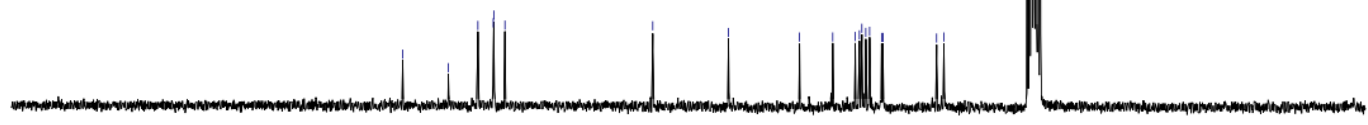

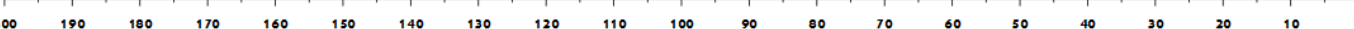




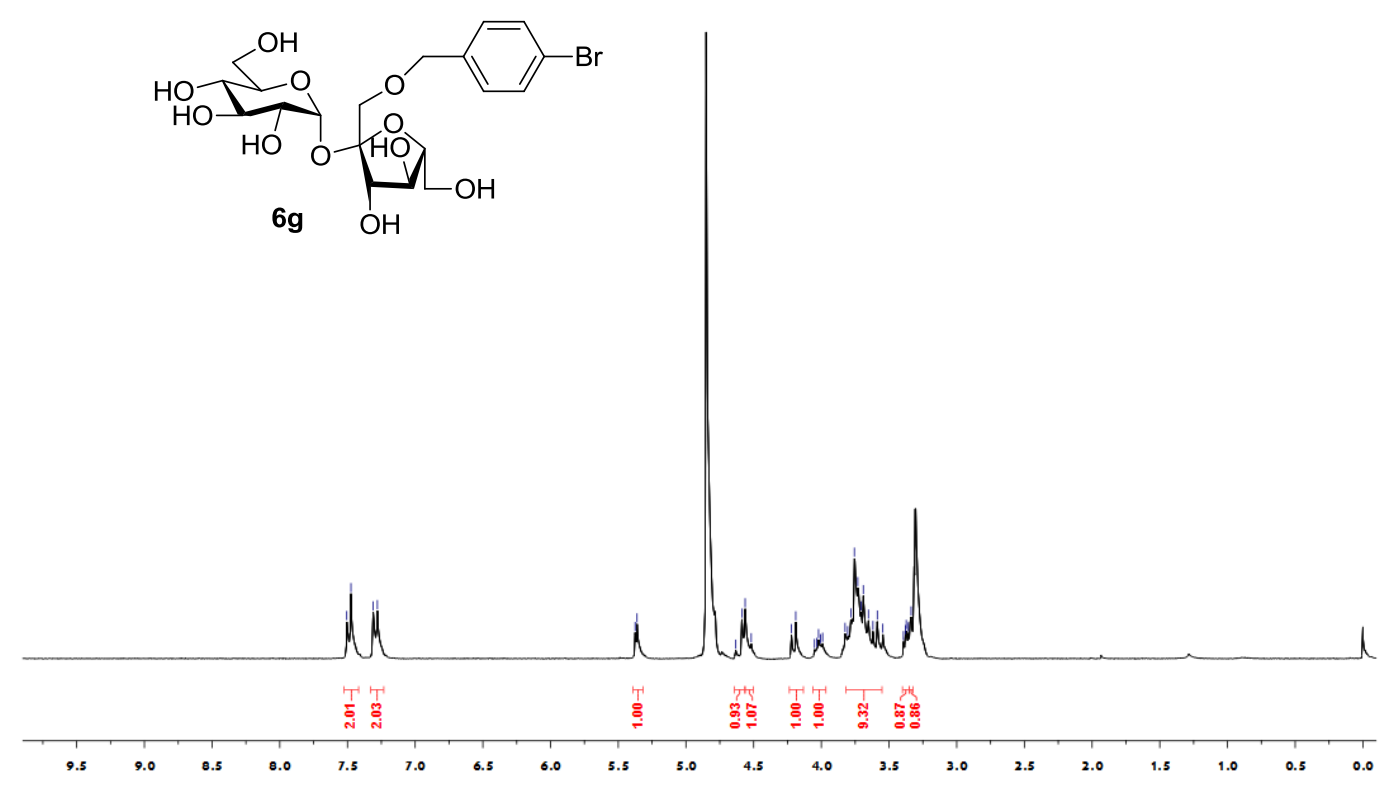

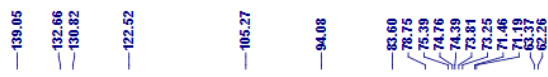
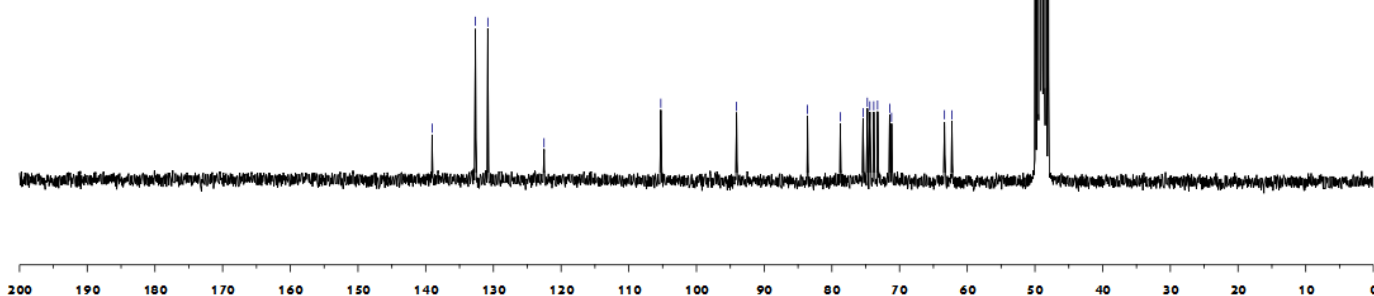


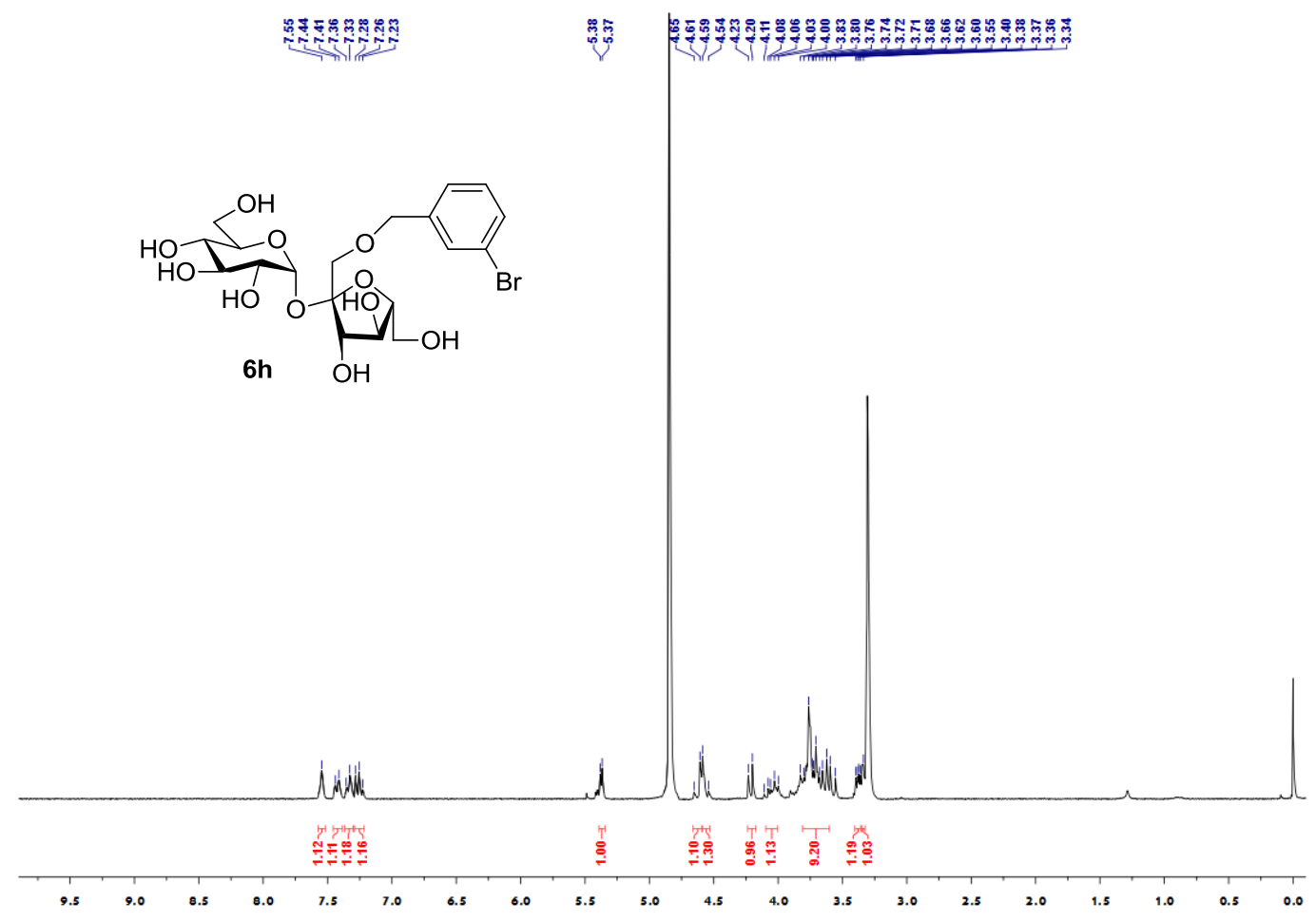

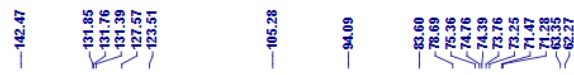
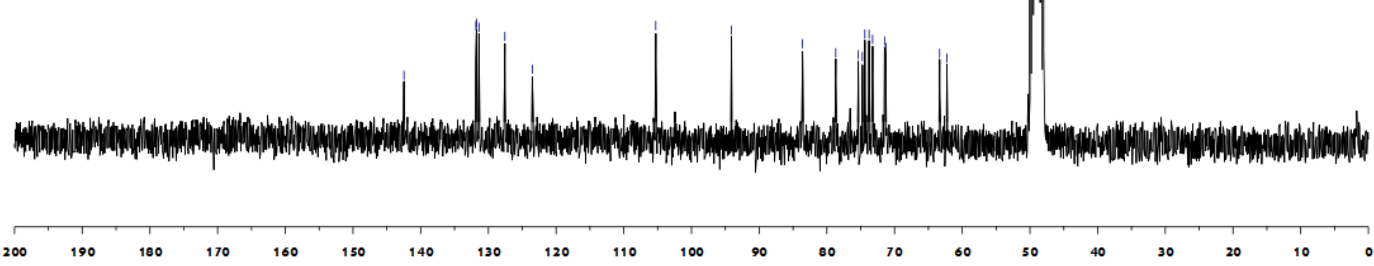

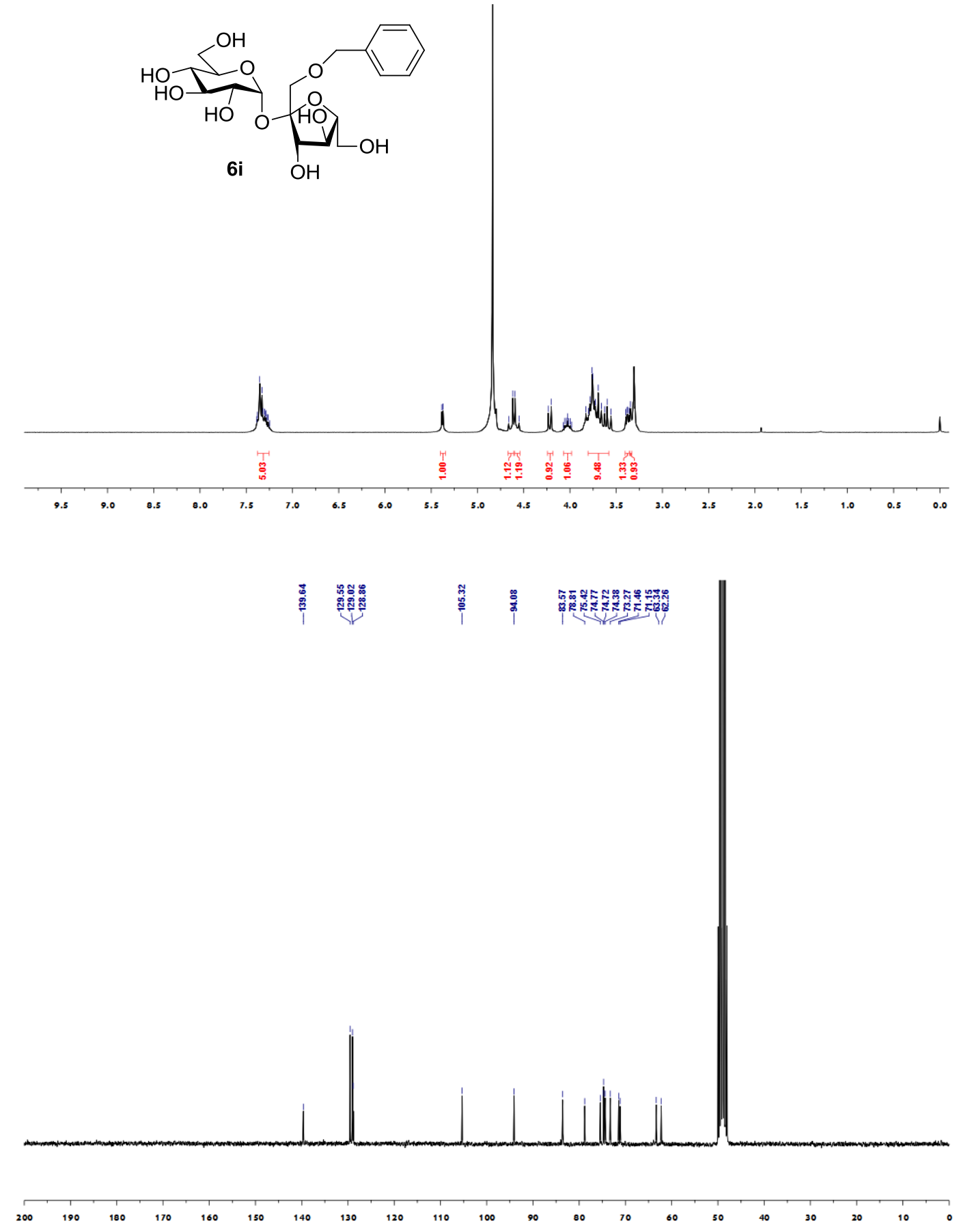

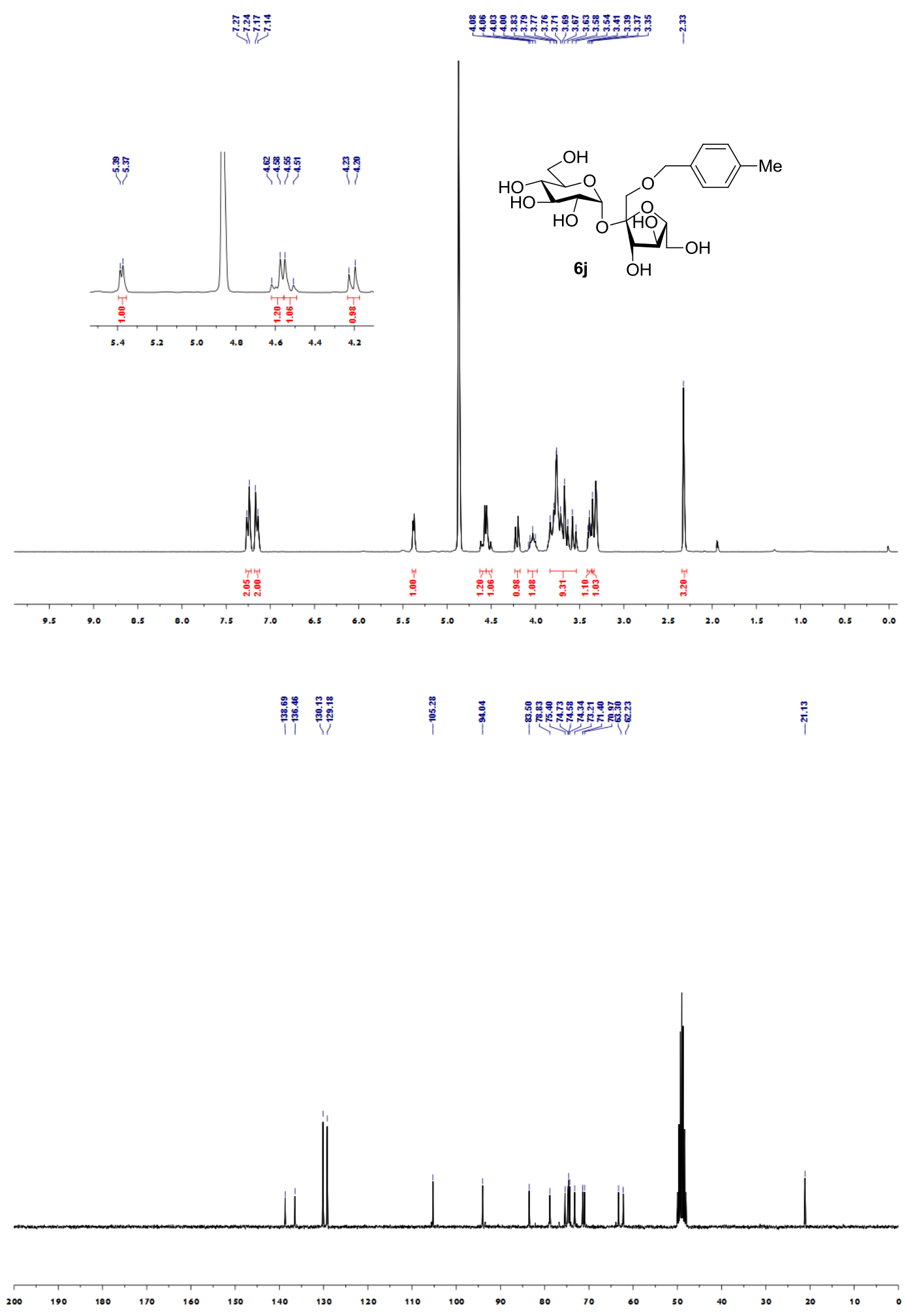

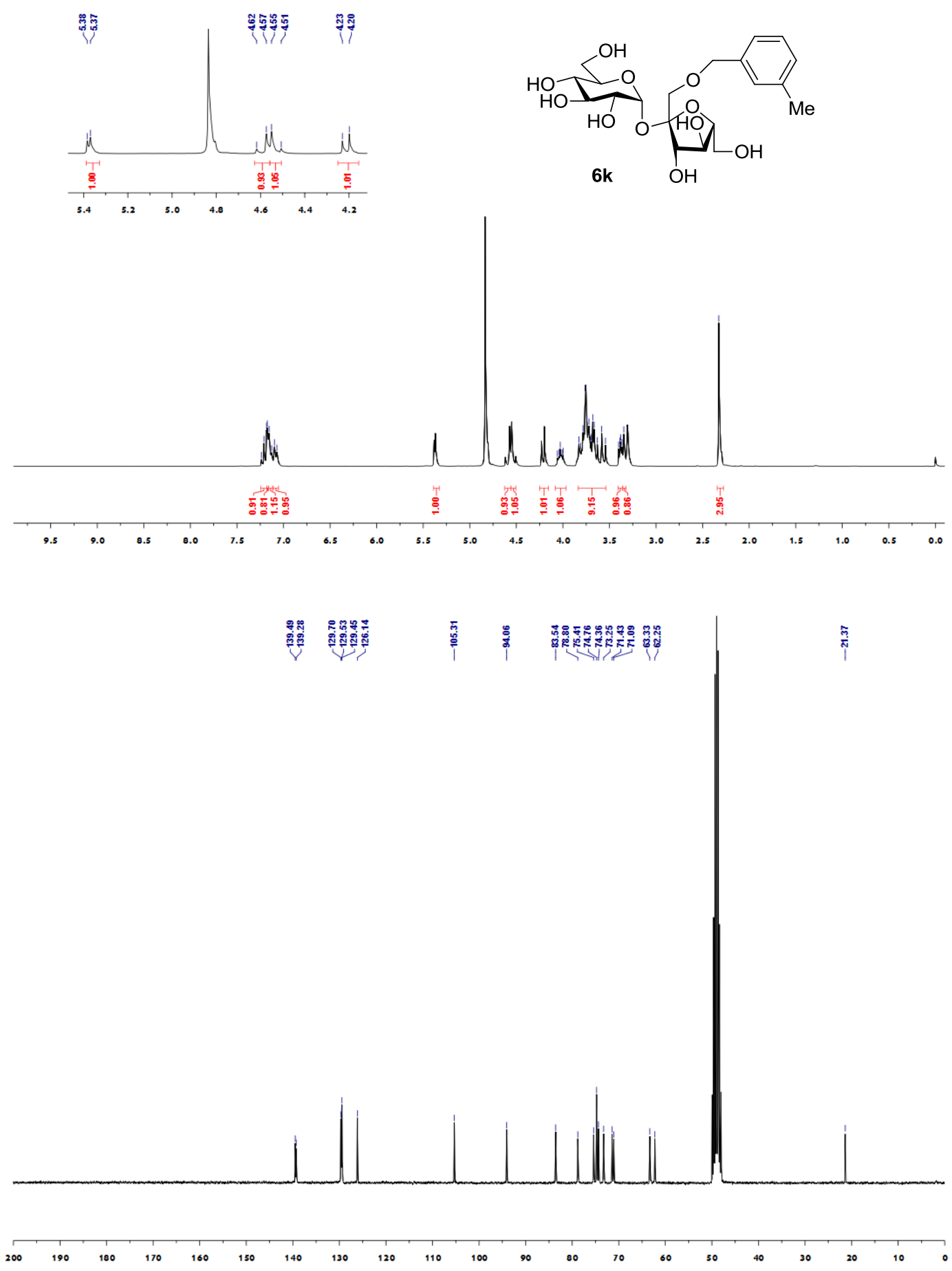

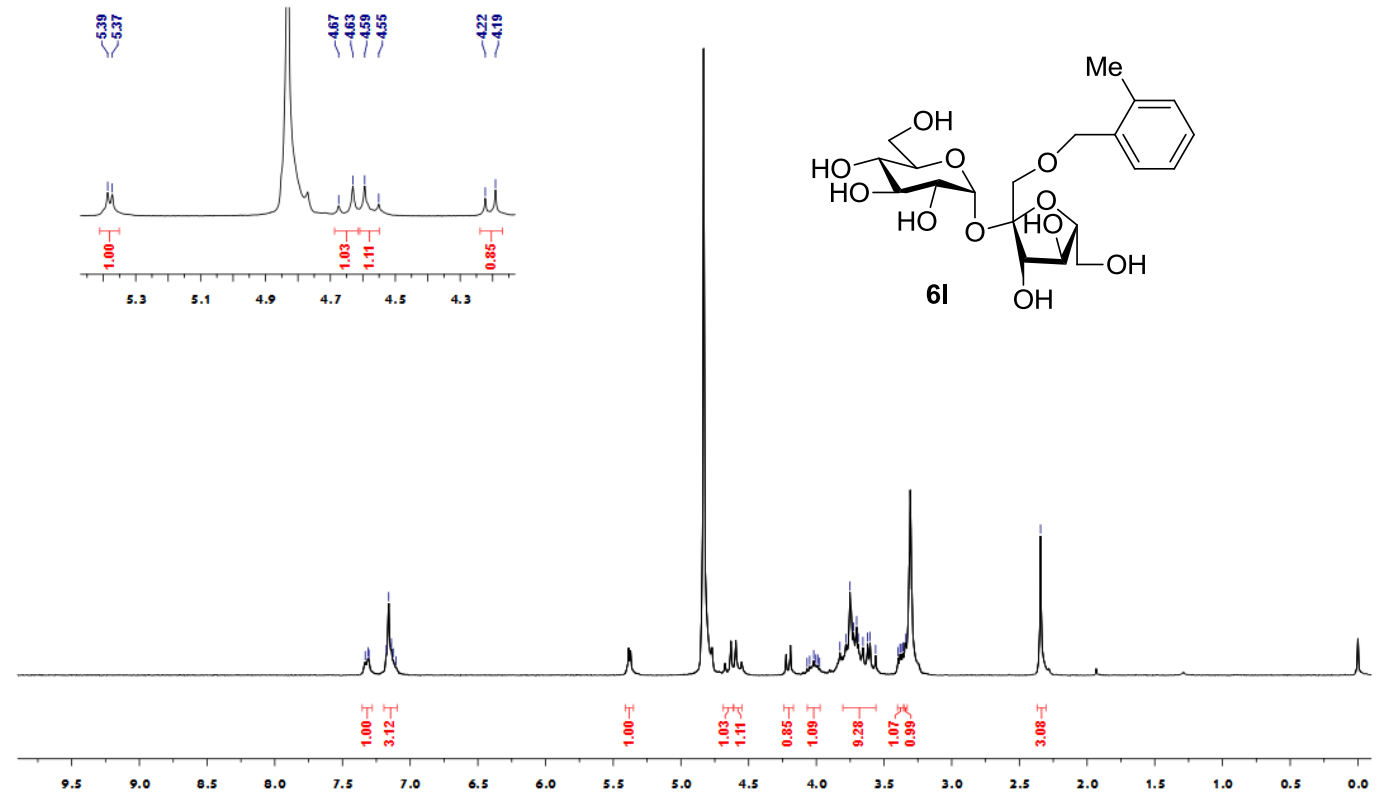

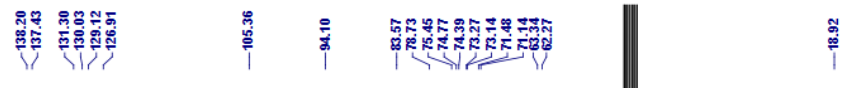

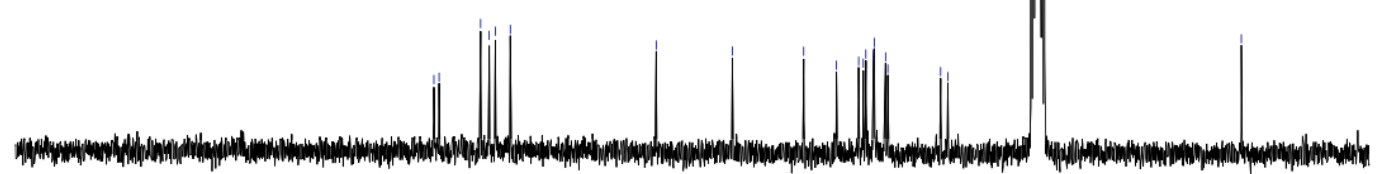

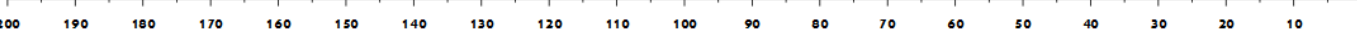




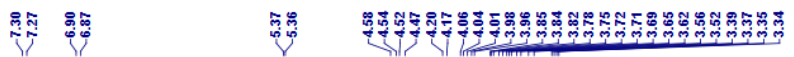

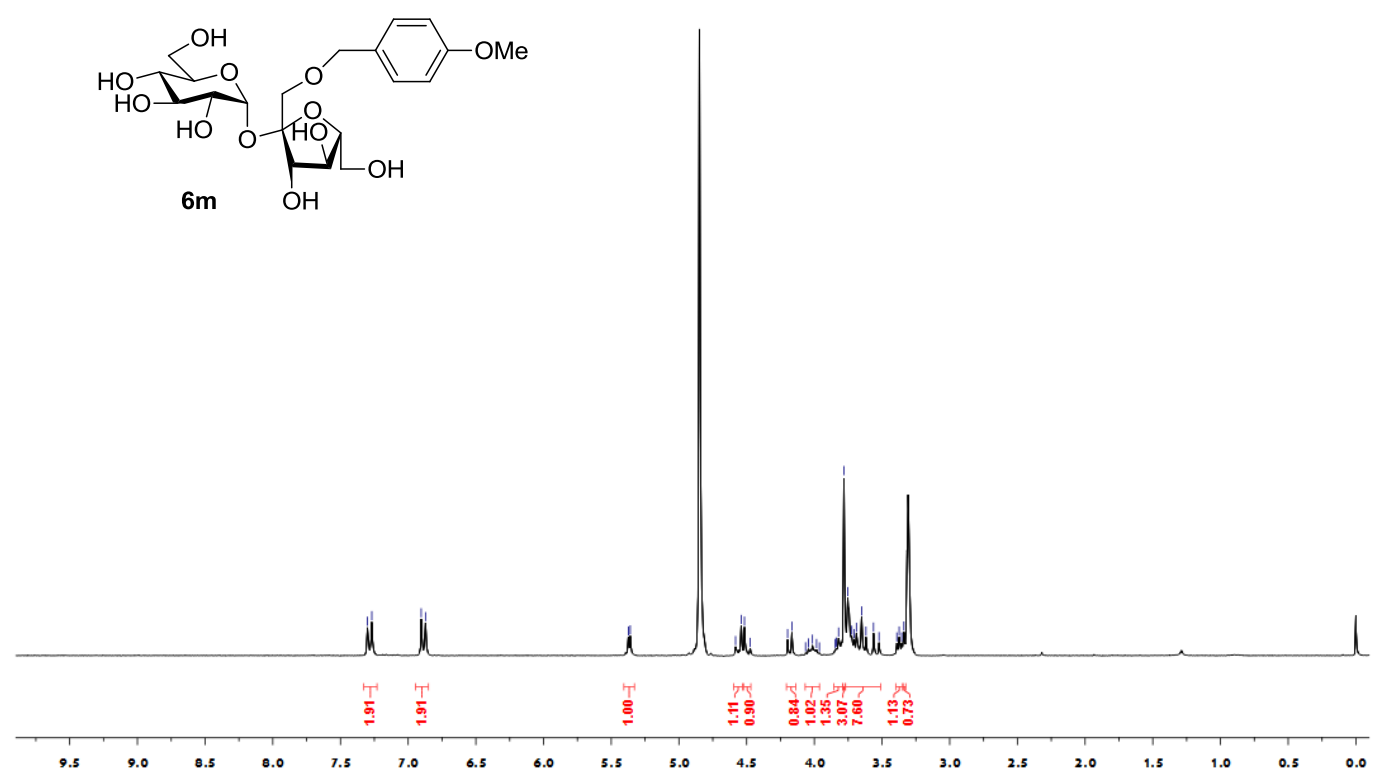

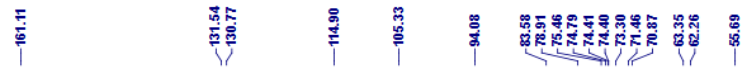



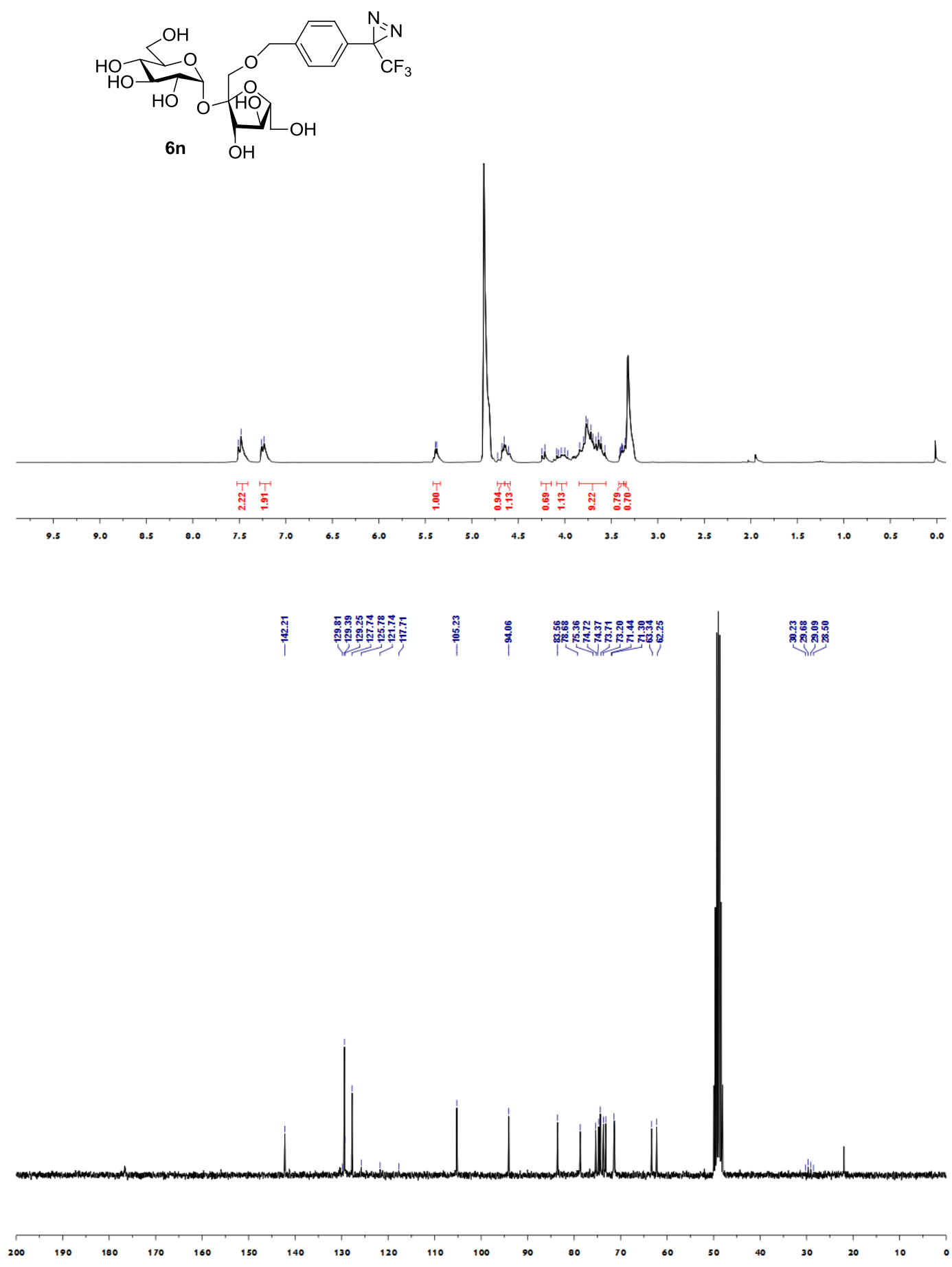

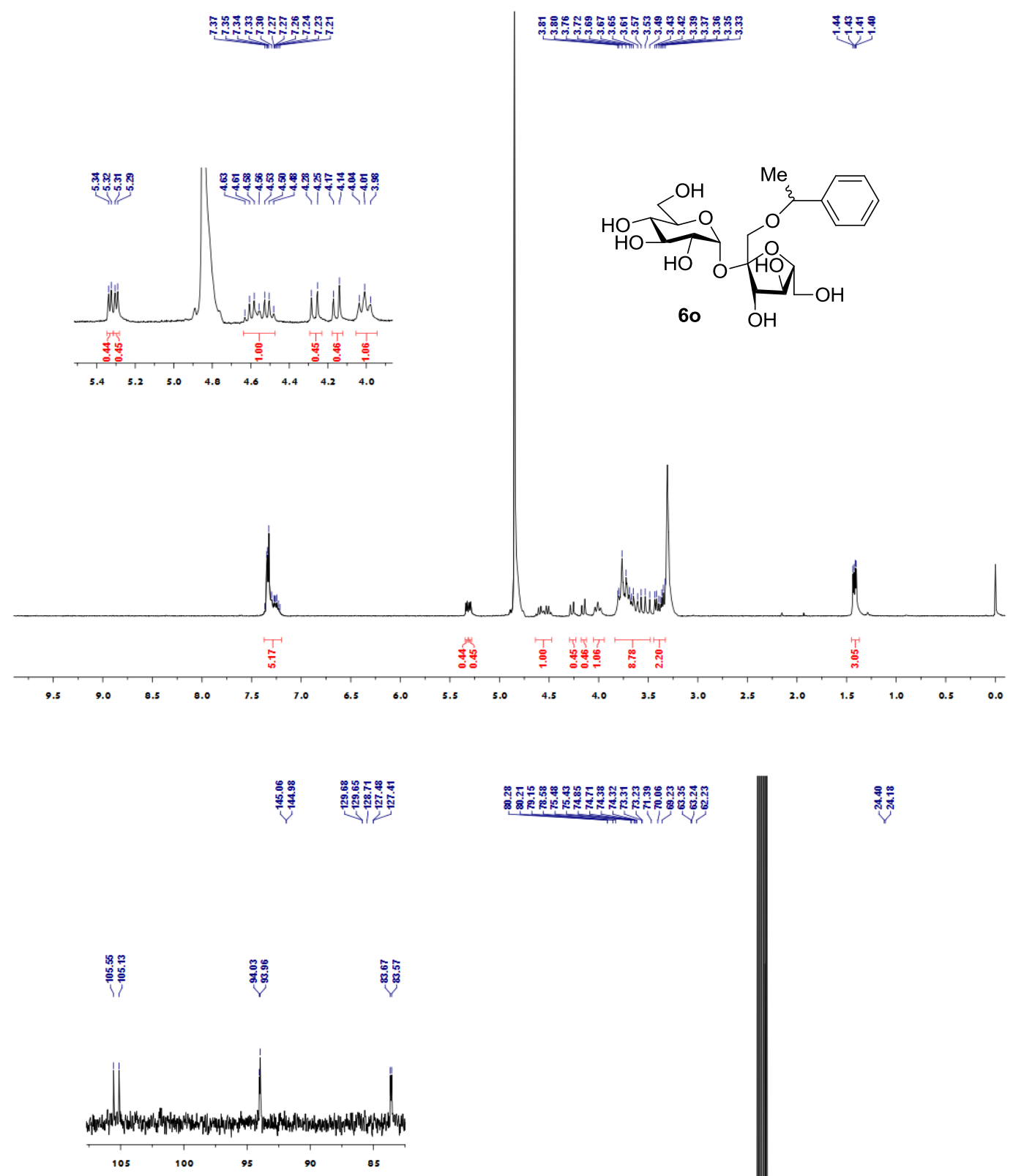

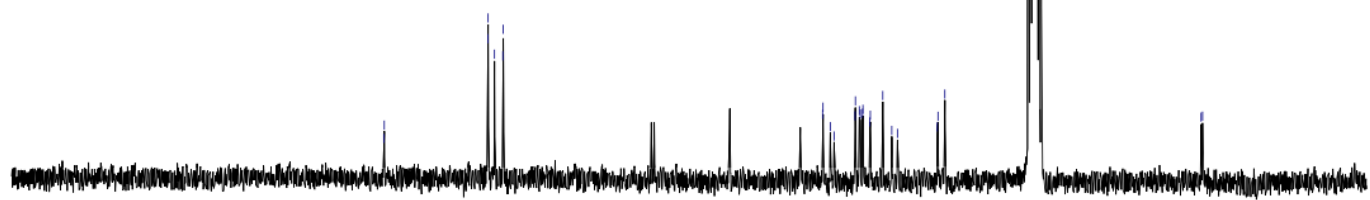

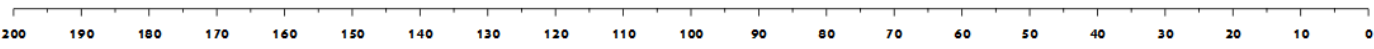



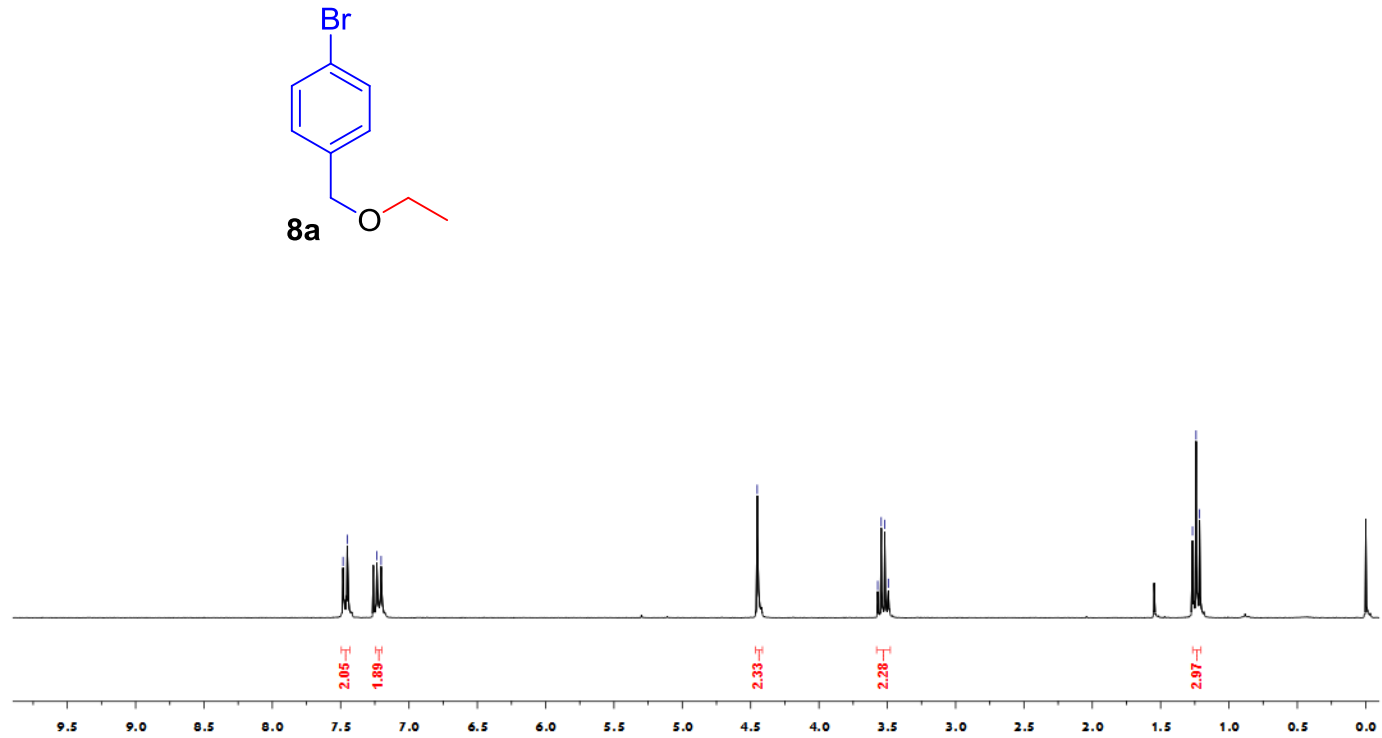

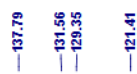

栗誉

$\stackrel{\circ}{10}$

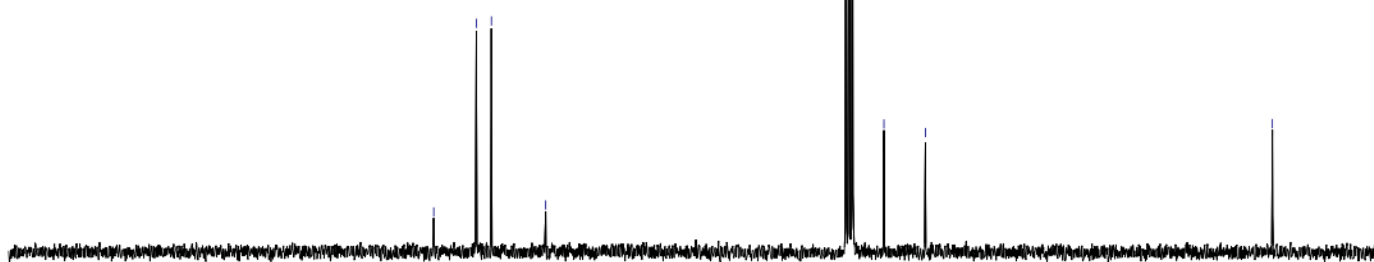

20

$200 \quad 190$

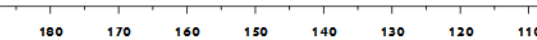

$100 \quad 90$ 

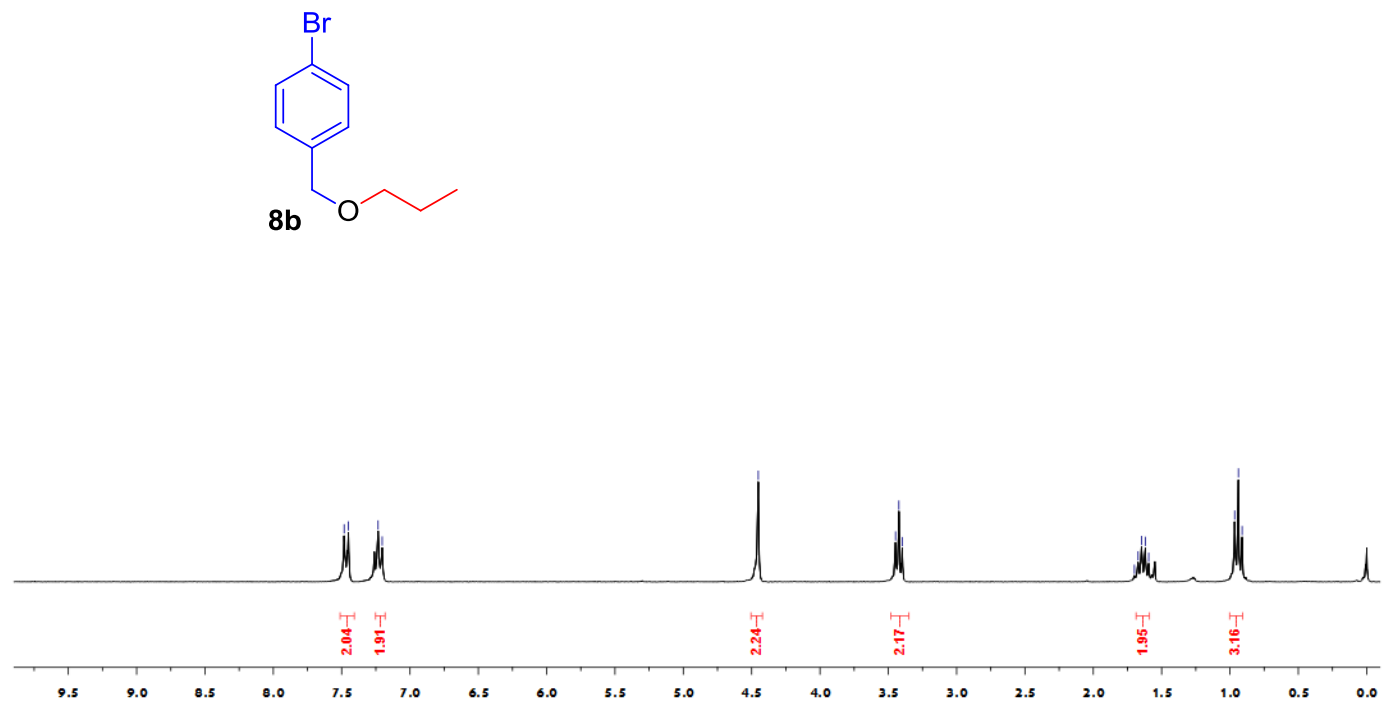

广

ชูกับ

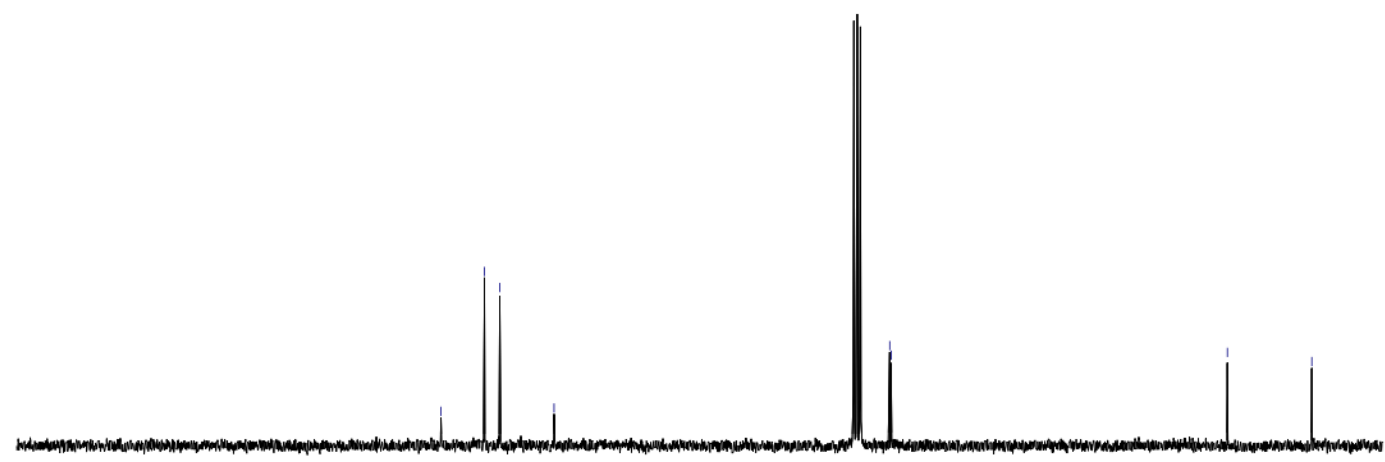

20

$200 \quad 190$
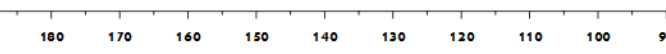

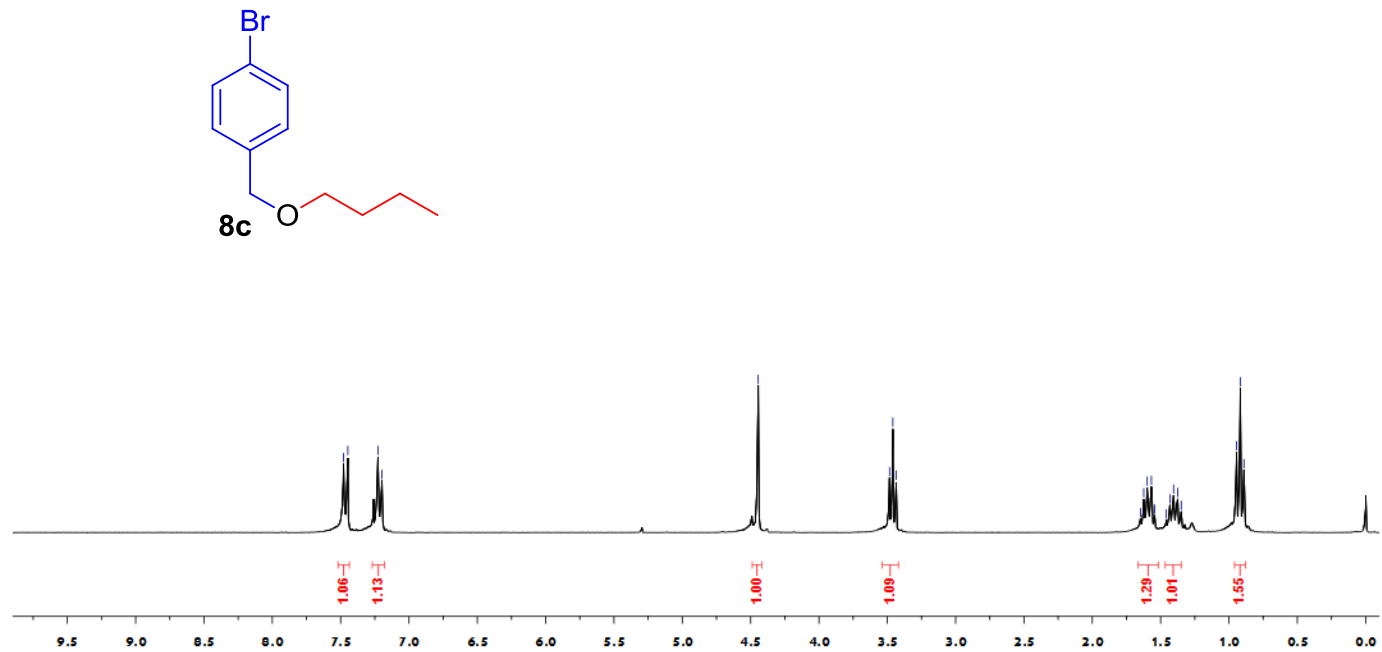

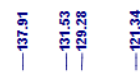
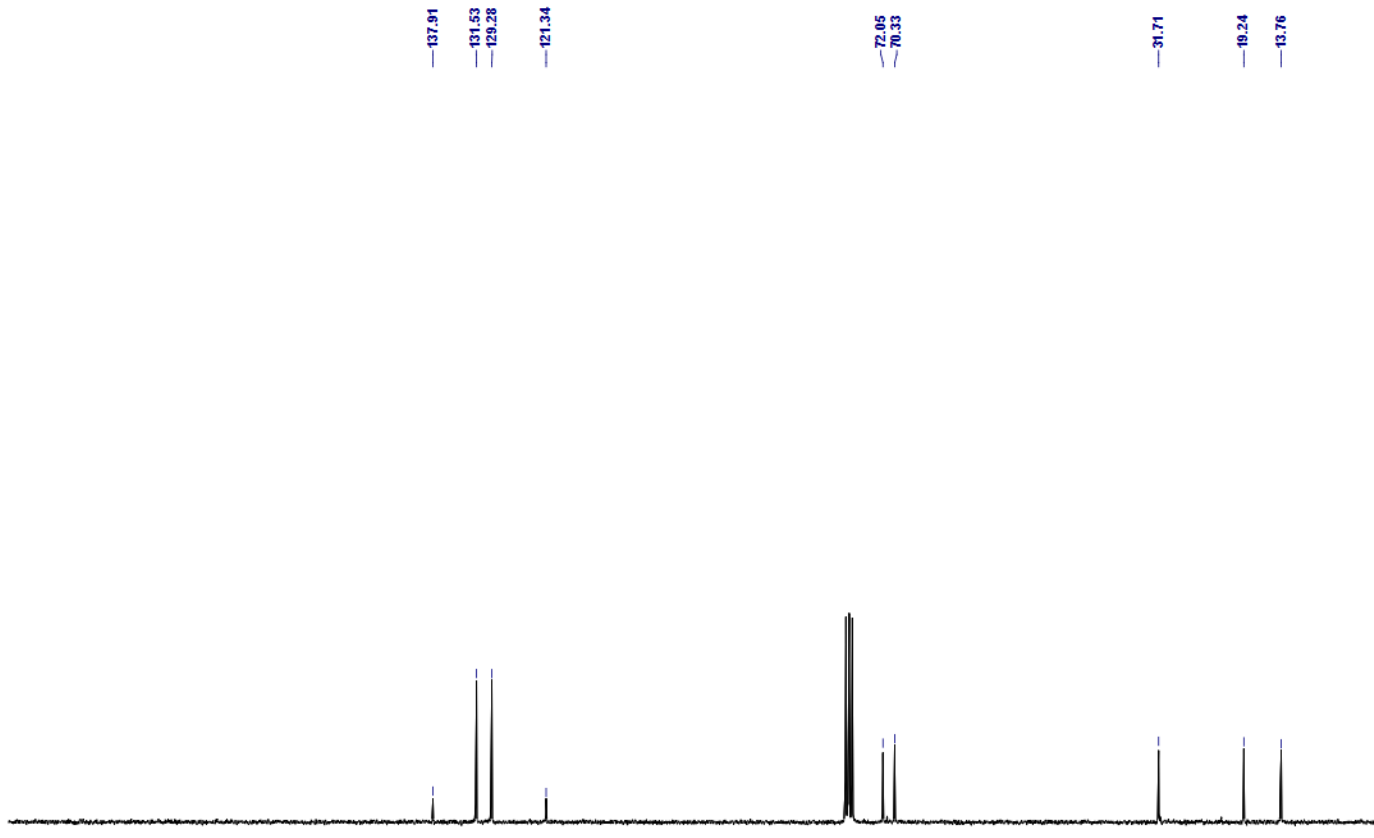

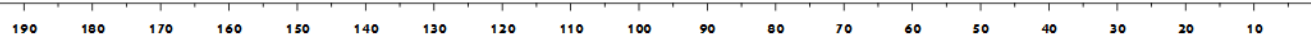



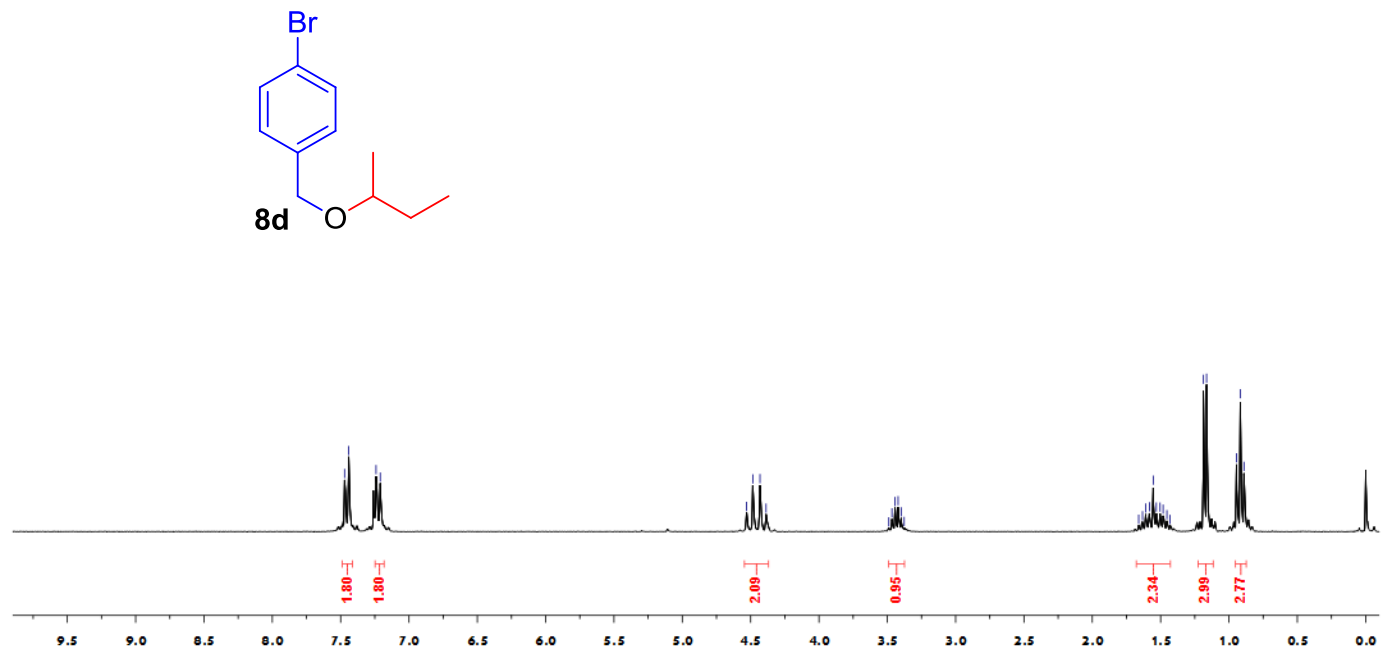

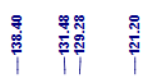

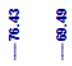

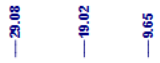

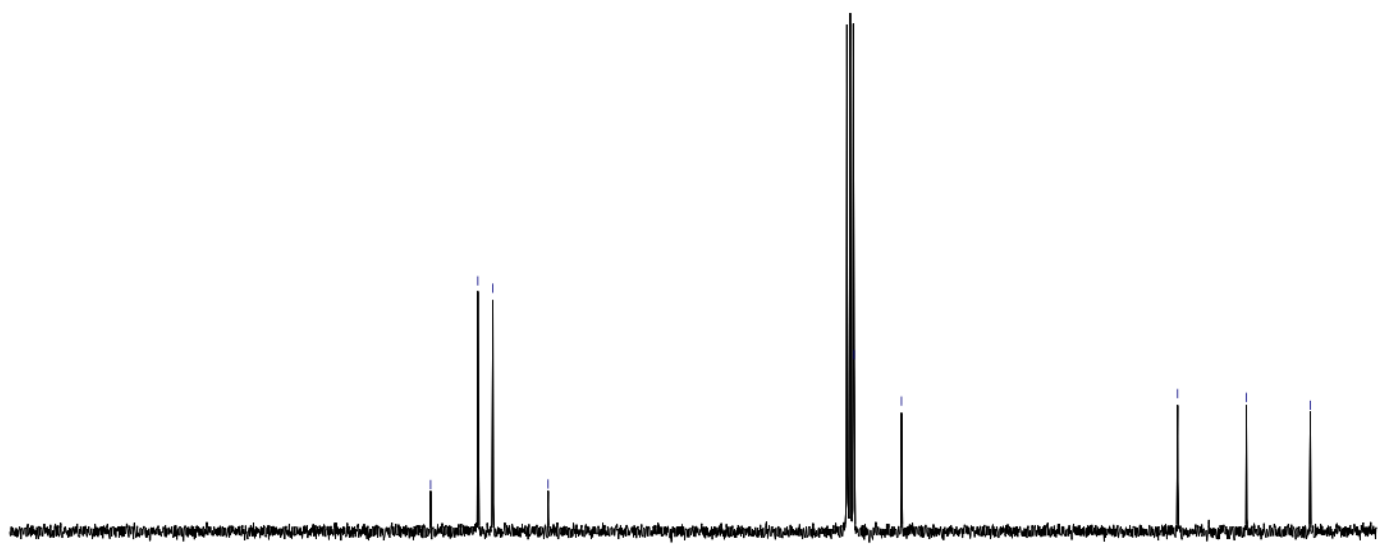

$\begin{array}{llllllllllllllllllll}190 & 180 & 170 & 160 & 150 & 140 & 130 & 120 & 110 & 100 & 90 & 80 & 70 & 60 & 50 & 40 & 30 & 20 & 10 & 0\end{array}$ 


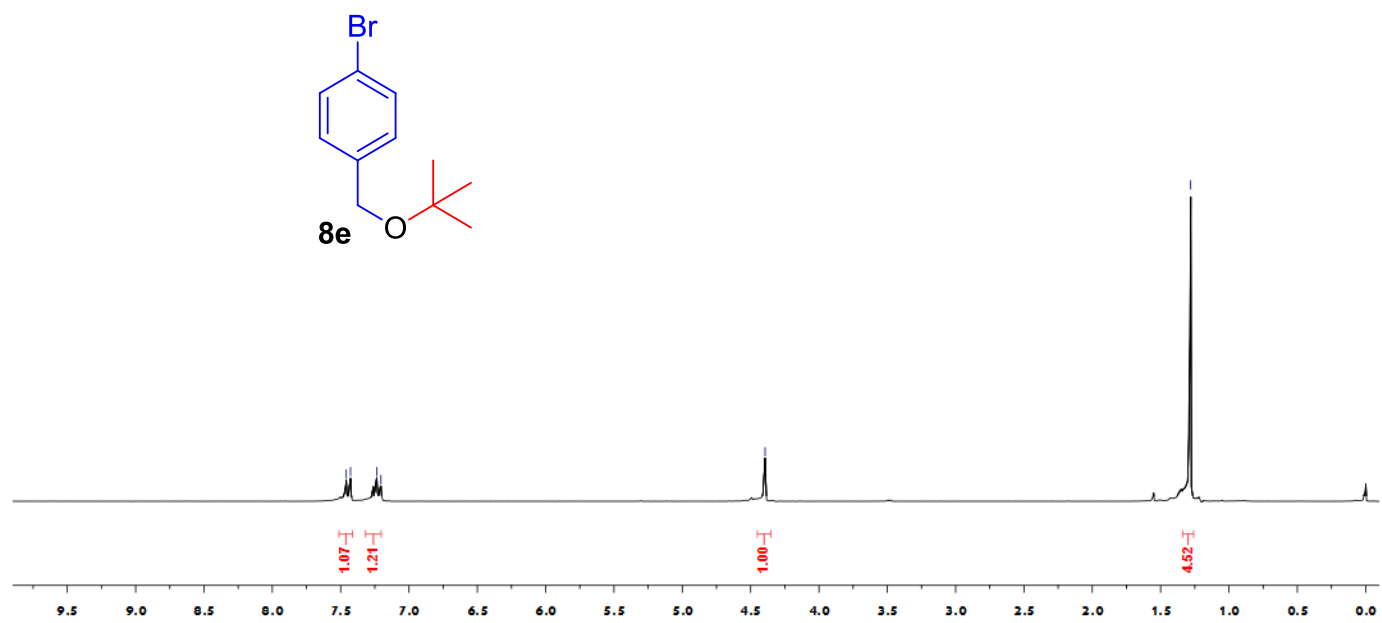

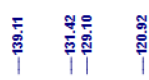

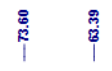

象

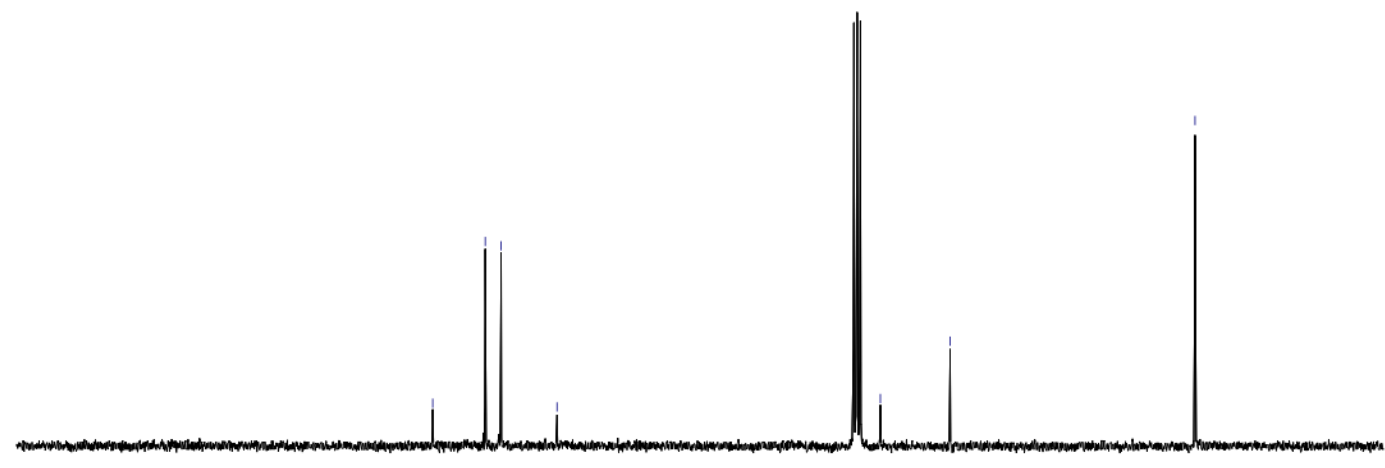

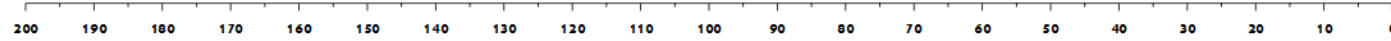



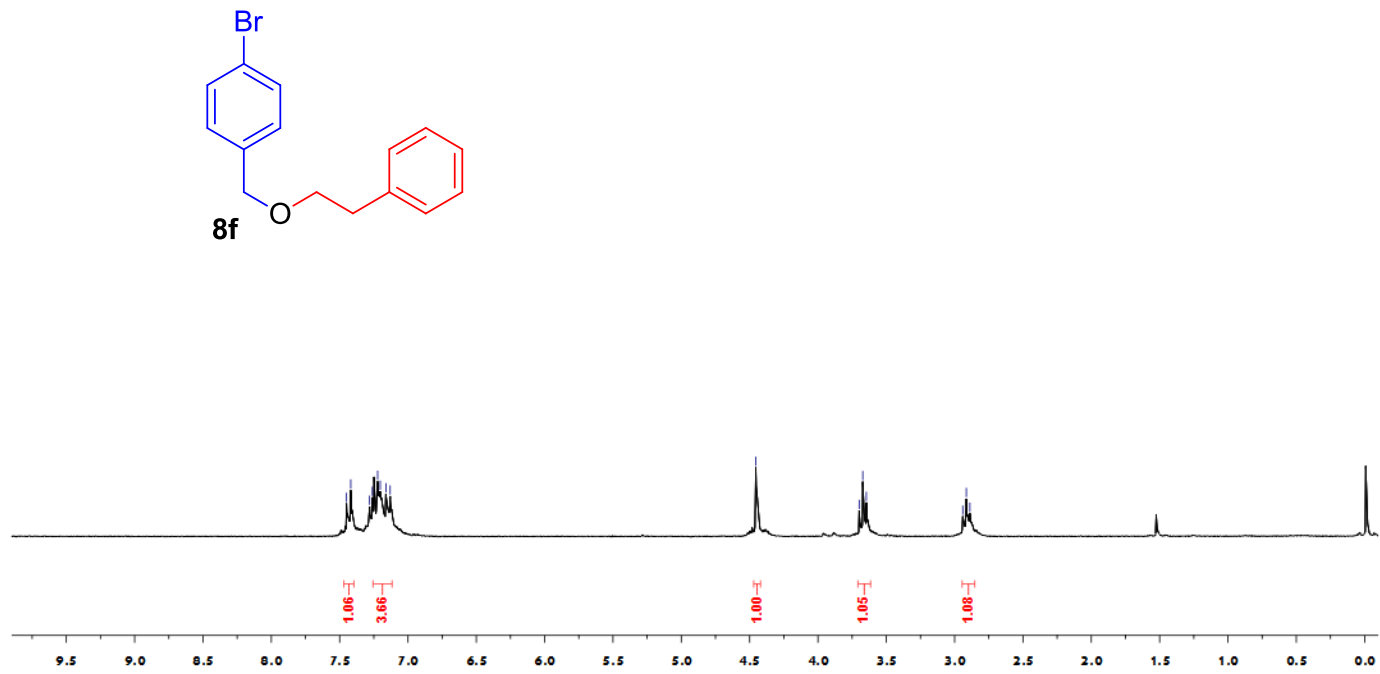

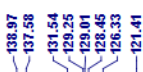

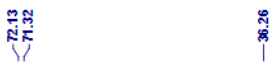

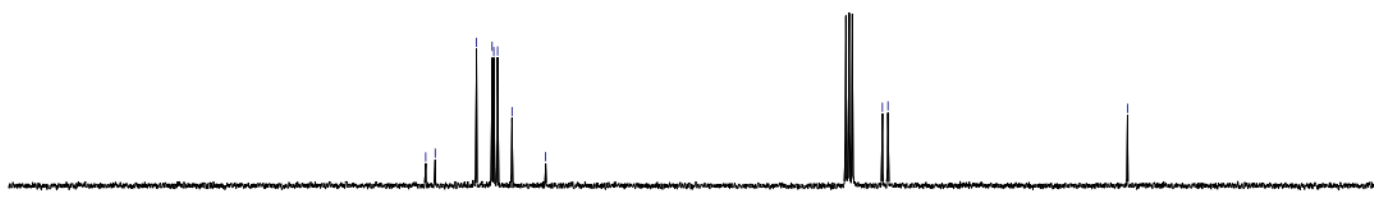

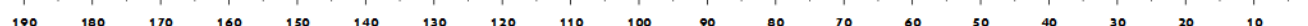



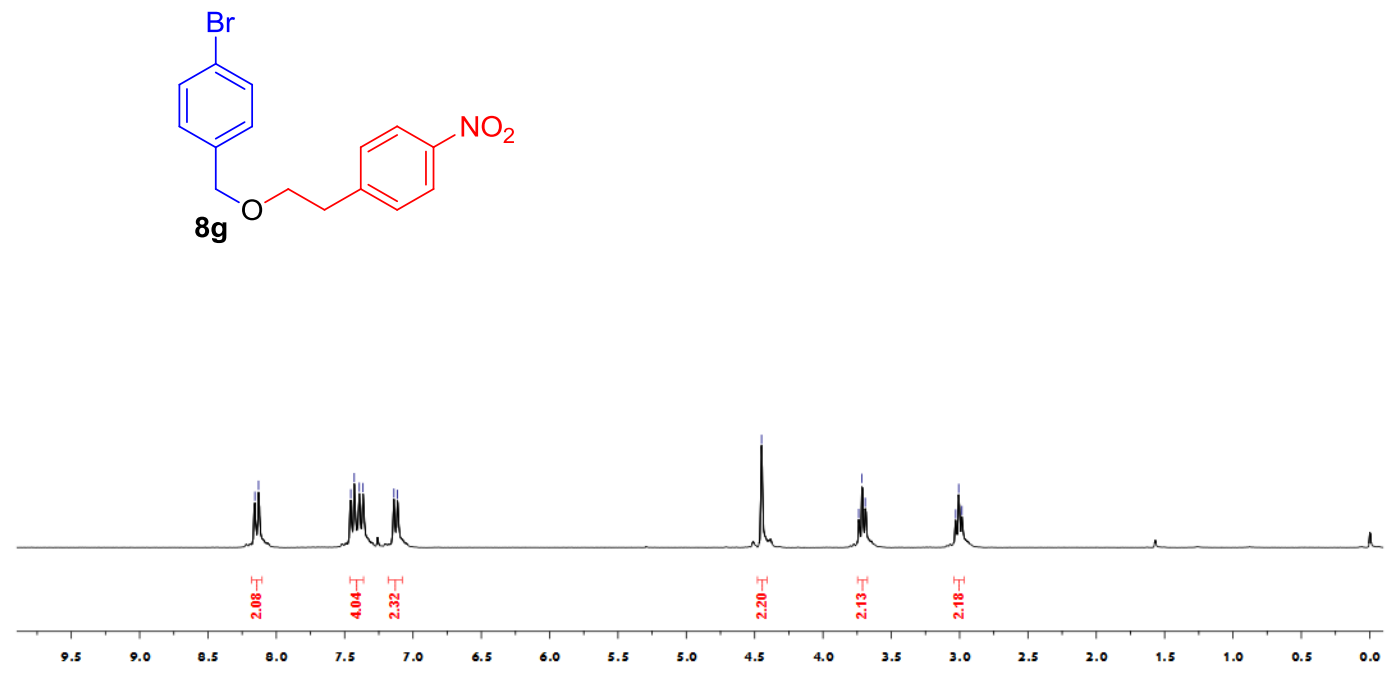

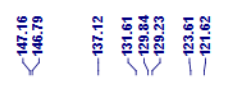

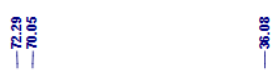
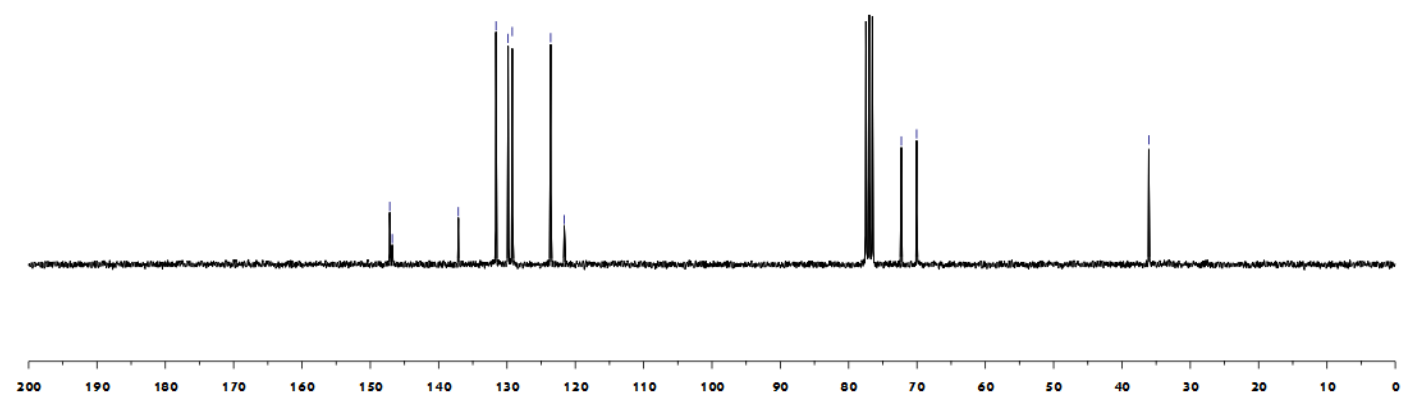

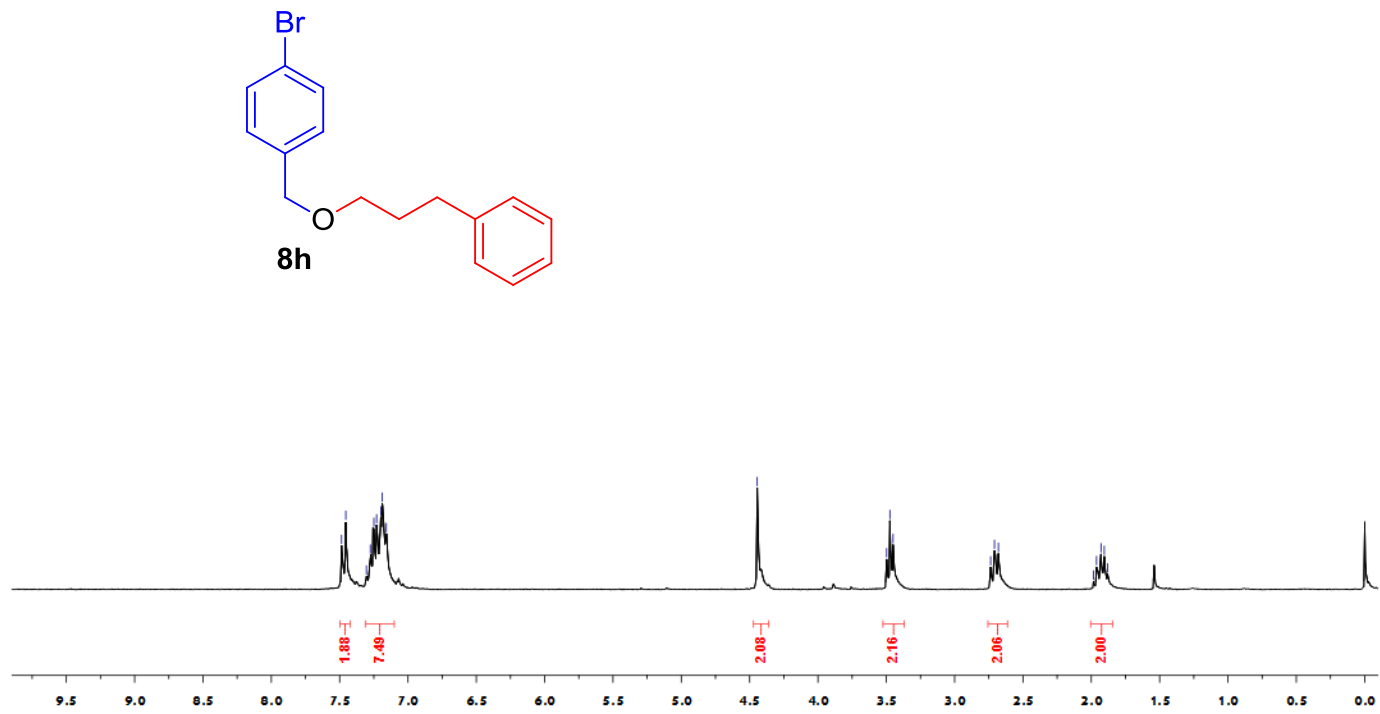

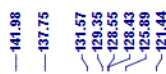

嘎

กัด

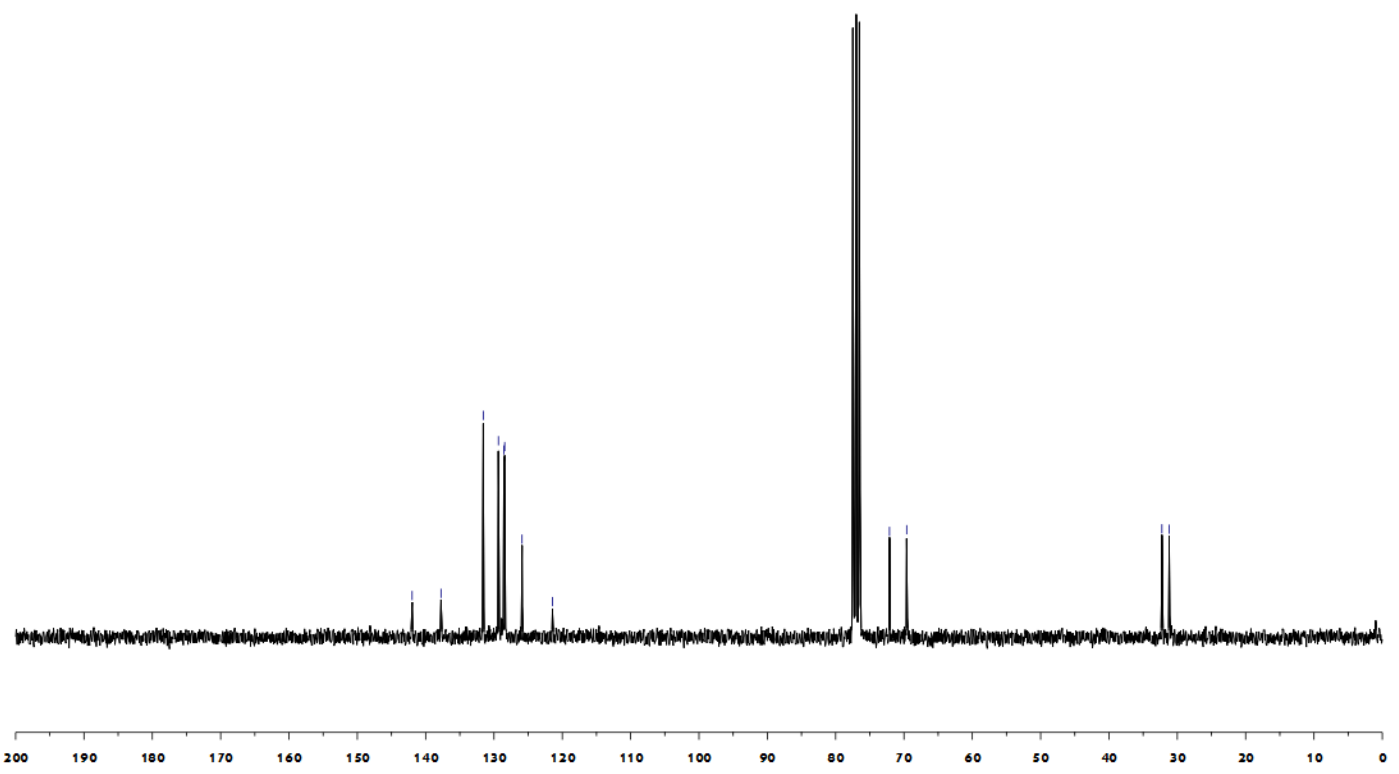




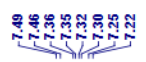

跂
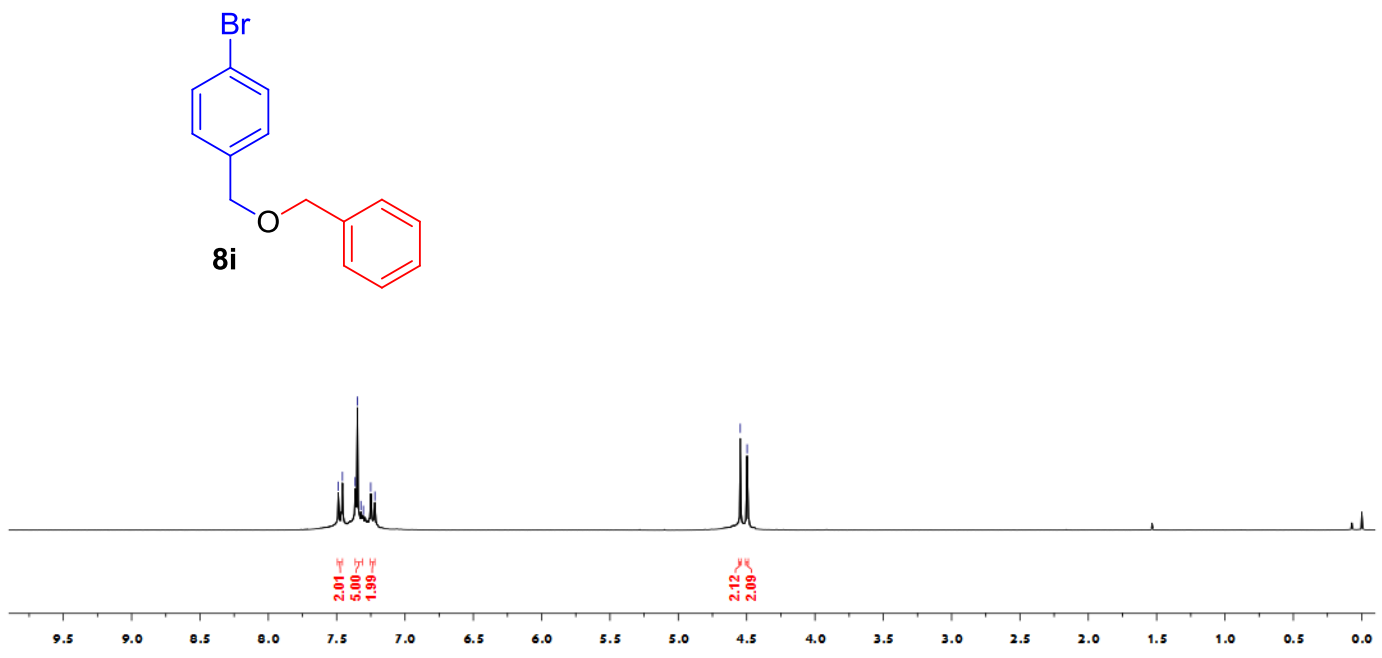

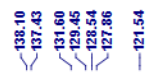

สำ
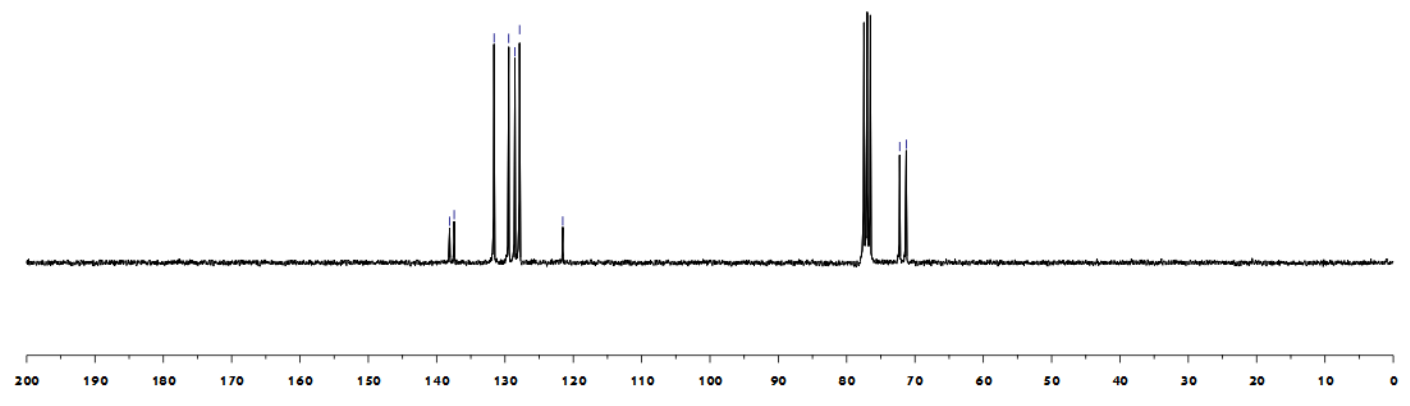

S41 

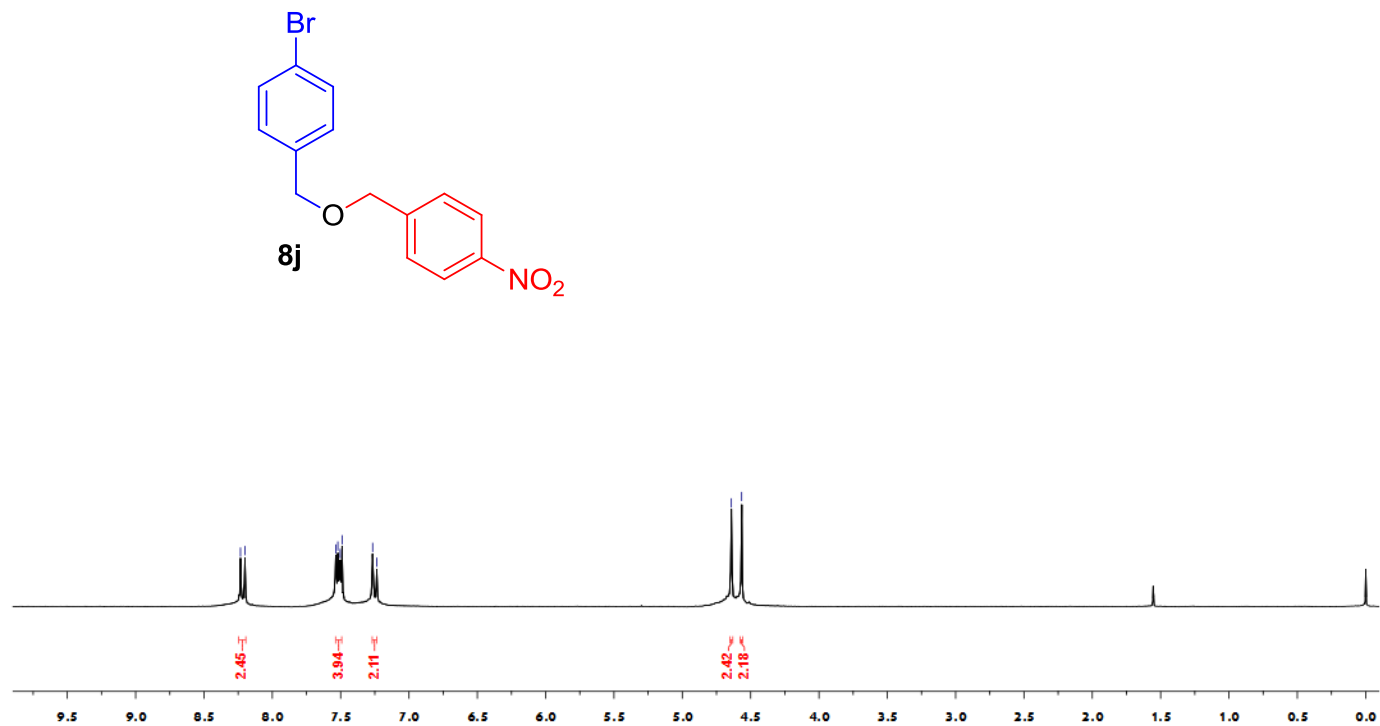

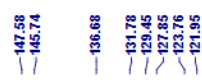

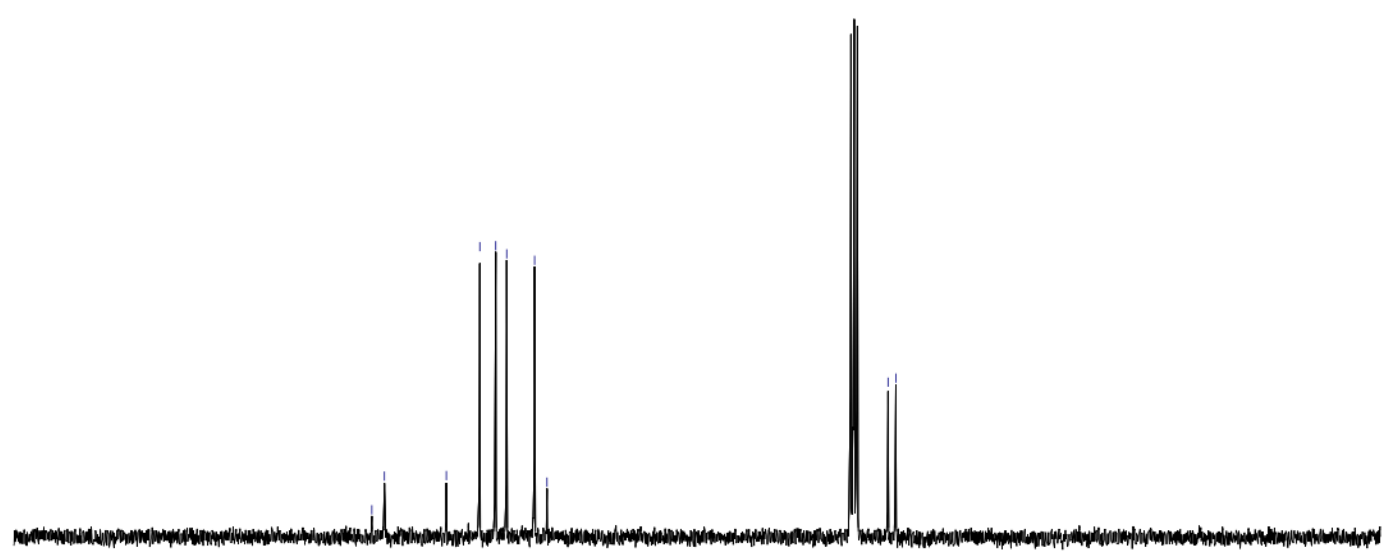

200

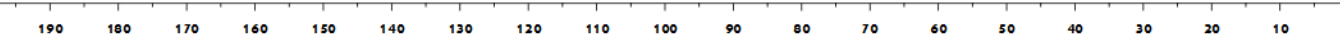



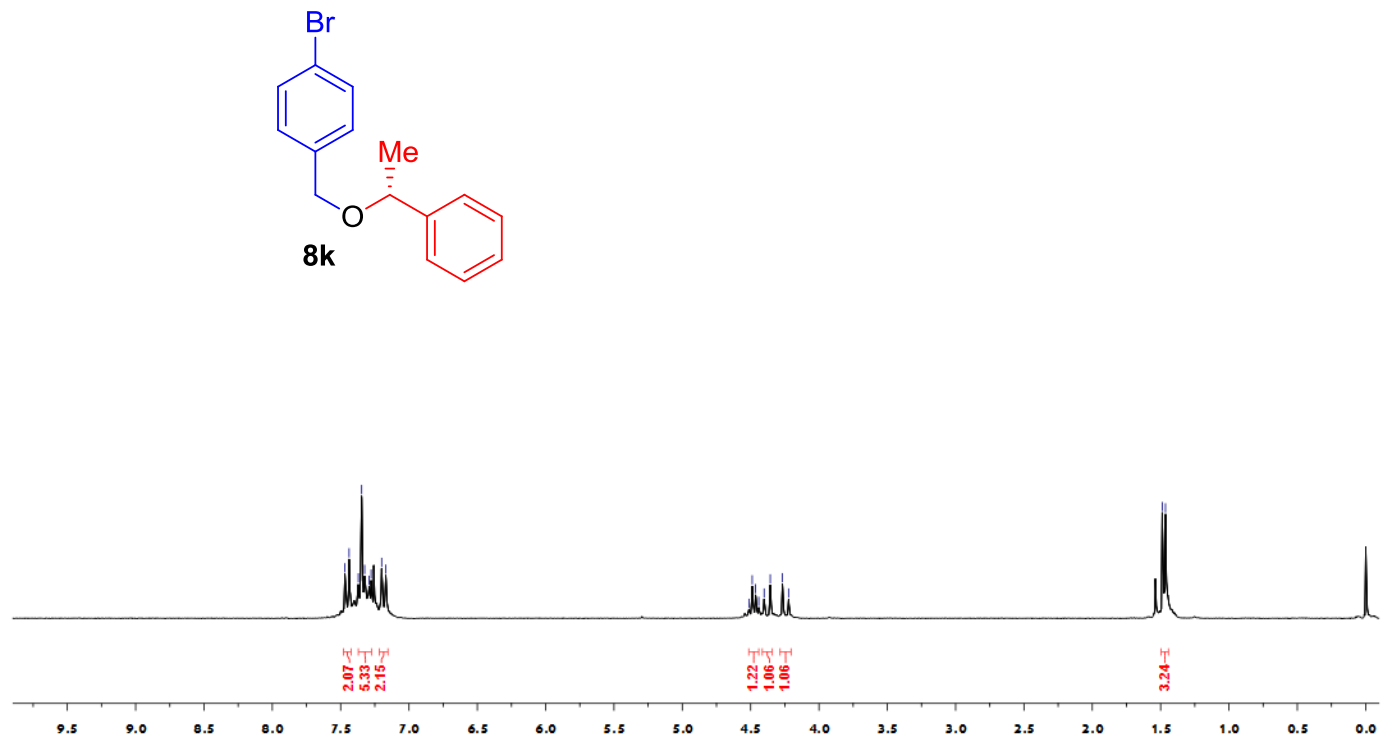

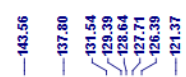

嵒

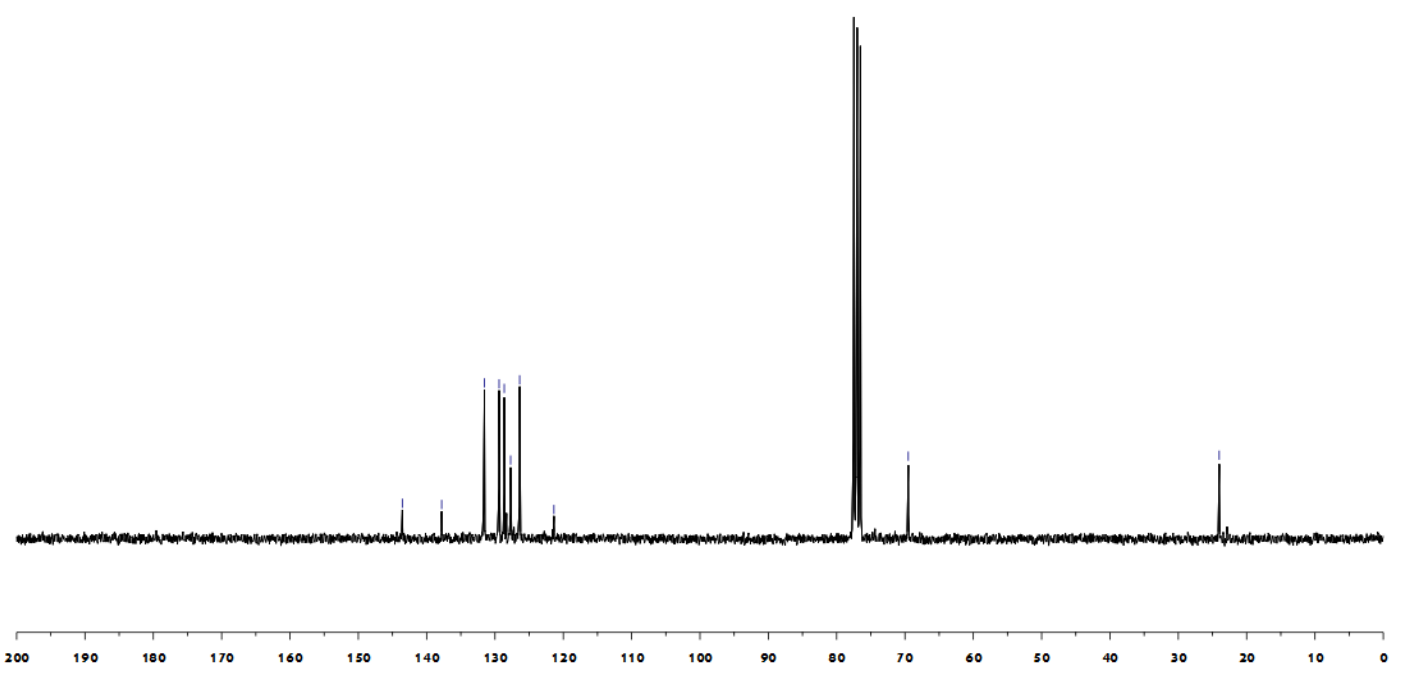



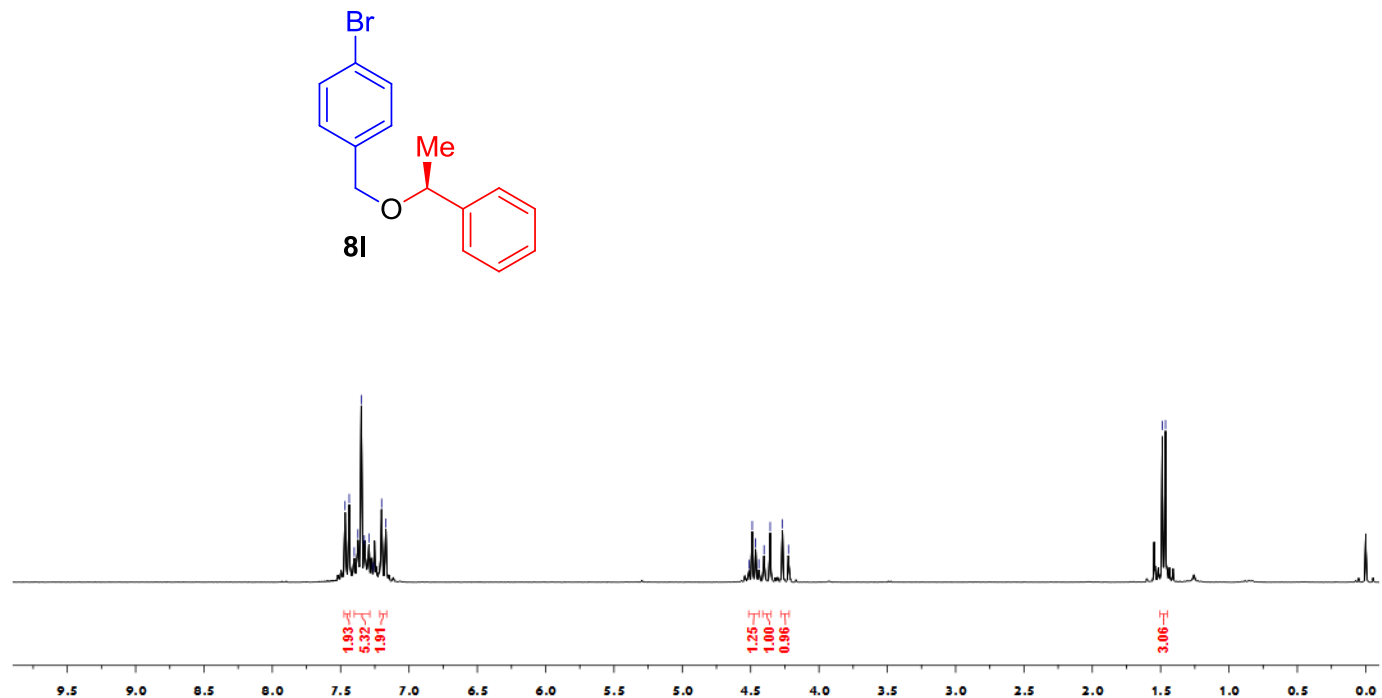

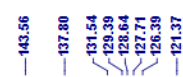

章

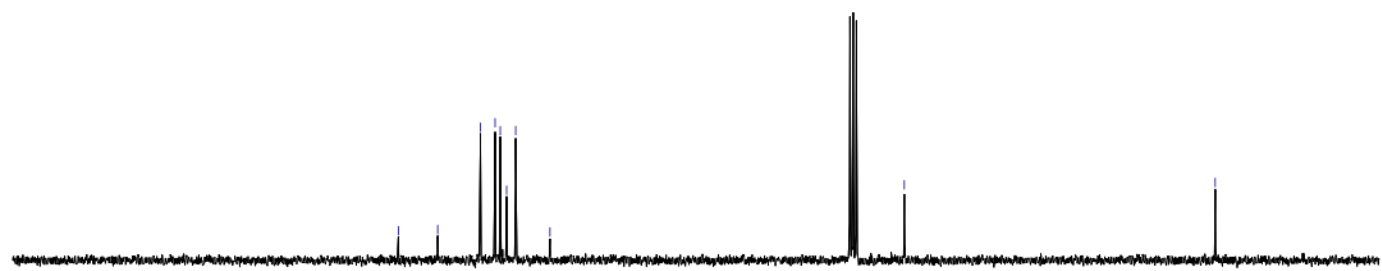

200

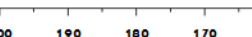

$\begin{array}{lllll}190 \quad 180 & 170 \quad 160 & 150\end{array}$

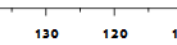

100 

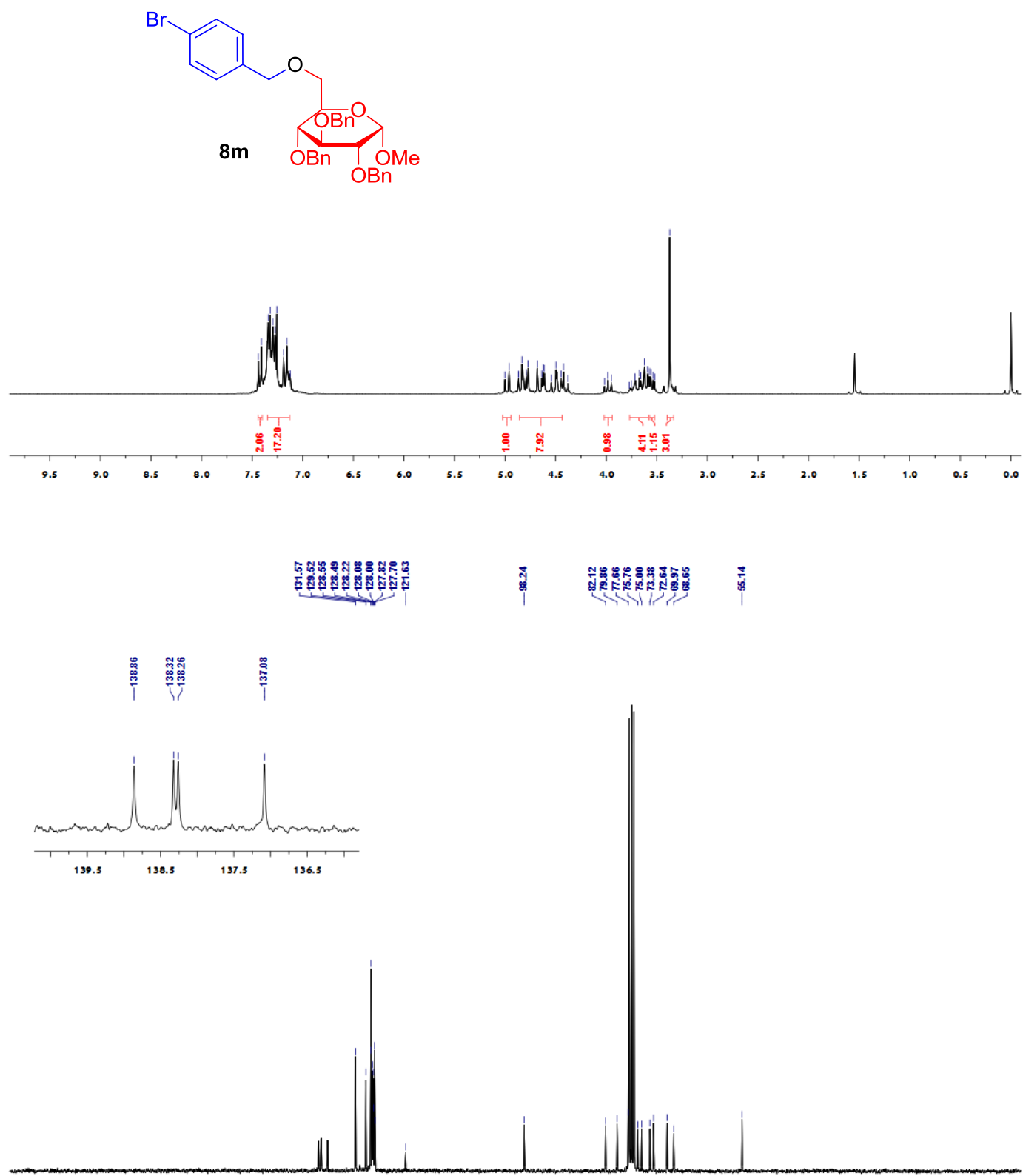

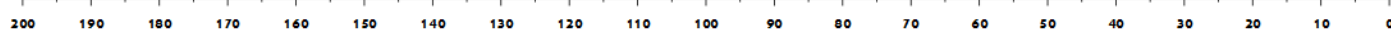



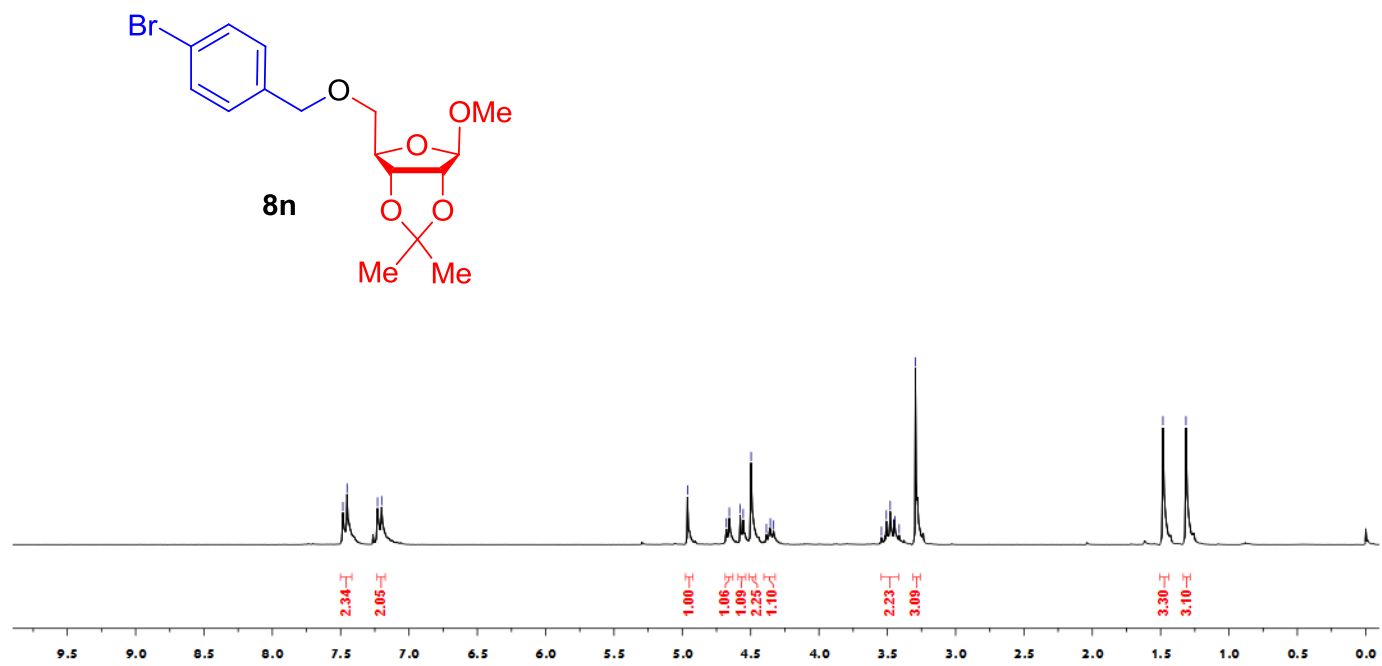

春影

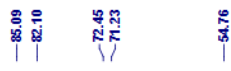

骨量

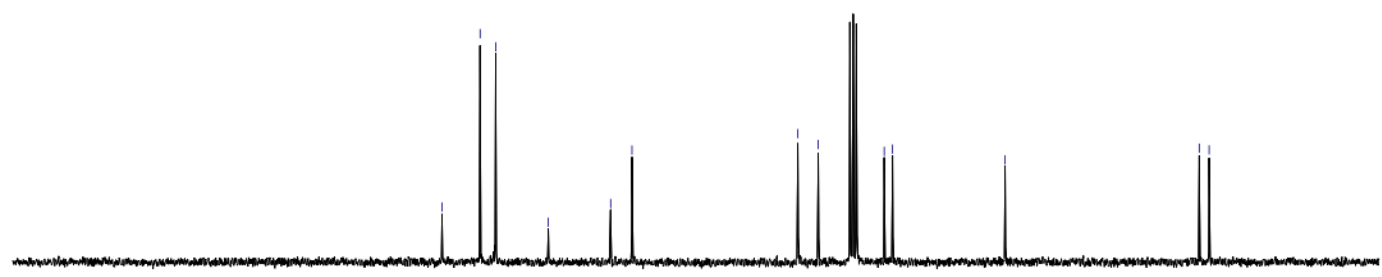

20

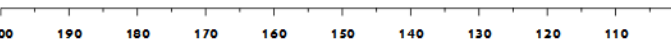



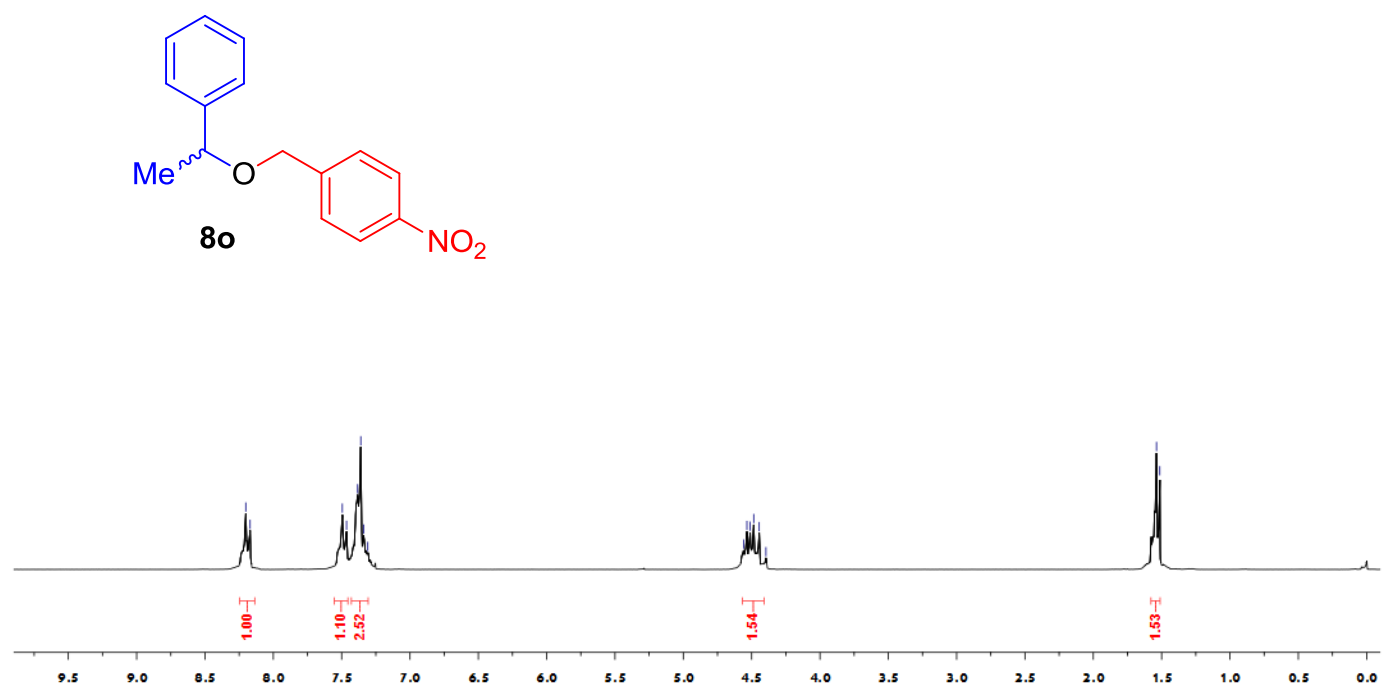

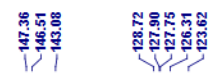

।

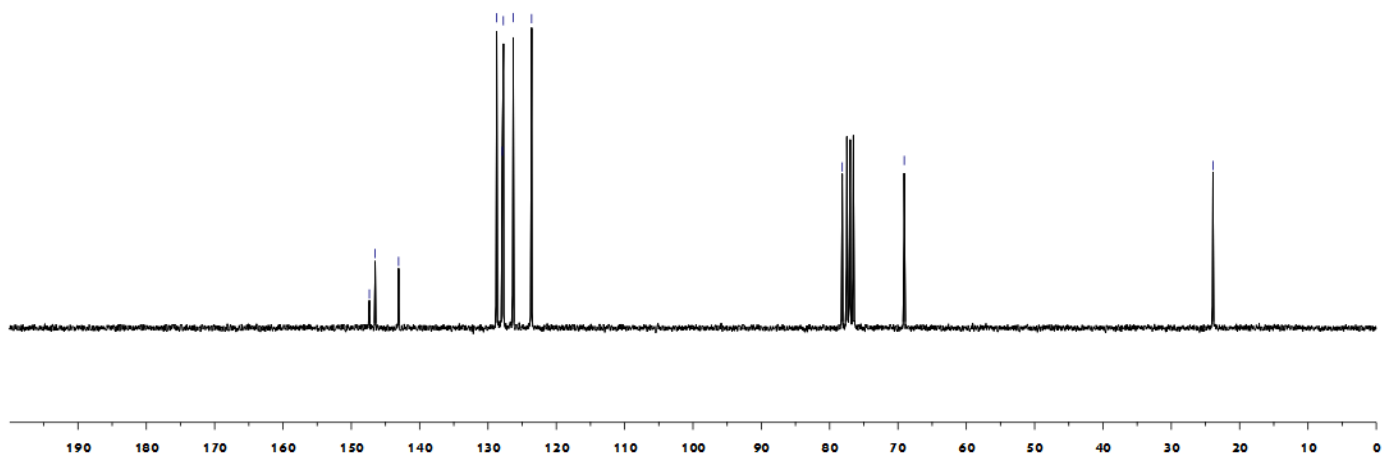



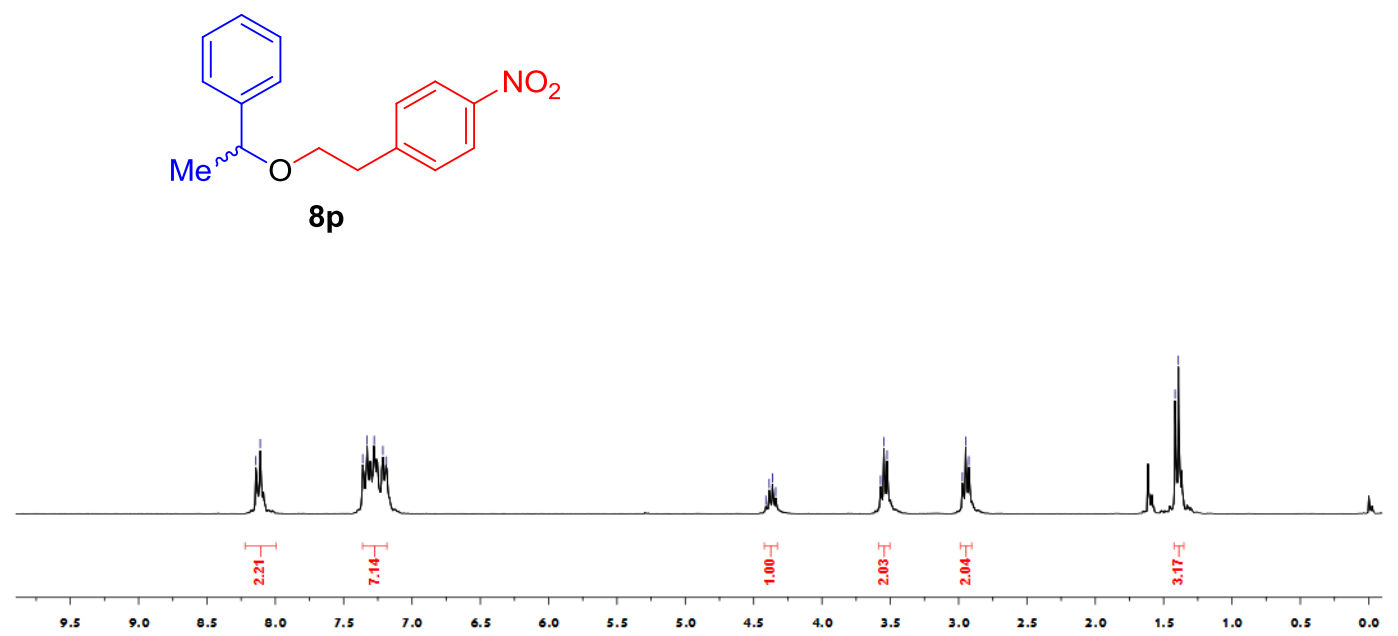

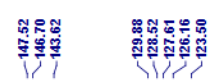
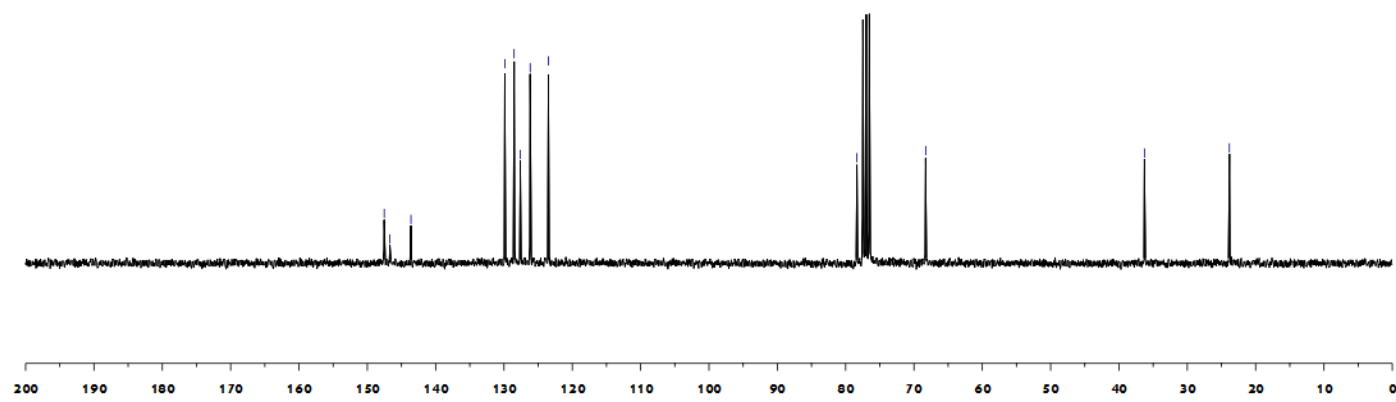

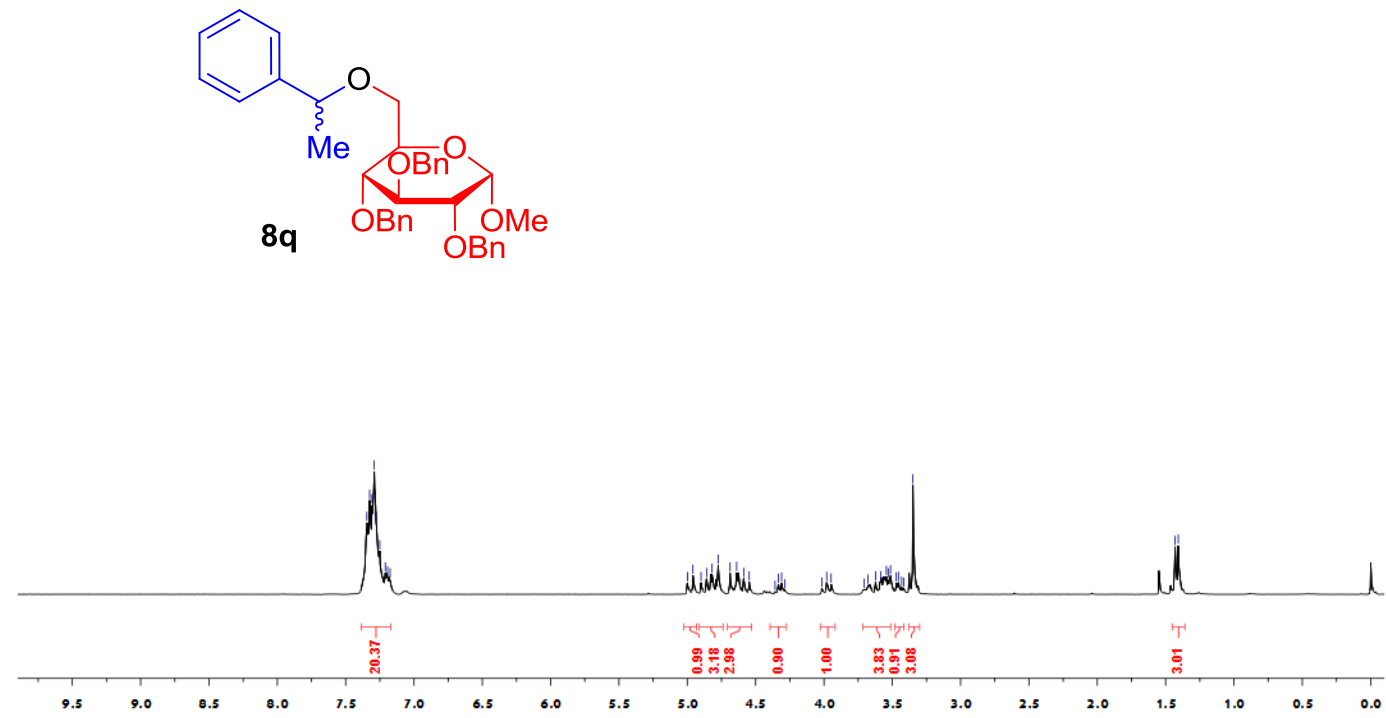

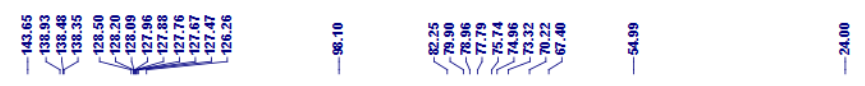

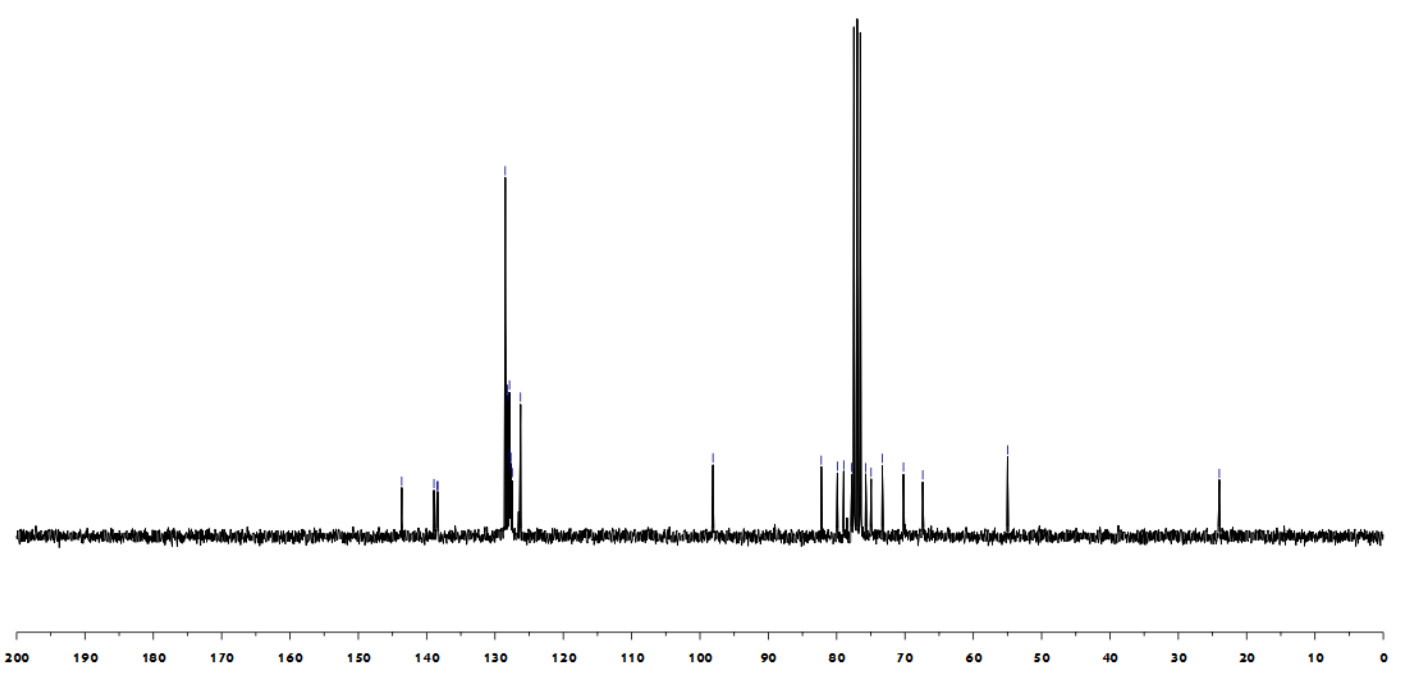



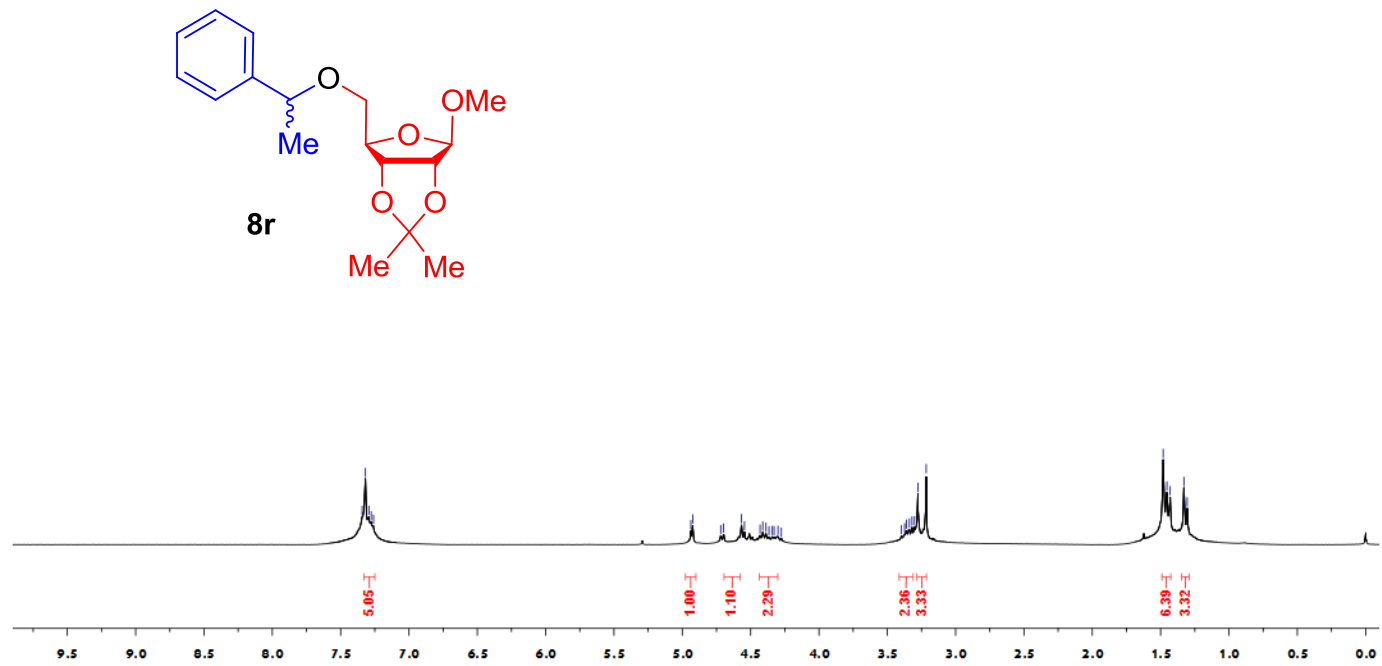

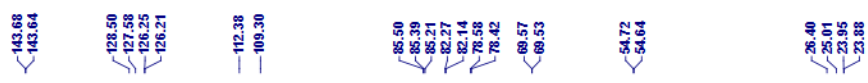

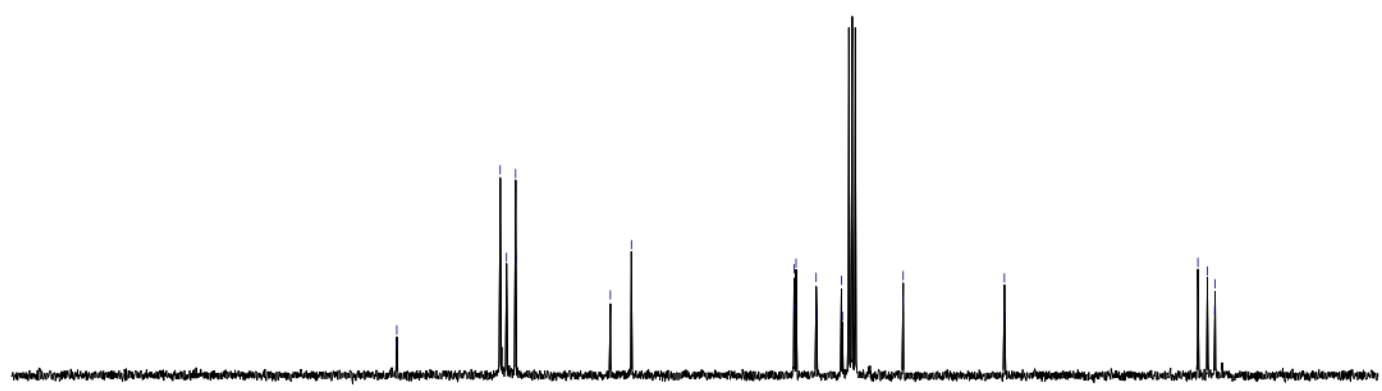

200

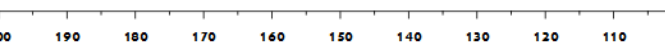


繁照

\%
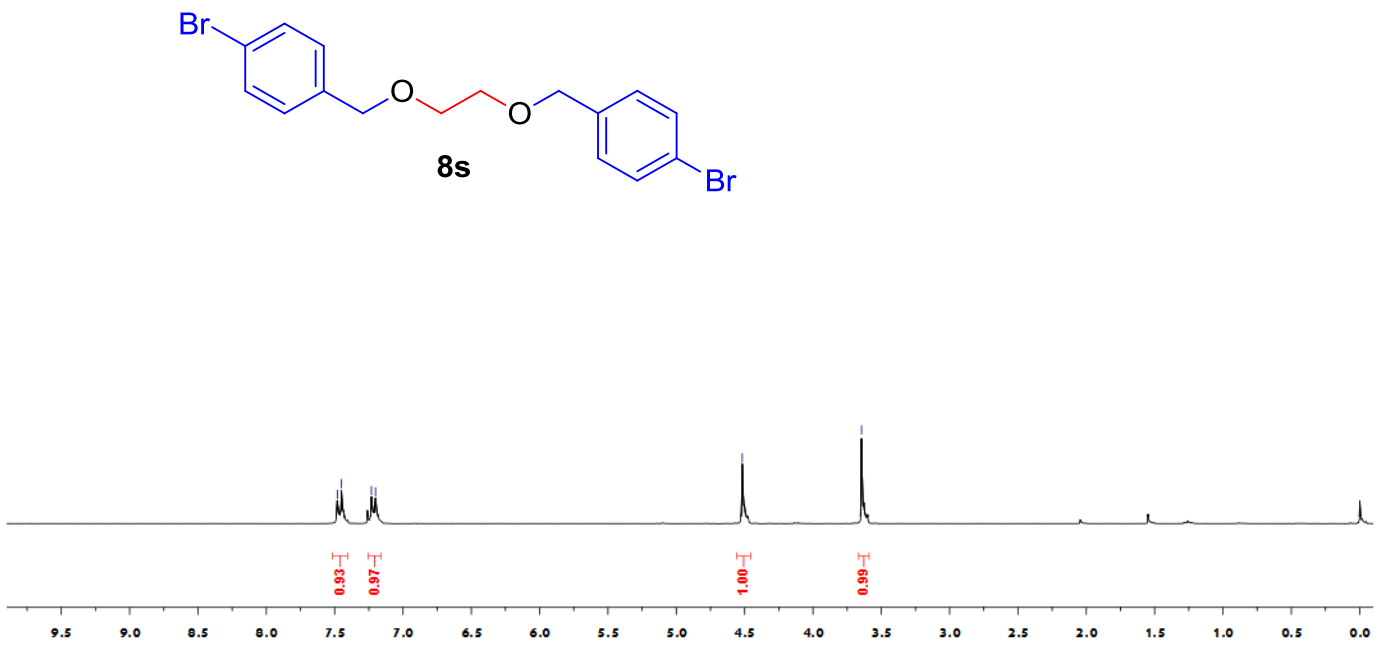

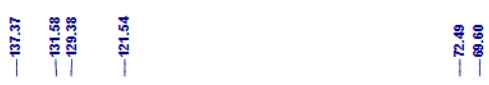
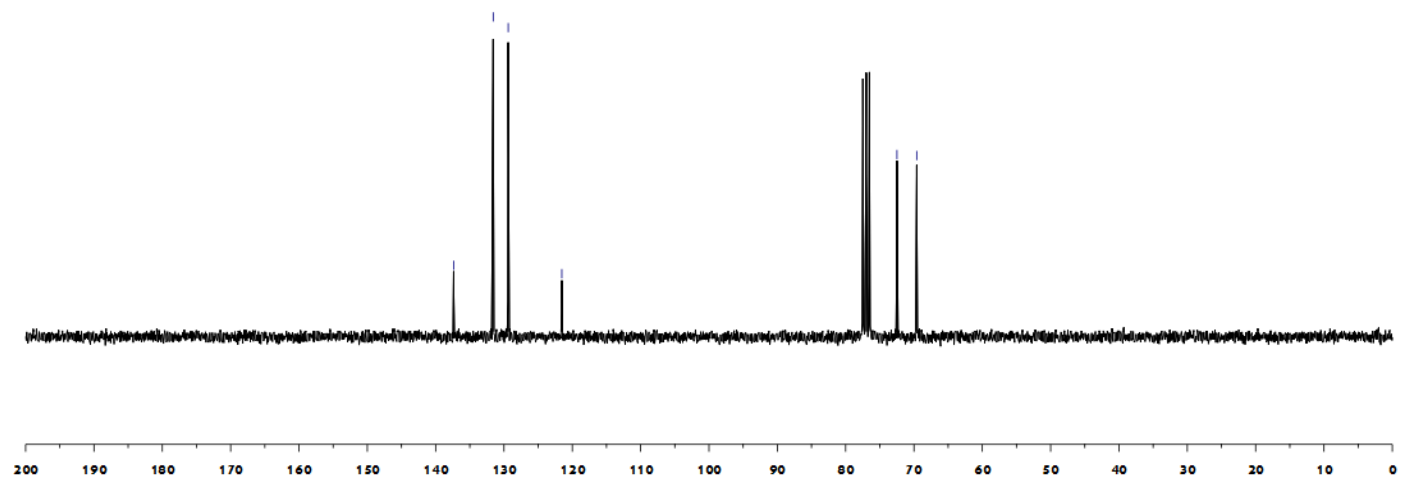

S51 

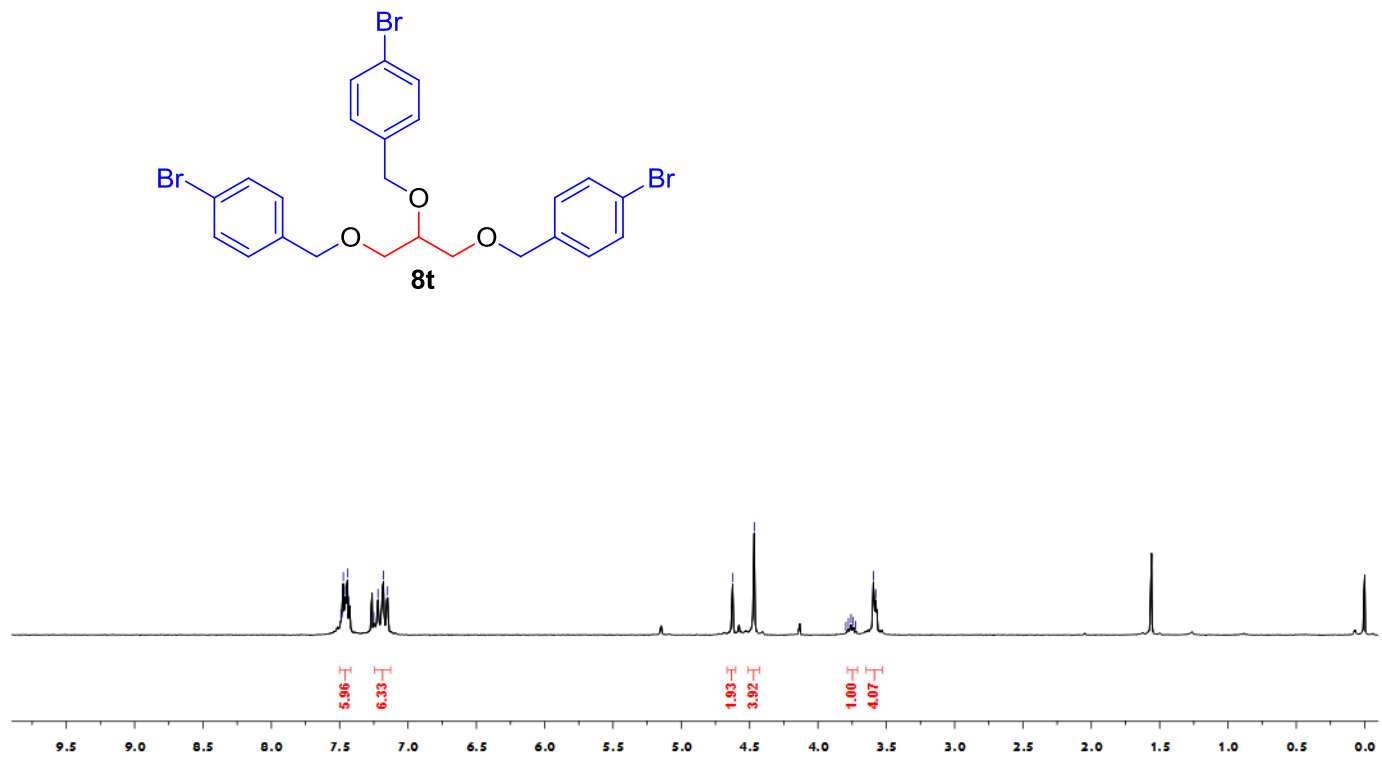

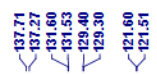
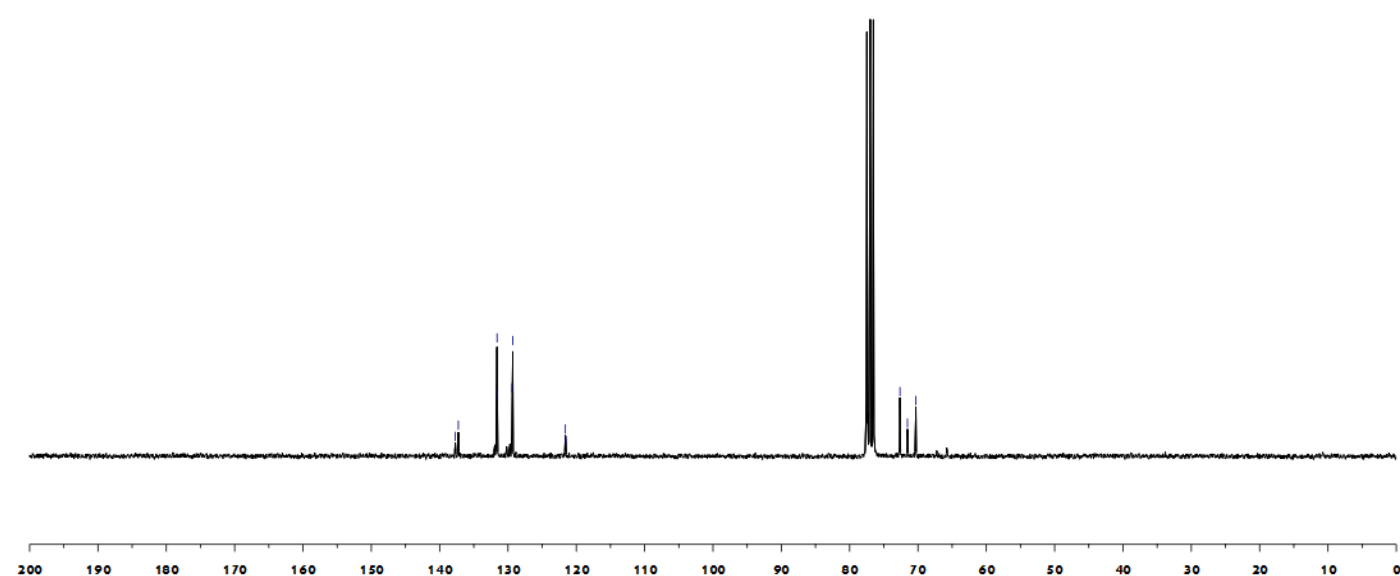

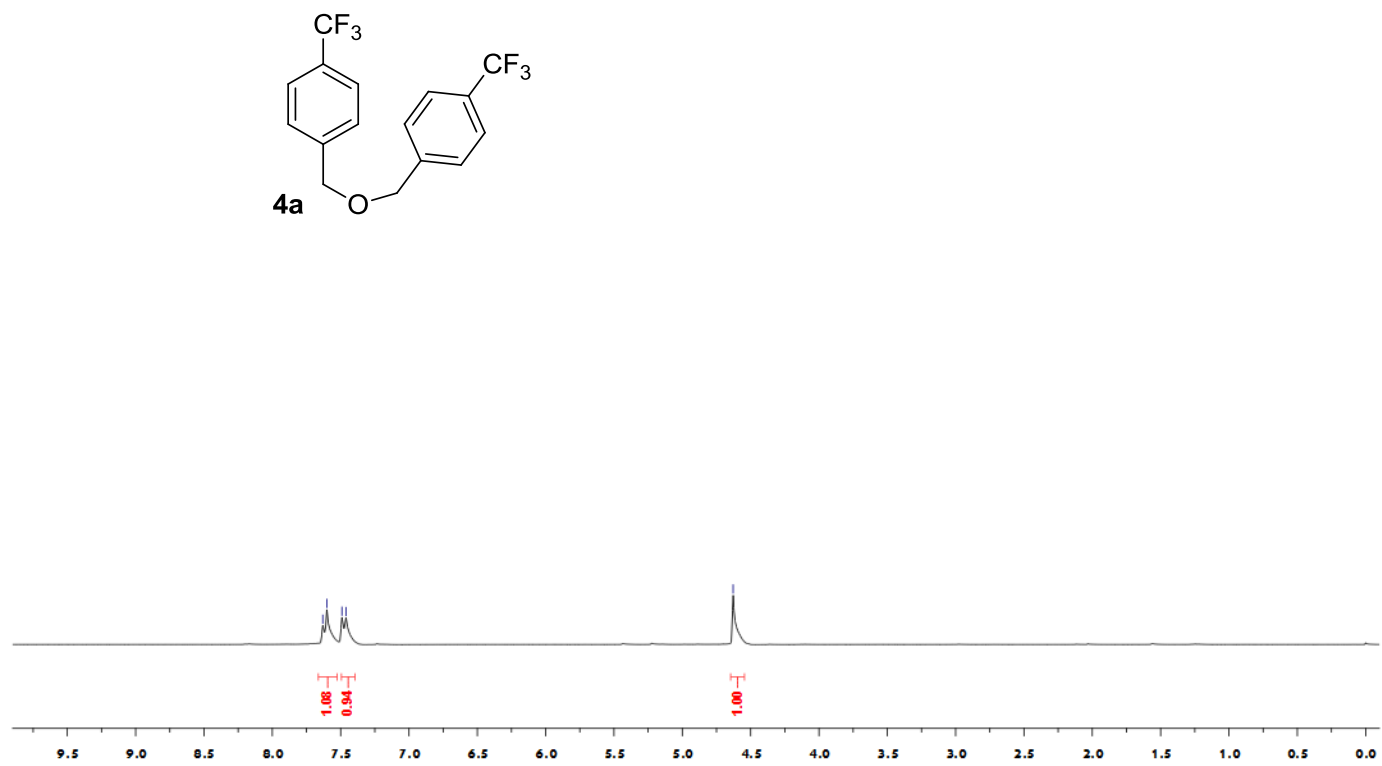

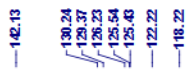

$\stackrel{乛}{i}$
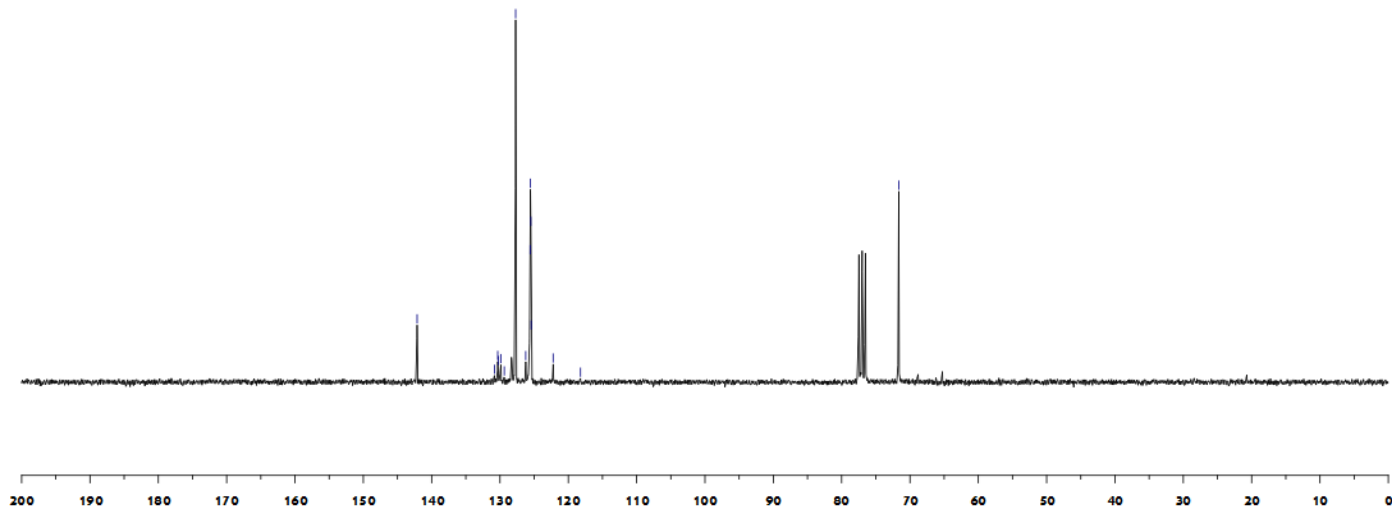


\section{Two types of ${ }^{1} \mathrm{H}$-NMR for 1 '-hydrogens of compound 1}
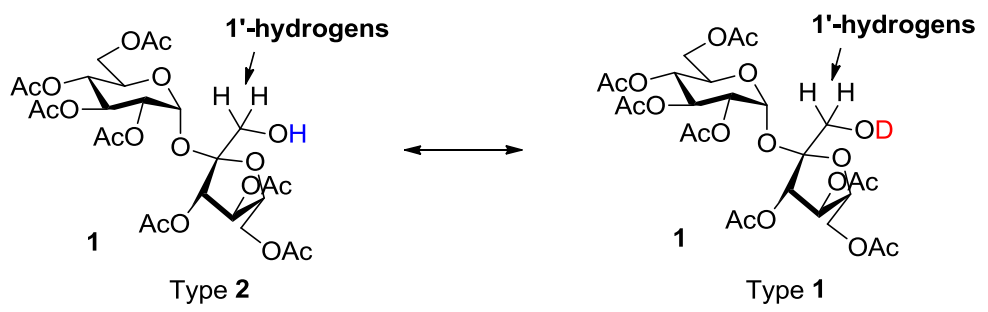

Type 1 (signal of 1'-hydrogens: $3.5-3.8 \mathrm{ppm}$ )

$\delta 3.70(\mathrm{~d}, J=12.5 \mathrm{~Hz}, 1 \mathrm{H})$

$\delta 3.58(\mathrm{~d}, J=12.5 \mathrm{~Hz}, 1 \mathrm{H})$
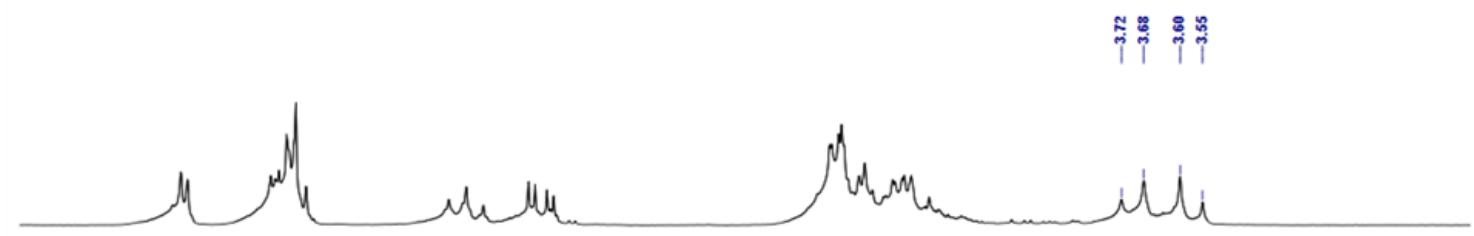

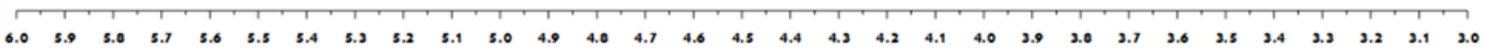

Type 2 (signal of 1'-hydrogens: $3.5-3.8 \mathrm{ppm}$ )

$\delta 3.71(\mathrm{dd}, J=12.5,8.0 \mathrm{~Hz}, 1 \mathrm{H})$

$\delta 3.59(\mathrm{dd}, J=12.5,8.0 \mathrm{~Hz}, 1 \mathrm{H})$
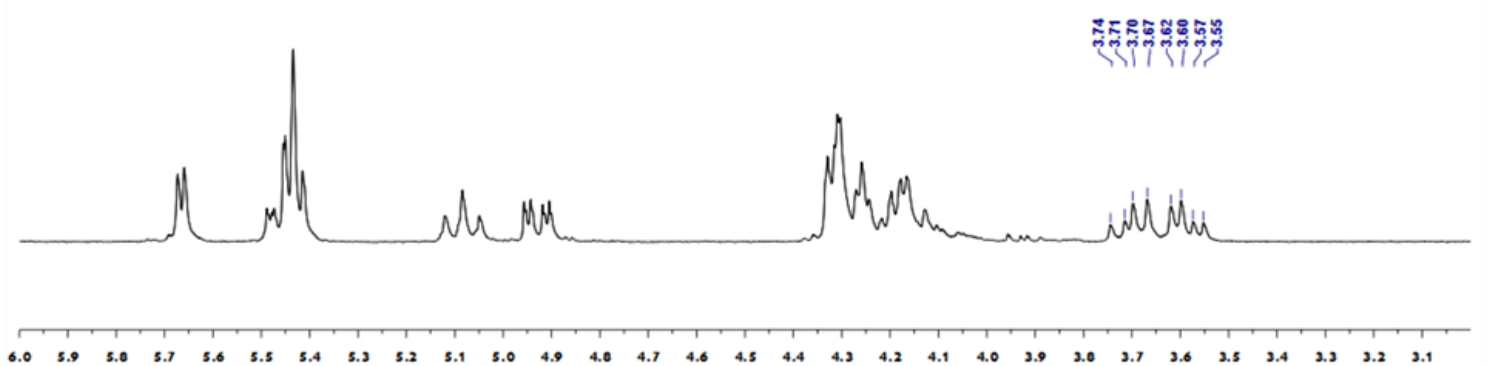

( ${ }^{1} \mathrm{H}-\mathrm{NMR}$ of compound 1. Chemical shift: 3-6 ppm. Measured in $\mathrm{CDCl}_{3}$ )

Previous report (Carbohydr. Res. 1991, 222, 121-129) provided the same ${ }^{1} \mathrm{H}-\mathrm{NMR}$ data as type $\mathbf{1}$. While, type 2 was always obtained during the measurement by $\mathrm{CDCl}_{3}$ in this study. The difference between type $\mathbf{1}$ and $\mathbf{2}$ should be possibly derived from the deuterium exchange occurred at 1'-hydroxyl in the presence of some active proton containing reagents $\left(\mathrm{D}_{2} \mathrm{O}\right.$, etc) existed in $\mathrm{CDCl}_{3}$ or introduced during the measurement. (With the addition of one drop of $\mathrm{D}_{2} \mathrm{O}$, type $\mathbf{2}$ can be converted to type $\mathbf{1}$ ) 
Kinetic investigation of benzylation of 1 by $\mathrm{Ag}_{2} \mathrm{O}$ in $\mathrm{CD}_{2} \mathrm{Cl}_{2}$ and deuterated cosolvent
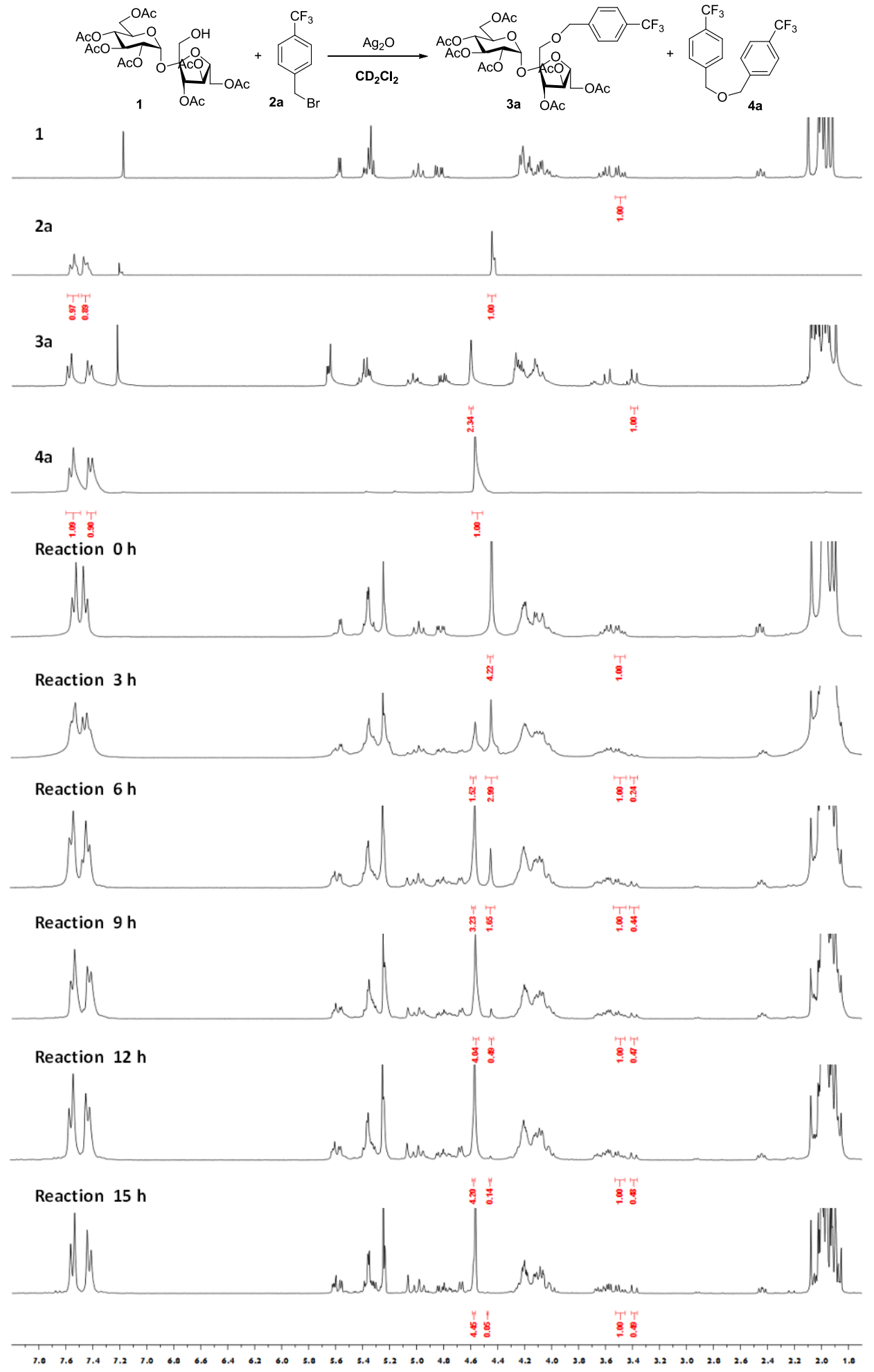

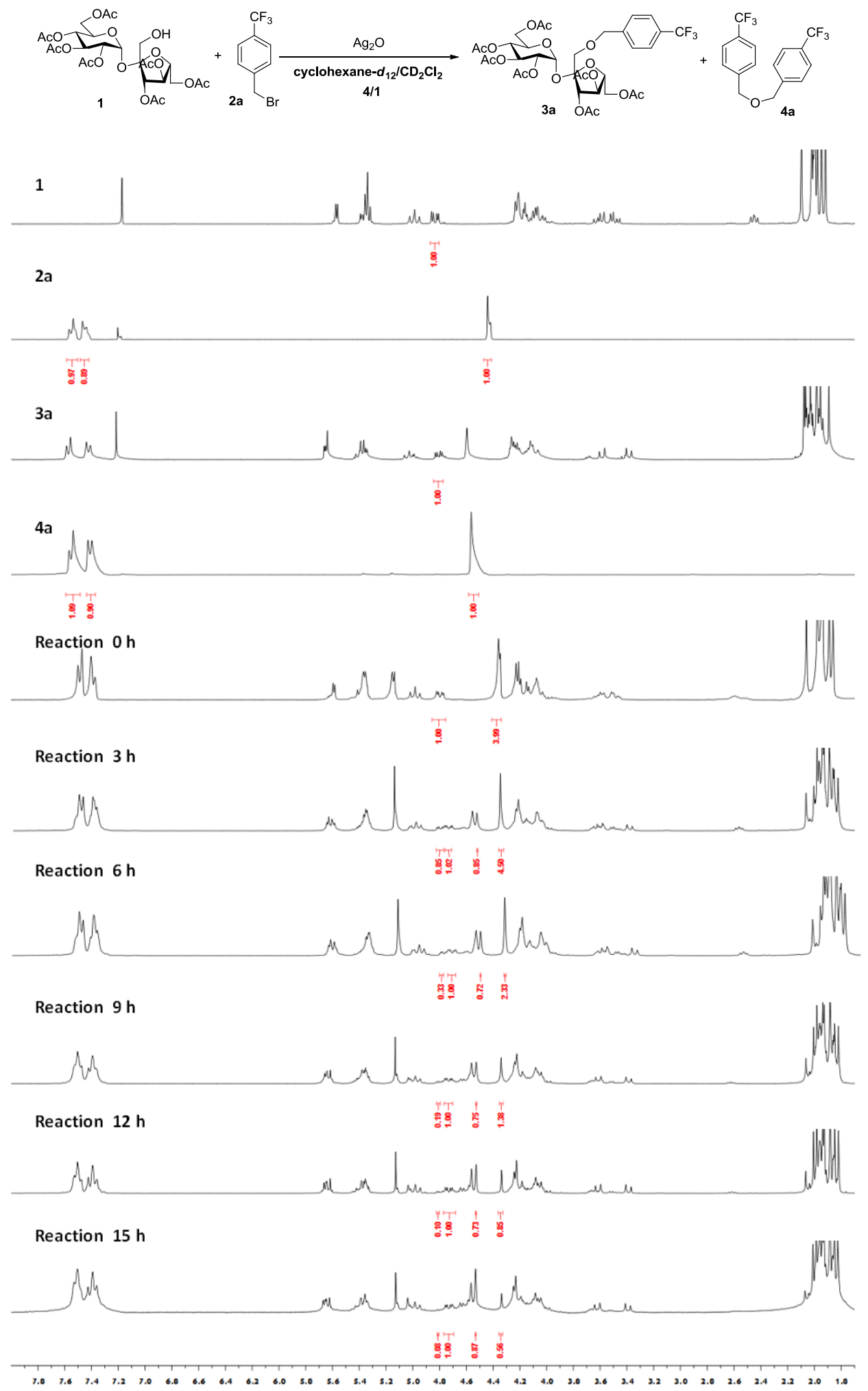
Mass spectra of $6 \mathrm{n}$ after irradiation for $10 \mathrm{~min}$ in $\mathrm{CH}_{3} \mathrm{OH}$ or $\mathrm{CD}_{3} \mathrm{OD}$

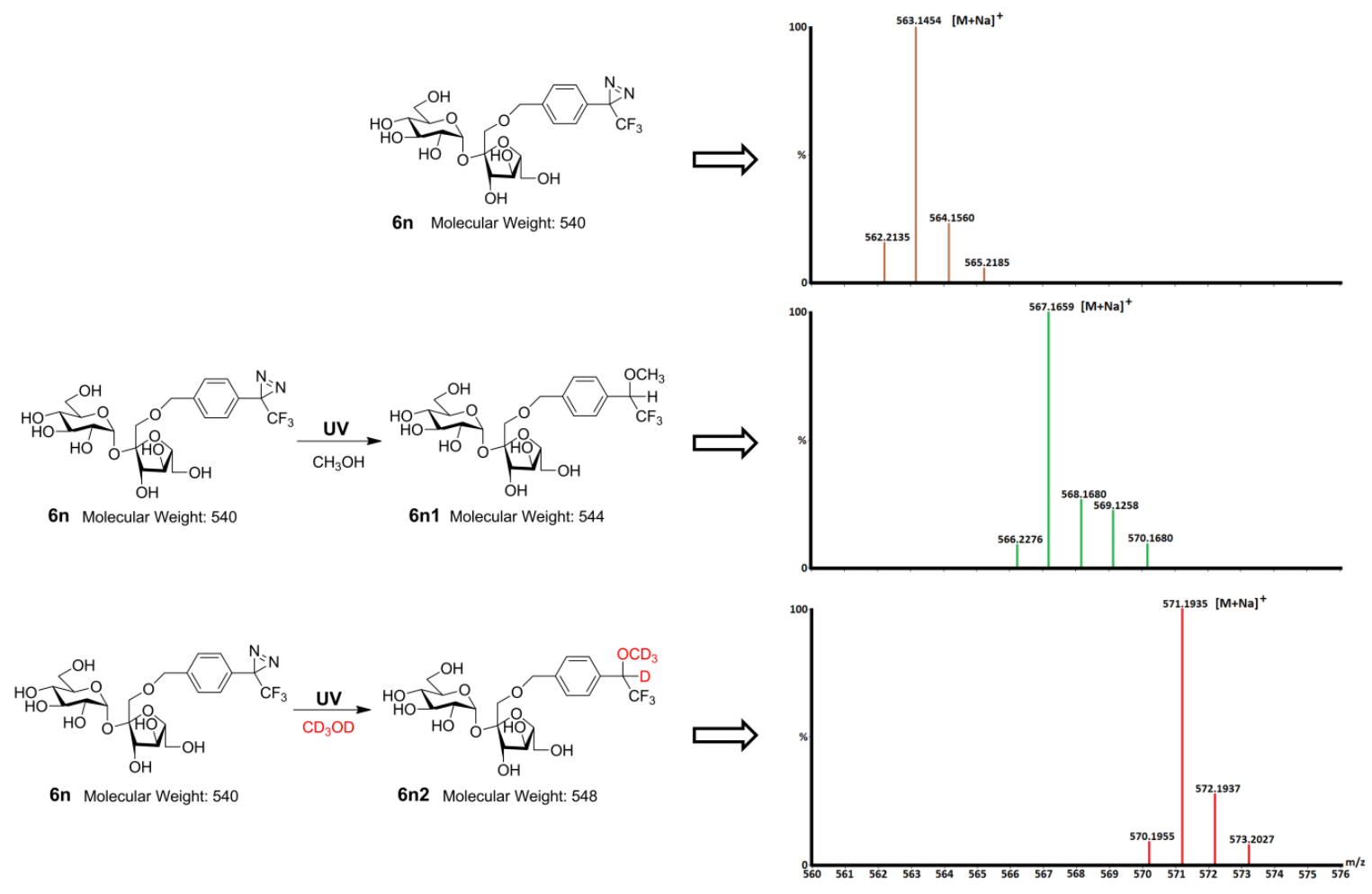




\section{HPLC analysis data for compounds 8k and 81}
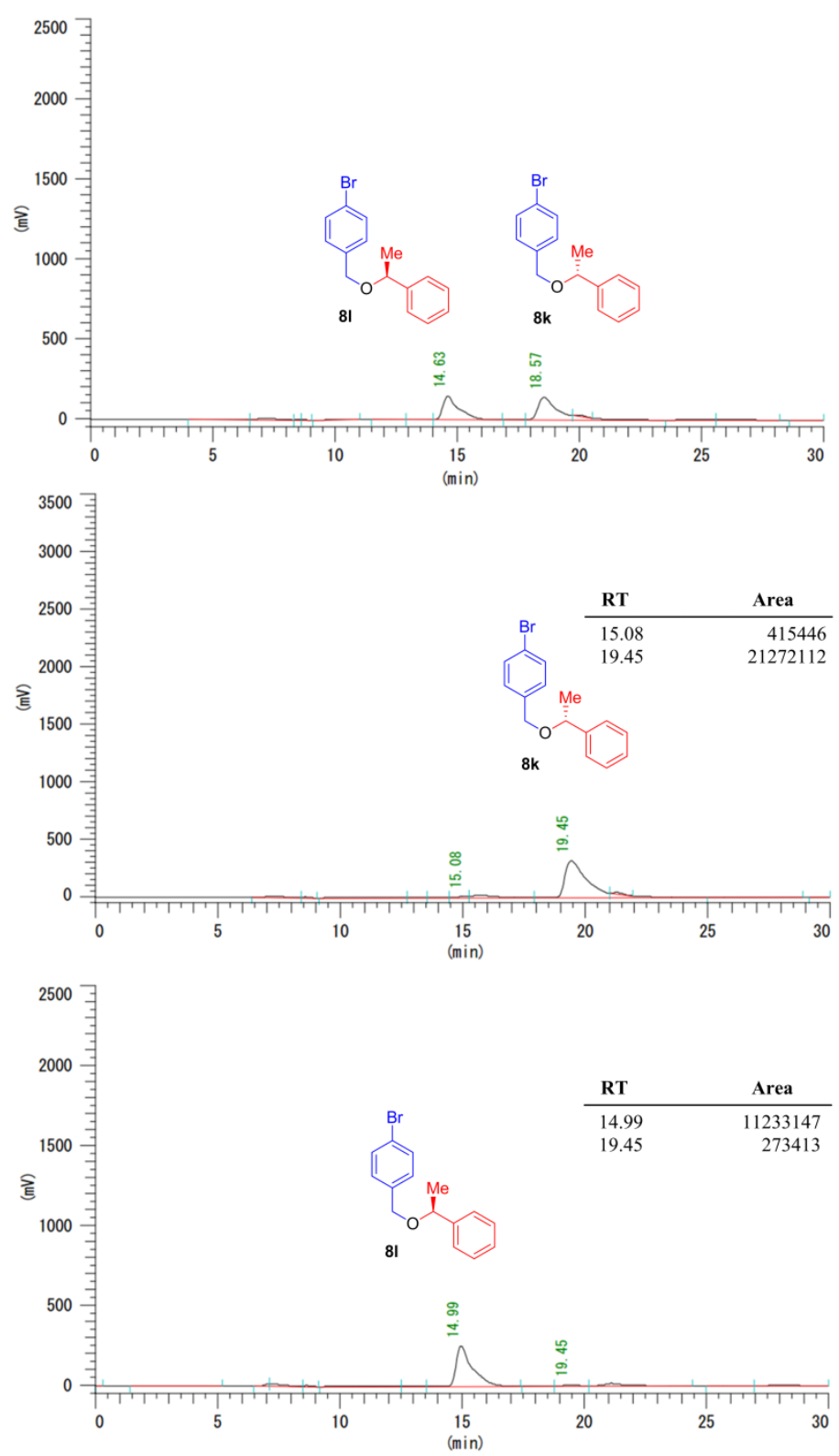

HPLC (Chiralcel OJ column, $n$-hexane $/ i-\mathrm{PrOH}=85: 15,0.5 \mathrm{~mL} / \mathrm{min}, 210 \mathrm{~nm}$ ),

8k: $\mathrm{t}_{\mathrm{R}}($ major $)=19.45 \mathrm{~min}, \mathrm{t}_{\mathrm{R}}($ minor $)=15.08 \mathrm{~min} ;$ ee $=96 \%$

81: $\mathrm{t}_{\mathrm{R}}($ major $)=14.99 \mathrm{~min}, \mathrm{t}_{\mathrm{R}}($ minor $)=19.45 \mathrm{~min} ;$ ee $=95 \%$ 